\title{
Interventions used to improve control of blood pressure in patients with hypertension (Review)
}

\author{
Fahey T, Schroeder K, Ebrahim S
}

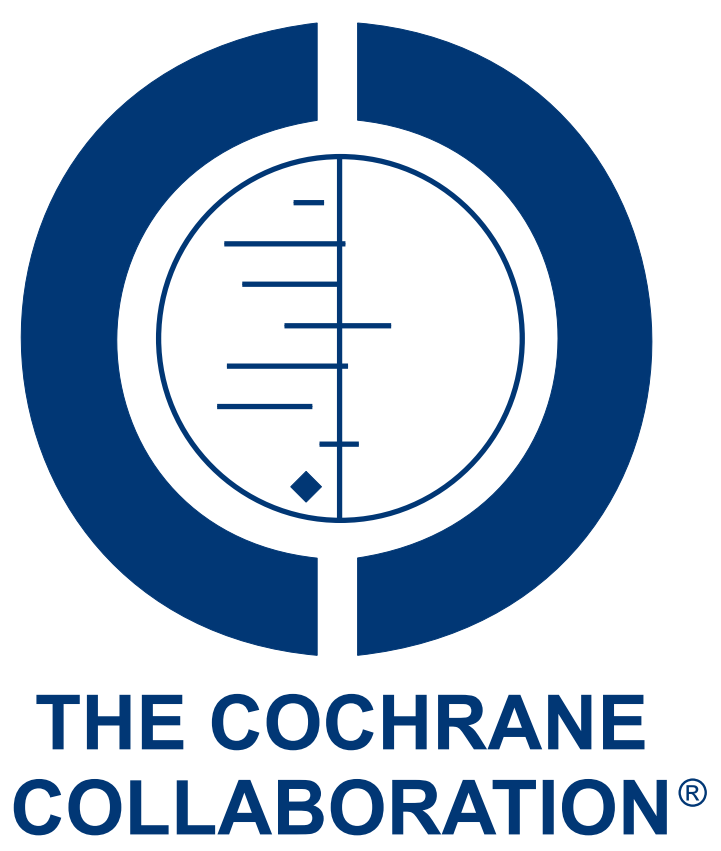

This is a reprint of a Cochrane review, prepared and maintained by The Cochrane Collaboration and published in The Cochrane Library 2006, Issue 2

http://www.thecochranelibrary.com

\section{WILEY}

Interventions used to improve control of blood pressure in patients with hypertension (Review)

Copyright $\odot 2006$ The Cochrane Collaboration. Published by John Wiley \& Sons, Ltd. 


\section{TABLE OF CONTENTS}

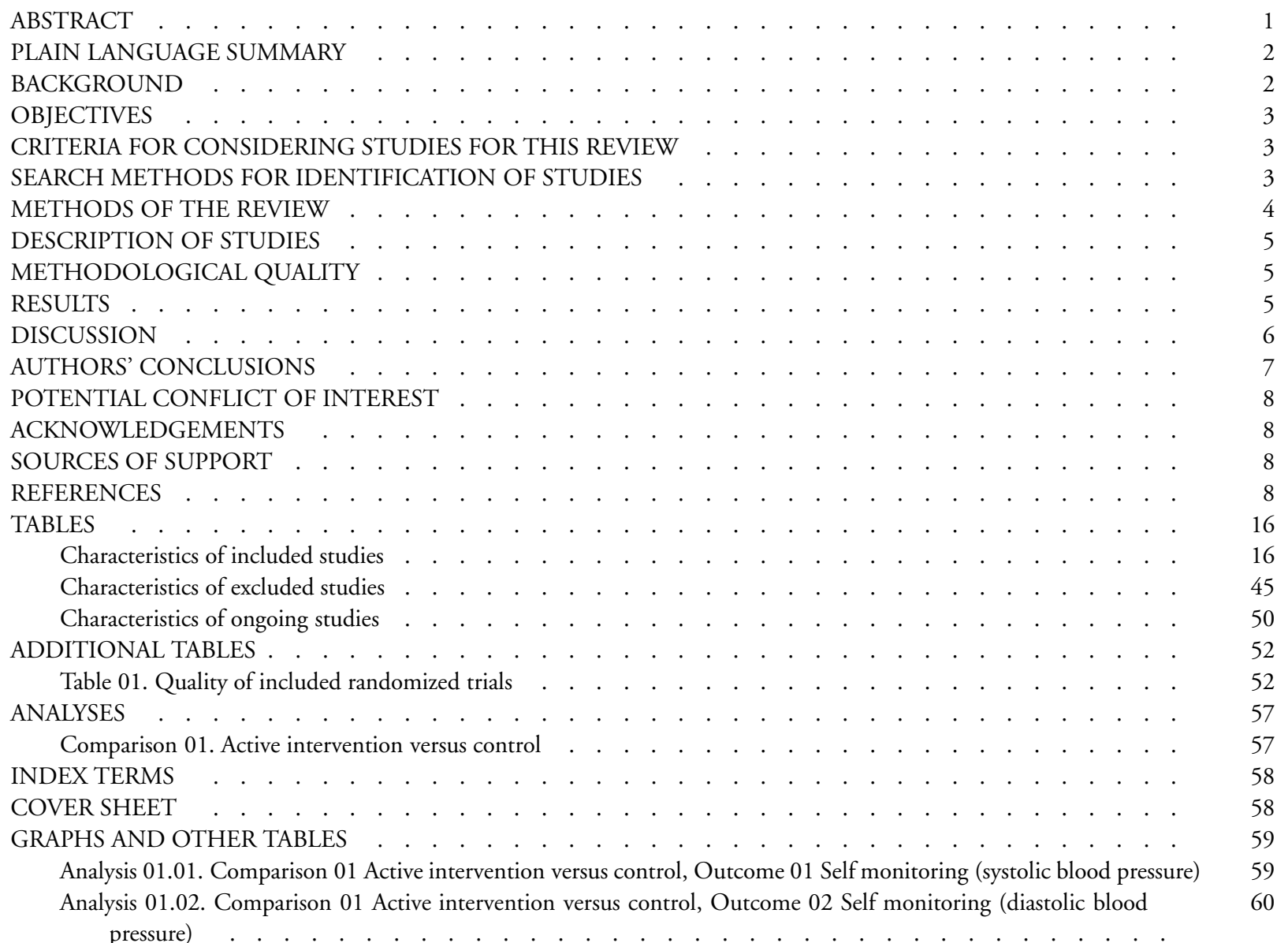

Analysis 01.03. Comparison 01 Active intervention versus control, Outcome 03 Self monitoring (BP control) . . . . 61

Analysis 01.11. Comparison 01 Active intervention versus control, Outcome 11 Patient education (systolic blood 61 pressure)

Analysis 01.12. Comparison 01 Active intervention versus control, Outcome 12 Patient education (diastolic blood pressure)

Analysis 01.13. Comparison 01 Active intervention versus control, Outcome 13 Patient education (BP control) .

Analysis 01.21. Comparison 01 Active intervention versus control, Outcome 21 Physician education (systolic blood pressure)

Analysis 01.22. Comparison 01 Active intervention versus control, Outcome 22 Physician education (diastolic blood pressure)

Analysis 01.23. Comparison 01 Active intervention versus control, Outcome 23 Physician education (BP control) .

Analysis 01.31. Comparison 01 Active intervention versus control, Outcome 31 Health professional led care (systolic blood pressure)

Analysis 01.32. Comparison 01 Active intervention versus control, Outcome 32 Health professional led care (diastolic blood pressure)

Analysis 01.33. Comparison 01 Active intervention versus control, Outcome 33 Health professional led care (BP control)

Analysis 01.41. Comparison 01 Active intervention versus control, Outcome 41 Organisation/protocol driven care (systolic blood pressure)

Analysis 01.42. Comparison 01 Active intervention versus control, Outcome 42 Organisation/protocol driven care (diastolic blood pressure)

Analysis 01.43. Comparison 01 Active intervention versus control, Outcome 43 Organisation/protocol driven care 
Analysis 01.51. Comparison 01 Active intervention versus control, Outcome 51 Appointment reminder (appointment

interventions) (outcome: lost to follow up at clinic) . . . . . . . . . . . . . . . . . . . . . . . . . 


\title{
Interventions used to improve control of blood pressure in patients with hypertension (Review)
}

\author{
Fahey T, Schroeder K, Ebrahim S
}

This record should be cited as:

Fahey T, Schroeder K, Ebrahim S. Interventions used to improve control of blood pressure in patients with hypertension. Cochrane Database of Systematic Reviews 2006, Issue 2. Art. No.: CD005182. DOI: 10.1002/14651858.CD005182.pub2.

This version first published online: 19 April 2006 in Issue 2, 2006.

Date of most recent substantive amendment: 16 February 2006

\begin{abstract}
A B S T R A C T
Background

It is well recognized that patients with high blood pressure (hypertension) in the community frequently fail to meet treatment goals - a condition labeled as "uncontrolled" hypertension. The optimal way in which to organize and deliver care to patients who have hypertension so that they reach treatment goals has not been clearly identified.
\end{abstract}

\section{Objectives}

To determine the effectiveness of interventions to improve control of blood pressure in patients with hypertension. To evaluate the effectiveness of reminders on improving the follow-up of patients with hypertension.

\section{Search strategy}

All-language search of all articles (any year) in the Cochrane Controlled Trials Register (CCTR), Medline and Embase from June 2000.

Selection criteria

Randomized controlled trials (RCTs) of patients with hypertension that evaluated the following interventions:

(1) self-monitoring

(2) educational interventions directed to the patient

(3) educational interventions directed to the health professional

(4) health professional (nurse or pharmacist) led care

(5) organisational interventions that aimed to improve the delivery of care

(6) appointment reminder systems

Outcomes assessed were:

(1) mean systolic and diastolic blood pressure

(2) control of blood pressure

(3) proportion of patients followed up at clinic

Data collection and analysis

Two authors extracted data independently and in duplicate and assessed each study according to the criteria outlined by the Cochrane Collaboration Handbook.

\section{Main results}

56 RCTs met our inclusion criteria. The methodological quality of included studies was variable. An organized system of regular review allied to vigorous antihypertensive drug therapy was shown to reduce blood pressure (weighted mean difference $-8.2 /-4.2 \mathrm{mmHg}$, 11.7/-6.5 mmHg, -10.6/-7.6 $\mathrm{mmHg}$ for 3 strata of entry blood pressure) and all-cause mortality at five years follow-up (6.4\% versus $7.8 \%$, difference $1.4 \%$ ) in a single large RCT- the Hypertension Detection and Follow-Up study. Other interventions had variable effects. Self-monitoring was associated with moderate net reduction in diastolic blood pressure (weighted mean difference (WMD): $2.0 \mathrm{mmHg}$, 95\%CI: -2.7 to $-1.4 \mathrm{mmHg}$, respectively. Appointment reminders increased the proportion of individuals who attended

Interventions used to improve control of blood pressure in patients with hypertension (Review)

Copyright @ 2006 The Cochrane Collaboration. Published by John Wiley \& Sons, Ltd 
for follow-up. RCTs of educational interventions directed at patients or health professionals were heterogeneous but appeared unlikely to be associated with large net reductions in blood pressure by themselves. Health professional (nurse or pharmacist) led care may be a promising way of delivering care, with the majority of RCTs being associated with improved blood pressure control, but requires further evaluation.

\section{Authors' conclusions}

Family practices and community-based clinics need to have an organized system of regular follow-up and review of their hypertensive patients. Antihypertensive drug therapy should be implemented by means of a vigorous stepped care approach when patients do not reach target blood pressure levels.

\section{PLAIN LANGUAGE SUMMARY}

There is a paucity of evidence as to how care for hypertensive patients should be organized and delivered in the community to help improve blood pressure control. This review aimed to determine the effectiveness of interventions whose objective was to improve follow-up and control of blood pressure in patients taking blood pressure lowering drugs. We included studies that had as population of interest adult patients with essential hypertension in an ambulatory setting. The interventions included all those that aimed to improve blood pressure control. The outcomes assessed were mean systolic and diastolic blood pressure, control of blood pressure and the proportion of patients followed up at clinic.

Fifty six randomised controlled trials met our inclusion criteria. The range of interventions used included (1) self-monitoring, (2) educational interventions directed to the patient, (3) educational interventions directed to the health professional, (4) health professional (nurse or pharmacist) led care, (5) organizational interventions that aimed to improve the delivery of care, (6) appointment reminder systems. The trials showed a wide variety of methodological quality, part of which may be attributed to poor reporting. An organized system of regular review allied to vigorous antihypertensive drug therapy was shown to reduce blood pressure and all-cause mortality in a single large RCT- the Hypertension Detection and Follow-Up study. Other interventions had variable effects. Self-monitoring was associated with moderate net reductions in diastolic blood pressure (weighted mean difference (WMD): $-2.0 \mathrm{mmHg}, 95 \% \mathrm{confidence}$ interval (CI): -2.7 to $-1.4 \mathrm{mmHg}$. Appointment reminders increased the proportion of individuals who attended for follow-up (absolute difference $16 \%$, but this pooled result should be treated with caution because of the heterogeneous results from individual RCTs). Trials of educational interventions directed at patients or health professionals were heterogeneous but appeared unlikely to be associated with large net reductions in blood pressure by themselves. Health professional (nurse or pharmacist) led care appears to be a promising way of delivering care but requires further evaluation.

We conclude that an organized system of registration, recall and regular review allied to a vigorous stepped care approach to antihypertensive drug treatment appears the most likely way to improve the control of high blood pressure. Health professional (nurse or pharmacist) led care requires further evaluation. Education alone, either to health professionals or patients, does not appear to be associated with large net reductions in blood pressure.

\section{B A C K G R O U N D}

High blood pressure (hypertension) is an important public health problem. Evidence from randomized trials has shown that effective drug treatment reduces the risk of cardiovascular morbidity and mortality (Collins 1994; Gueyffier 1999). However, there is ongoing concern that the benefits demonstrated in randomized trials of antihypertensive drug treatment are not implemented in everyday clinical practice (Burnier 2002). Community-based studies throughout the world show that blood pressure goals are achieved in only $25-40 \%$ of the patients who take antihypertensive drug treatment (Burnier 2002; Hyman 2001; Chobanian 2001; Smith 1990), a situation that has remained unchanged for the last 30 years (Wilber 1972).

The quality of care patients with hypertension receive from health professionals has a clear impact on their risk of suffering a cardiovascular event. Observational studies in the UK have shown that inadequate control of blood pressure is associated with a significant risk of stroke (Du 1997; Payne 1993). In terms of the process of care that hypertensive patients receive, characteristics of both the patient, health professional and the healthcare system in which they are given their medical care have been implicated in poor blood pressure control. Lack of adherence to medication and not having a primary care physician were associated with poor blood pressure control in a US study (Shea 1992). More recent studies have shown that frequent contact with health care pro- 
fessionals does not guarantee better blood pressure control unless there is more vigorous use of antihypertensive drugs (Hyman 2001; Berlowitz 1998), and that individual practitioners vary substantially in their clinical performance when managing hypertension in the community (Frijling 2001). These observations have led some commentators to suggest that poor control of blood pressure in the community may be due to ineffective management and inadequate practice organisation, described jointly as "clinical inertia" (Phillips 2001)

Whilst there is a strong evidence-base for the benefits of antihypertensive drug therapy (Collins 1994; Blood 2000; Staessen 2001), there is little clear evidence as to how care for hypertensive patients should be organized and delivered in the community to help improve blood pressure control. This systematic review aims to update and build upon a previous review (Ebrahim 1998), to summarize the evidence from randomized controlled trials that evaluate different models of care that have been used to improve the control and follow-up of patients with hypertension.

\section{O B J E C T I V E S}

The objectives of this review are to:

(1) Evaluate which models of care are effective in improving "control" of high blood pressure;

(2) Evaluate the effectiveness of reminders on improving the follow-up of patients with hypertension.

\section{CRITERIA FOR CONSIDERING STUDIES FOR THIS REVIEW}

\section{Types of studies}

Randomized trials of interventions that have sought to evaluate different models of care for patients with hypertension with the overall aim of improving blood pressure control or follow-up care of patients. Included studies had to be RCTs with a contemporaneous control group where patient care in the intervention group(s) was compared with either no intervention or usual care. We excluded studies using interventions not intended to increase blood pressure control by organisational means, particularly drug trials and trials of non-pharmacological treatment.

\section{Types of participants}

The population of interest was composed of adult patients (aged 18 years or over) with essential hypertension (treated or not currently treated with blood pressure lowering drugs) in a primary care, outpatient or community setting.

\section{Types of intervention}

The interventions were aimed at improving control of blood pressure or clinic attendance and were classified as:
(1) self-monitoring

(2) educational interventions directed to the patient

(3) educational interventions directed to the health professional

(4) health professional (nurse or pharmacist) led care

(5) organisational interventions that aimed to improve the delivery of care

(6) appointment reminder systems

\section{Types of outcome measures}

Studies were included if they reported:

(1) mean systolic blood pressure (mean SBP) and/or mean diastolic blood pressure (mean DBP)

(2) control of blood pressure (blood pressure threshold that determines "control" being pre-specified or defined by each randomized trial's investigators)

(3) proportion of patients followed-up at clinic

\section{SEARCH METHODS FOR IDENTIFICATION OF STUDIES}

See: methods used in reviews.

We identified original RCTs by an all-language search of all articles in the Cochrane Central Register of Controlled Trials (CENTRAL), from The Cochrane Library issue 2, 2004; from MEDLINE January 2000 to July 2004; and EMBASE January 2000 to July 2004 . We screened the references of all retrieved articles to identify additional publications and contacted experts in the field about other relevant trials or unpublished material.

We used the following search strategy:

1. exp HYPERTENSION/

2. exp Antihypertensive Agents/

3. (blood adj pressure).ti.

4. hypertens\$.tw.

5. or/1-4

6. exp PHYSICN/

7. exp Patient Care Management/

8. exp Patient Care Planning/

9. exp Patient Care Team/

10. exp Patient Education/

11. exp Patient Participation/

12. exp Ambulatory Care Information Systems/

13. exp FEEDBACK/

14. exp Information Systems/

15. exp Management Information Systems/

16. exp Decision Support Systems, Clinical/

17. exp Decision Making, Computer-Assisted/

18. exp Reminder Systems/

19. exp Practice Guidelines/

20. $\exp$ GUIDELINES/

21. exp Medical Audit/

22. exp Medical Records/ 
23. exp "Outcome and Process Assessment (Health Care)/

24. exp Medical Records Systems, Computerized/

25. exp Primary Health Care/

26. exp Physicians, Family/

27. exp Primary Nursing Care/

28. exp Nurse Practitioners/

29. exp Nurse Clinicians/

30. exp Health Behavior/

31. remind\$.tw.

32. motiv\$.tw.

33. Patient Care/

34. Nursing Care/

35. Guideline Adherence/

36. Ambulatory Care/

37. exp Behavior Therapy/

38. Counseling/

39. counsel\$.tw.

40. Motivation/

41. self monitor\$.tw.

42. ((patient $\$$ or program $\$$ ) adj3 (educat $\$$ or manage $\$$ or train $\$$ or teach\$)).tw.

43. self manage $\$ . t w$.

44. ((manage\$ or monitor\$) adj3 (hypertension or blood pressure)).tw.

45. Health Promotion/

46. exp Health Education/

47. (reward\$ or incentivtte\$)

48. uncontrol\$.tw.

49. Self Care/

50. or/6-49

51.5 and 50

52. randomized controlled trial.pt.

53. controlled clinical trial.pt.

54. Randomized Controlled Trials/

55. random allocation/

56. double blind method/

57. single blind method/

58. or/52-57

59. animal/ not human/

60.58 not 59

61. clinical trial.pt.

62. exp clinical trials/

63. (clin\$ adj25 trial\$).ti,ab.

64. ((singl\$ or doubl\$ or treble\$ or tripl\$) adj25 (blind\$ or mask\$)).ti,ab.

65. placebos/

66. "placebo\$.ti,ab.

67. "random $\$ . t i$,

68. research design/

69. or/61-68

70. 69 not 59

71. comparative study/

72. exp evaluation studies/
73. follow-up studies/

74. prospective studies/

75. (control\$ or prospectiv\$ or volunteer\$).ti,ab.

76. or/71-75

77. 76 not 59

78. 60 or 70 or 77

79.51 and 78

80.60 or 70

81.51 and 80

82. limit 81 to $\mathrm{yr}=2000-2002$

This search strategy was slightly amended for searching Cochrane Central Register of Controlled Trials (CENTRAL) and EMBASE.

\section{METHODS OF THEREVIEW}

Two of the authors (TF and KS) assessed lists of citations and abstracts independently. We were not masked with regard to authors or journal. Each reviewer indicated whether a citation was potentially relevant (i.e. appearing to meet the inclusion criteria), was clearly not relevant, or gave insufficient information to make a judgement. To be included a study had to meet all the inclusion criteria. We resolved differences by discussion and obtained reprints of all potentially relevant citations.

We (TF and either KS or SE) independently extracted data in duplicate on study design, methods, clinicians and patients, interventions, outcomes and potential sources of bias using a structured data collection form. We wrote to the corresponding authors of studies to request missing data, clarify study details and enquire about unpublished studies.

For assessment of study quality we collected data on randomization procedure, allocation concealment, blinding of participants, providers of care, outcome assessors and losses to follow-up (Clarke 2000).

We examined the effects on blood pressure between interventions at follow-up (systolic and diastolic blood pressure) according to the six pre-defined intervention categories. We compared and pooled the mean blood pressure differences from baseline to final follow-up in the intervention and control groups using the weighted mean difference approach (see Cochrane Heart Group website: http://www.epi.bris.ac.uk/cochrane/stats3.html). When only partial information about the variance was provided in RCT reports, we calculated variances using the method described by Follman (Follman 1992). We have taken account of the correlation of baseline and final blood pressure measurements by using empirical data from the Caerphilly dataset which examined the correlation between baseline and 5-year follow-up blood pressure measurements in 2000 men ( $r=0.568$ for systolic and $r=0.514$ for diastolic blood pressure) (personal communication Margaret May, Department of Social Medicine, University of Bristol). 
For blood pressure control and clinic attendance at follow-up statistical and clinical significance was evaluated by means of estimating odds ratios with $95 \%$ confidence intervals. Individual study definitions of control of blood pressure and attendance at clinic were used. For both continuous and categorical outcomes, we checked the meta-analyses for heterogeneity by visual inspection and by Cochran's test. When heterogeneity is significant, the individual study results are presented to illustrate the magnitude of blood pressure reduction reported but no overall pooled results are presented. Pooled odds ratios and their 95\% confidence intervals were calculated with The Cochrane Collaboration RevMan 4.1 software.

\section{DESCRIPTIONOFSTUDIES}

Fifty six randomized controlled trials met the inclusion criteria. Three randomised controlled trials had a factorial design and are included twice under separate intervention headings - Pierce (selfmonitoring and education- patient) (Pierce 1984), Sackett (education- patient and organisation of care) (Sackett 1975), and Dickinson (education- health professional and organisation of care) (Dickinson 1981). A further RCT was a three armed study of patient education, home monitoring from a family member actively participating in their care and a usual care arm (Earp 1982).

\section{METHODOLOGICAL QUALITY}

The reported methodological quality of included studies was generally poor to moderate. Nineteen randomised controlled trials $(32 \%)$ stated the randomization process, whilst only six (10\%) had adequate allocation concealment. In 11 studies (19\%) the outcome assessors were blind to the treatment allocation. Losses to follow-up of greater than $20 \%$ or more occurred in $12(20 \%)$ of studies.

For a detailed summary of each of the 56 included RCTs see Table 01 .

\section{R E S U L T S}

(1) Self-monitoring ( $\mathrm{n}=15 \mathrm{RCTs}$ ) (Pierce 1984; Bailey 1998; Carnahan 1975; Friedman 1996; Haynes 1976; Johnson 1978; Mehos 2000; Rogers 2001; Soghikian 1992; Vetter 2000; Zarnke 1997; Artinian 2001; Midanik 1991; Rudd 2004; Earp 1982).

In the ten RCTs that reported on differences in mean SBP (Carnahan 1975; Soghikian 1992; Friedman 1996; Bailey 1998; Mehos 2000; Vetter 2000; Rogers 2001; Artinian 2001; Midanik 1991; Rudd 2004), self-monitoring was associated was associated with significant between-group heterogeneity for mean SBP (range -10 to $+5 \mathrm{mmHg}$ ). Pooled data from twelve RCTs on difference of mean DBP (Carnahan 1975; Soghikian 1992; Fried- man 1996; Bailey 1998; Mehos 2000; Vetter 2000; Rogers 2001; Haynes 1976; Johnson 1978; Artinian 2001; Midanik 1991; Rudd 2004), showed that self-monitoring was associated with a significant reduction of $-2.0 \mathrm{mmHg}(95 \% \mathrm{CI}-2.7$ to $-1.4 \mathrm{mmHg})$. In the four RCTs that reported on control of blood pressure (Pierce 1984,Rogers 2001; Vetter 2000; Earp 1982), there was a trend towards improved blood pressure control but this was not significant (odds ratio 0.9 (95\% CI 0.7 to 1.2$)$. The remaining RCT that did not report any usable data concerning blood pressure control, reported a mean arterial blood pressure difference of $3 \mathrm{mmHg}$ in favour of the intervention (Zarnke 1997). However, this RCT was of a short duration (8 weeks follow-up).

(2) Educational interventions directed to the patient ( $\mathrm{n}=16 \mathrm{RCTs}$ ) (Pierce 1984; Sackett 1975; Billault 1995; Burrelle 1986; Earp 1982; Fielding 1994; Gullion 1987; Hamilton 1993; MartinezAmenos 1990; Morisky 1983 and Levine 1979; Muhlhauser 1993; Roca-Cusachs 1991; Tanner 1981; Watkins 1987; Webb 1980; Zismer 1982) .

Seven RCTs reported mean difference SBP, nine RCTs reported mean difference DBP and five on BP control. For mean difference in SBP and DBP outcomes pooling of results from individual RCTs produced heterogeneous results, so pooled mean differences are not valid. Mean difference in SBP was reported with a range of difference in mean SBP reported between $-15.7 \mathrm{mmHg}$ to +0.6 $\mathrm{mmHg}$, mean difference in DBP was reported with a range DBP $-8.7 \mathrm{mmHg}$ to $+7.1 \mathrm{mmHg}$. In terms of blood pressure control (five RCTs) there was a trend towards improved blood pressure control but this was not significant (odds ratio 0.7 (95\%CI 0.4 to 1.0). Three RCTs did not report relevant outcome data (Gullion 1987; Hamilton 1993; Martinez-Amenos 1990), but did report increases in patient knowledge (Martinez-Amenos 1990). Two of these RCTs reported no difference in blood pressure control (Gullion 1987; Martinez-Amenos 1990). One RCT reported an improvement in SBP but not DBP at 6 months follow-up (Hamilton 1993).

(3) Educational interventions directed to the physician ( $\mathrm{n}=9$ RCTs) (Dickinson 1981; Coe 1977; Evans 1986; Hetlevik 1998; McAlister 1986; Montgomery 2000; Ornstein 2004; New 2004; Sanders 2002).

Educational interventions directed towards the physician were associated with a small reduction in systolic blood pressure, pooled mean difference in SBP was $-2.0 \mathrm{mmHg}, 95 \% \mathrm{CI}-3.5$ to -0.6 $\mathrm{mmHg}$. However, educational interventions directed at the physician were not associated with a significant decrease in mean DBP (mean difference $-0.4 \mathrm{mmHg}, 95 \% \mathrm{CI}-1.1$ to $+0.3 \mathrm{mmHg}$ ) whilst control of blood pressure produced heterogeneous results (reported range 0.8 to 1.0 ).

(4) Health professional (nurse or pharmacist) led care ( $\mathrm{n}=7$ RCTs) ( Bogden 1998; Garcia-Pena 2001; Hawkins 1979; Jewell 1988; Logan 1979; Park 1996; Solomon 2002). 
Health professional (nurse or pharmacist) led care may be a promising way of delivering care, with the majority of RCTs being associated with improved blood pressure control. For all three outcomes pooling of results from individual RCTs produced heterogeneous results, so pooled mean differences are not valid. Mean difference in SBP was reported in five RCTs with a range of difference in mean SBP from $-13 \mathrm{mmHg}$ to $0 \mathrm{mmHg}$. Mean difference in DBP was reported in six RCTs, ranging from $-8 \mathrm{mmHg}$ to $0 \mathrm{mmHg}$. Control of blood pressure produced heterogeneous results (reported range 0.1 to 0.9 ).

(5) Organisational interventions that aimed to improve the delivery of care (n=7 RCTs) (Sackett 1975; Dickinson 1981; Brook 1983; Bulpitt 1976; Hypertension 1979; Hypertension 1979a; Hypertension 1982; Robson 1989; Takala 1979; Takala 1983). For all three outcomes pooling of results from individual RCTs produced heterogeneous results, so pooled mean differences are not valid and the range of mean difference in SBP and DBP is illustrated in MetaView. Of note, the largest RCT, the Hypertension Detection and Follow-Up Program (HDFP), produced substantial reductions in SBP and DBP across the three groups in this RCT (patient were stratified according to level of entry DBP level, weighted mean difference -8.2/-4.2 $\mathrm{mmHg},-11.7 /-6.5 \mathrm{mmHg}$, $10.6 /-7.6 \mathrm{mmHg}$ for the three strata of entry blood pressure) ). At five year follow-up these reductions in blood pressure were associated with a significant reduction in all cause mortality at five years follow-up (6.4\% versus $7.8 \%$, risk difference $1.4 \%)$.

(6) Appointment reminder systems ( $\mathrm{n}=6 \mathrm{RCTs}$ ) (Ahluwalia 1996; Barnett 1983; Bloom 1979; Cummings 1985; Fletcher 1975; Krieger 1999).

In five RCTs reminder systems were associated with an improvement in follow-up. One RCT of a mailed postcard reminder was not associated with improved follow-up (Ahluwalia 1996). The pooled results though favouring appointment reminder systems for follow-up of patients, odds ratio of being lost to follow-up $0.4,95 \%$ confidence interval $(\mathrm{CI}) 0.3$ to 0.5 are heterogenous because of the single outlying RCT and the pooled results should be treated with caution. Four other RCTs (studies classified under the other intervention headings but incorporated some form of reminder intervention such as postal reminders or computer generated feedback) were associated with significantly improved follow-up attendance by patients (Dickinson 1981; Hamilton 1993; Hawkins 1979; Takala 1979; Takala 1983).

\section{I S C USS I O N}

\section{Key findings from this review}

The main finding from this systematic review are to a large extent dominated by the findings from the largest RCT, the HDFP study (Hypertension 1979; Hypertension 1979a; Hypertension 1982). Though partly intended as a trial to assess the value of systematic identification of hypertensive patients (Davis 2001), the key ingredients of how patients with established hypertension and taking antihypertensive drug treatment were managed- free care, registration, recall and regular review in tandem with a rigorous stepped care approach to antihypertensive drug treatment- should be emphasized as this multi-faceted intervention was effective in terms of reaching blood pressure goals and reducing all-cause mortality. It is interesting to note that a two-year post trial surveillance study showed that blood pressure control was attenuated when the stepped-care arm of the study was discontinued. This lack of control was associated with a decline in the use of antihypertensive medication (Hypertension 1986).

Other interventions assessed in this systematic review did not produce clear results. None of the interventions were associated with large, clinically important, reductions in either systolic or diastolic pressure, see MetaView. Self-monitoring was associated with a significant decline in diastolic blood pressure and further evaluation in larger RCTs is warranted. Education alone, directed either to patients or health professionals appears unlikely to influence control of blood pressure as a single intervention, as results were highly heterogeneous or of marginal clinical importance. Use of health care professionals such as nurses and pharmacists, though producing significantly heterogeneous results, did have mainly favourable effects, and merit further definitive evaluation in larger RCTs. Lastly, reminders (postal or computer-based) were associated with an improvement in the follow up of patients with hypertension in all RCTs aside from one small study. This finding is consistent with the organisational structure of the HDFP study and re-iterates the importance of systematic recall systems when organising care for hypertensive patients.

\section{Context of other studies}

There are elements identified from this review that appear to be associated with improved blood pressure control and are consistent with findings from observational studies and previous systematic reviews. In a large community-based study, patients who received intensive antihypertensive drug therapy were significantly more likely to have reduced systolic blood pressure of $6.3 \mathrm{mmHg}$ compared to an increase of $4.8 \mathrm{mmHg}$ in those who received less intensive antihypertensive drug therapy (Berlowitz 1998). A more recent observational study showed that antihypertensive drug therapy was initiated or changed in only $38 \%$ of episodes of care, despite documented uncontrolled hypertension for at least six months (Davis 2001; Davis 2001; Davis 2001; Oliveria 2002). Lack of practice organisation is associated with a failure to achieve treatment surrogate goals in hypertension, diabetes and secondary prevention of coronary heart disease (Phillips 2001). A recent systematic review of self monitoring also produced similar findings of modest but potentially important benefit (Cappuccio 2004).

We have found substantially more RCT evidence in terms of hypertension management than a recent systematic review that examined interventions used in disease management programmes for patients with chronic illness (Weingarten 2002). In this re- 
view, eight hypertension-related RCTs were cited which provided some evidence of benefit in terms of education directed at the patient and provider (health professional) (Weingarten 2002). In this systematic review of 56 RCTs, the subset of RCTs where the intervention was directed at the patient $(\mathrm{n}=16)$ or physician $(\mathrm{n}=9)$ does not support this finding, showing no clinically important evidence for patient or health professional education as an effective implementation strategy in the management of hypertension.

\section{Study limitations}

There are several shortcomings that need to be highlighted in this systematic review. The HDFP study was designed as an intervention that would identify newly diagnosed hypertensive patients and then start or modify antihypertensive treatment in those with untreated as well as uncontrolled hypertension (Davis 2001). A consequence of this study design is that a differential number of people were receiving antihypertensive drug treatment in the two arms, percentage of patients taking antihypertensive medication higher for stepped care $81.2 \%$, compared to referred care $64.2 \%$ at follow-up in year 5 (see details on included studies). So though it appears that the systematic follow-up and stepped care approach in HDFP is an important element in effective clinical care and prompts rigorous antihypertensive drug treatment, it is not possible to distinguish between the independent effect of these interventions on blood pressure control. Several other RCTs included both treated and untreated hypertensive patients and had differential rates of antihypertensive drug prescribing (Vetter 2000; Midanik 1991; Rudd 2004; Ornstein 2004), with rates of prescribing at higher levels in the intervention arm at follow up. Secondly, many RCTs contained multi-faceted interventions that did not fit into a single intervention category. For example several RCTs that were included under categories of patient education, physician education, health professional led care and organisation of care also incorporated some form of reminder intervention such as postal reminders or computer generated feedback (Dickinson 1981; Hamilton 1993; Hawkins 1979; Takala 1979; Takala 1983). Consequently, it has been difficult to attribute how far single elements that make up complex interventions exert their independent effect on blood pressure control. In terms of self monitoring, it is well established that "office" blood pressure readings are around $10 / 5 \mathrm{mmHg}$ higher when compared to ambulatory or self monitored readings (Staessen 1997; Staessen 2004; Williams 2004). Several of the RCTs did not make any recommendations about the need for adjustment of target blood pressure readings when self monitoring was the intervention being assessed, nor did they appear to anticipate lower blood pressure readings in the self monitoring group (Bailey 1998; Johnson 1978; Pierce 1984). This may have attenuated the impact of self monitoring on blood pressure control because of failure to intensify treatement. Poor adherence to therapy is thought to be associated with poor control of blood pressure (Shea 1992). Only a few trials examined the relation between adherence to medication and control of blood pressure (Haynes 1976; Johnson 1978; Sackett 1975). Future studies will need to be designed to assess the relationship between poor adherence and poor response to antihypertensive drugs in patients with good adherence. Lastly, not all RCTs reported on the outcomes of blood pressure achieved or blood pressure control. This has meant that the relevant a priori outcomes have not been reported for all included RCTs, and pooling of data from all RCTs has not been possible.

\section{A U THORS' CONCLUSIONS}

\section{Implications for practice}

Despite these limitations important messages emerge from this systematic review. Effective delivery of hypertensive care requires a systematic approach in the community, incorporating regular review of patients and a willingness to intensify antihypertensive drug treatment, usually by adding additional classes of antihypertensive drugs, when blood pressure goals are not being met $(\mathrm{Hy}$ pertension 1979; Hypertension 1979a; Hypertension 1986Davis 2001). This approach of intensive drug therapy and "tight" control of blood pressure has been demonstrated to be possible in clinical trials in hypertensive and diabetic patients alike (Hansson 1999; UK PDS 1998). There are reports of successful systematic care of hypertensive patients in the community over a 20 year period (Hart 1991), but the challenge is to translate these findings into usual clinical care.

\section{Implications for research}

In terms of future studies, careful preliminary work is needed when developing and testing complex interventions and thought needs to be given as to how their individual and combined effects are measured (Campbell 2000). Aside from definitive RCTs examining the effects of self-monitoring and allied health professional led care (pharmacist and nurses), there is also a paucity of evidence in terms of computer-based clinical decision support systems (CDSSs) in hypertension and how adherence-enhancing strategies influence subsequent blood pressure control (Ebrahim 1998). HDFP was a well-funded study with substantial staffing resources. This meant that the "stepped care" intervention was provided by a highly motivated workforce. An economic evaluation of delivering organised care to hypertensive patients should accompany future studies. Lastly, none of the included RCTs attempted to manage hypertension in the context of overall cardiovascular risk. Future studies need to be congruent with hypertension guidelines that recommend treatment and control of blood pressure in combination with multi-factorial risk reduction (Ramsay 1999).

\section{Conclusions}

Effective delivery of hypertension care in the community requires a rigorous approach in terms of identification, follow-up and treatment with antihypertensive drugs. This systematic review shows that such an approach is likely to translate into reductions in car- 
diovascular mortality and morbidity (Hypertension 1979; Hypertension 1979a; Hypertension 1986; Davis 2001). Supplementary and alternative models of care, including self monitoring of blood pressure by patients, blood pressure management by allied health care professionals and CDSSs require further development and evaluation. Educational interventions directed to either patients or health professionals alone are unlikely to produce clinically important reductions in either systolic or diastolic blood pressure.

\section{POTENTIAL CONFLICTOF IN TEREST}

None declared

\section{ACKNOWLEDGEMENTS}

We are very grateful to Margaret Burke (Cochrane Heart Group) for help with searching. Our thanks also to Alison Blenkinsopp, Brian Haynes, David Jewell, Jim Krieger, Richard McManus,
Steven Ornstein, Mike Phelan, Mary Rogers, Lin Song, Kelly Zarnke and Peter Whincup concerning clarification about individual RCTs and providing additional data. Thanks to Craig Ramsay for advice concerning factorial trials. We are grateful to Curt Furberg for facilitating contact with the investigators of US-based studies. Our particular thanks to Charlie Ford for information regarding the Hypertension Detection and Follow-Up Program (HDFP) study. Lastly, we are grateful to Debbie Farrell for administrative support.

\section{SOURCES OF SUPPORT}

\section{External sources of support}

- NHS R\&D Primary Care Career Scientist Award UK

- Medical Research Council Health Services Research Training Fellowship Scheme UK

Internal sources of support

- No sources of support supplied

\section{R E F E R E N C E S}

\section{References to studies included in this review}

Ahluwalia 1996 \{published data only\}

*Ahluwalia J, McNagny S, Kanuru N. Journal of Health Care for the Poor and Underserved 1996;7:377-389.

Artinian 2001 \{published data only\}

Artinian N, Washington O, Templin T. Effects of home telemonitoring and community-based monitoring on blood pressure control in urban African Americans: A pilot study. Heart \& Lung 2001;30: 191-199.

Bailey 1998 \{published data only\}

Bailey B, Carney S, Gillies A, Smith AJ. Antihypertensive drug treatment: a comparison of usual care with self blood pressure measurement. Journal of Human Hypertension 1998;13:147-150.

Barnett 1983 \{published data only\} Barnett GO, Winickoff RN, Morgan MM, Zielstorff RD. A computer-based monitoring system for follow-up of elevated blood pressure. Medical Care 1983;21(4):400-409.

Billault 1995 \{published data only\}

Billault B, Degoulet P, Devries C, Plouin PF, Chatellier G, Menard J. Use of a standardized personal medical record by patients with hypertension: a randomized controlled prospective trial. MD Computing 1995;12(1):31-35.

Bloom 1979 \{published data only\}

Bloom JR, Jordan SC. From screening to seeking care: removing obstacles in hypertension control. Preventive Medicine 1979;8(4):500506.

Bogden 1998 \{published data only\}

Bogden P, Abbott R, Williamson P, Onopa J, Koontz L. Comparing standard care with a physician and pharmacist team approach for uncontrolled hypertension. Journal of General Internal Medicine YR: 1998 1998;13:740-5.

Brook 1983 \{published data only\}

Brook RH, Ware JE, Jr, Rogers WH, Keeler EB, Davies AR, Donald CA, Goldberg GA, Lohr KN, Masthay PC, Newhouse JP. Does free care improve adults' health? Results from a randomized controlled trial. New England Journal of Medicine 1983;309(23):1426-1434.

Bulpitt 1976 \{published data only\}

Bulpitt CJ, Beilin LJ, Coles EC, Dollery CT, Johnson BF, MunroFaure, AD, Turner SC. Randomised controlled trial of computerheld medical records in hypertensive patients. British Medical Journal 1976;1(6011):677-679.

Burrelle 1986 \{published data only\}

Burrelle TN. Evaluation of an interdisciplinary compliance service for elderly hypertensives. J Geriatr Drug Ther YR:1986 Vol. 1, issue 2:23-51'.

Carnahan 1975 \{published data only\}

Carnahan JE, Nugent CA. The effects of self-monitoring by patients on the control of hypertension. American Journal of the Medical Sciences 1975;269(1):69-73.

Coe 1977 \{published data only\}

Coe FL, Norton E, Oparil S, Tatar A, Pullman TN. Treatment of hypertension by computer and physician-a prospective controlled study. Journal of Chronic Diseases 1977;30(2):81-92.

Cummings 1985 \{published data only\}

Cummings KM, Frisof KB, Demers P, Walsh D. An appointment reminder system's effect on reducing the number of hypertension patients who drop out from care. American Journal of Preventive Medicine 1985;1(5):54-60. 
Dickinson 1981 \{published data only\}

Dickinson JC, Warshaw GA, Gehlbach SH, Bobula JA, Muhlbaier LH, Parkerson GR, Jr. Improving hypertension control: impact of computer feedback and physician education. Medical Care 1981;19 (8):843-854

Earp 1982 \{published data only\}

Earp JA, Ory MG, Strogatz DS. The effects of family involvement and practitioner home visits on the control of hypertension. American Journal of Public Health 1982;72(10):1146-1154.

Evans 1986 \{published data only\}

Evans CE, Haynes RB, Birkett NJ, Gilbert JR, Taylor DW, Sackett DL, Johnston ME, Hewson SA. Does a mailed continuing education program improve physician performance? Results of a randomized trial in antihypertensive care. JAMA 1986;255(4):501-504.

Fielding 1994 \{published data only\} Fielding JE, Knight K, Mason T, Klesges RC, Pelletier KR. Evaluation of the IMPACT blood pressure program. Journal of Occupational Medicine 1994;36(7):743-746.

Fletcher 1975 \{published data only\}

Fletcher SW, Appel FA, Bourgeois MA. Management of hypertension. Effect of improving patient compliance for follow-up care. JAMA 1975;233(3):242-244.

Friedman 1996 \{published data only\}

Friedman RH, Kazis LE, Jette A, Smith MB, Stollerman J, Torgers J, Carey K. A telecommunications system for monitoring and counseling patients with hypertension. Impact on medication adherence and blood pressure control. American Journal of Hypertension 1996; Vol. 9, issue 4 Pt 1:285-92.

Garcia-Pena 2001 \{published data only\}

Garcia-Pena C, Thorogood M, Armstrong B, Reyes-Frausto S, Munoz O. Pragmatic randomized trial of home visits by a nurse to elderly people with hypertension in Mexico. International Journal of Epidemiology 2001;30:1485-1491.

Gullion 1987 \{published data only\}

Gullion DS, Tschann JM, Adamson TE. Physicians' management of hypertension: a randomized controlled CME trial. Proceedings of the --- Annual Conference on Research in Medical Education 1987;26: 115-120.

Hamilton 1993 \{published data only\}

Hamilton G, Roberts S, Johnson J, Tropp J, Anthony-Odgren D, Johnson B. Increasing adherence in patients with primary hypertension: an intervention. Health Values 1993; Vol. 17:3-11.

Hawkins 1979 \{published data only\}

Hawkins D, Fridler F, Douglas H, Eschbach R. Evaluation of a clinical pharmacist in caring for hypertensive and diabetic patients. American Journal of Hosptial Pharmacy 1979; Vol. 36:1321-5.

Haynes 1976 \{published data only\} Haynes RB, Sackett DL, Gibson ES, Taylor DW, Hackett BC, Roberts RS, Johnson AL. Improvement of medication compliance in uncontrolled hypertension. Lancet 1976;1(7972):1265-1268.

Hetlevik 1998 \{published data only\}

Hetlevik I, Holmen J, Kruger O, Kristensen P, Iversen H. Implementing Clinical Guidelines in the Treatment of Hypertension in General Practice. Blood Pressure 1998;7:270-276.
Hetlevik 1999 \{published data only\}

Hetlevik I, Holmen J, Kruger O. Implementing clinical guidelines in the treatment of hypertension in general practice Evaluation of patient outcome related to implementation of a computer-based clinical decision support system. Scandinavian Journal of Primary Health Care 1999; 17:35-40.

Hypertension 1979 \{published data only\}

Hypertension Detection \& Follow-up Program. Therapeutic control of blood pressure in the Hypertension Detection and Follow-up Program. Hypertension Detection and Follow-up Program Cooperative Group. Preventive Medicine 1979;8(1):2-13.

Hypertension 1979a \{published data only\}

Hypertension detection and follow-up Program Cooperative Group. Five-year findings of the hypertension detection and follow-up program I. Reduction in mortality of persons with high blood pressure, including mild hypertension. Journal of the American Medical Association 1979;242(23):2562-2571.

Hypertension 1982 \{published data only\}

Hypertension detection and follow-up Program Cooperative Group. The effect of treatment on mortality in "mild" hypertension Results of the Hypertension Detection and Follow-up Program. The New England Journal of Medicine 1982;307(16):976-980.

Hypertension 1986 \{published data only\}

Hypertension detection and follow-up Program Cooperative Group. Persistence of reduction in blood pressure and mortality of participants in the hypertension detection and follow-up program. Journal of the American Medical Association 1986;259(14):2113-2122.

Jewell 1988 \{published data only\}

Jewell D, Hope J. Evaluation of a nurse-run hypertension clinic in general practice. Practitioner 1988;232(1447):484-487.

Johnson 1978 \{published data only\}

Johnson AL, Taylor DW, Sackett DL, Dunnett CW, Shimizu AG Self-recording of blood pressure in the management of hypertension. Canadian Medical Association Journal 1978;119(9):1034-1039.

Krieger 1999 \{published data only\}

Krieger J, Collier C, Song L, Martin D. Linking community-based blood pressure measurement to clinical care: a randomized controlled trial of outreach and tracking by community health workers. American Journal of Public Health 1999;89:856-861.

Levine 1979 \{published data only\}

Levine DM, Green LW, Deeds SG, Chwalow J, Russell RP, Finlay J. Health education for hypertensive patients. JAMA 1979;241(16): 1700-1703.

Logan 1979 \{published data only\} Logan AG, Milne BJ, Achber C, Campbell WP, Haynes RB. Worksite treatment of hypertension by specially trained nurses. A controlled trial. Lancet 1979;2(8153):1175-1178.

Martinez-Amenos 1990 \{published data only\}

Martinez-Amenos A, Fernandez Ferre ML, Mota Vidal C, Alsina Rocasalbas, J. Evaluation of two educative models in a primary care hypertension programme. Journal of Human Hypertension 1990;4(4): 362-364.

McAlister 1986 \{published data only\}

McAlister NH, Covvey HD, Tong C, Lee A, Wigle ED. Randomised controlled trial of computer assisted management of hypertension in 
primary care. British Medical Journal Clinical Research Ed 1986;. 293 (6548):670-674.

Mehos 2000 \{published data only\}

Mehos BM, Saseen JJ, MacLaughlin EJ. Effect of Pharmacist Intervention and Initiation of Home Blood Pressure Monitoring in $\mathrm{Pa}$ tients with Uncontrolled Hypertension. Pharmacotherapy 2000;20 (11):1384-1389.

Midanik 1991 \{published data only\}

Midanik LT, Resnick B, Hurley LB, Smith EJ, McCarthy M. Home blood pressure monitoring for mild hypertensives. Public Health Reports 1991;106(1):85-89. [MedLine: 1039].

Montgomery 2000 \{published data only\}

Montgomery AA, Fahey T, Peters TJ, MacKintosh C, Sharp D. Evaluation of a computer-based clinical decision support system and chart guidelines in the management of hypertension in primary care: a randomised controlled trial. British Medical Journal 2000;320:686-690.

Morisky 1983 \{published data only\}

Morisky DE, Levine DM, Green LW, Shapiro S, Russell RP, Smith CR. Five-year blood pressure control and mortality following health education for hypertensive patients. American Journal of Public Health 1983;73(2):153-162.

Muhlhauser 1993 \{published data only\}

Muhlhauser I, Sawicki PT, Didjurgeit U, Jorgens V, Trampisch HJ, Berger M. Evaluation of a structured treatment and teaching programme on hypertension in general practice. Clinical \& Experimental Hypertension 1993;15(1):125-142.

New 2004 \{published data only\}

New J, Mason J, Freemantle N, Teasdale S, Wong L, Bruce N, Burns $\mathrm{J}$, Gibson J. Educational outreach in diabetes to encourage practice nurses to use primary care hypertension and hyperlipidaemia guidelines (EDEN): a randomized controlled trial. Diabetic Medicine 2004; 21:599-603. [MedLine: 2956].

Ornstein 2004 \{published data only\}

Ornstein S, Jenkins R, Nietert P, Feifer C, Roylance L, Nemthe L, Corley S, Dickerson L, Bradford D, Litvin C. A multimethod quality improvement intervention to improve preventive cardiovascular care. Annals of Internal Medicine 2004;141:523-532. [MedLine: 2960].

Park 1996 \{published data only\} Park JJ, Kelly P, Carter BL, Burgess PP. Comprehensive Pharmaceutical Care in the Chain Setting. Drug therapy monitoring and counseling be pharmacists contributed to improved blood pressure control in study patients. Journal of the American Pharmaceutical Association 1996;NS36(7):443-451.

Pierce 1984 \{published data only\} Pierce JP, Watson DS, Knights S, Gliddon T, Williams S, Watson R. A controlled trial of health education in the physician's office. Preventive Medicine 1984;13(2):185-194.

Robson 1989 \{published data only\}

Robson J, Boomla K, Fitzpatrick S, Jewell AJ, Taylor J, Self J, Colyer M. Using nurses for preventive activities with computer assisted follow up: a randomised controlled trial. BMJ 1989;298(6671):433436.

Roca-Cusachs 1991 \{published data only\}

Roca-Cusachs A, Sort D, Altimira J, Bonet R, Guilera E, Monmany J, Nolla J. The impact of a patient education programme in the control of hypertension. Journal of Human Hypertension 1991;5(5): 437-441.

Rogers 2001 \{published data only\}

Rogers M, Small D, Buchan D, Butch C, Stewart C, Krenzer B, Husovsky $\mathrm{H}$. Home monitoring services improves mean arterial pressure in patients with essential hypertension. Annals of Internal Medicine 2001;134:1024-1032.

Rudd 2004 \{published data only\}

Rudd P, Houston Miller N, Kaufman J, Kraemer H, Bandura A, Greenwald G, Debusk R. Nurse management for hypertension: a systems approach. American Journal of Hypertension 2004;17:921927. [MedLine: 2959].

Sackett 1975 \{published data only\}

Sackett DL, Haynes RB, Gibson ES, Hackett BC, Taylor DW, Roberts RS, Johnson AL. Randomised clinical trial of strategies for improving medication compliance in primary hypertension. Lancet 1975;1(7918):1205-1207.

Sanders 2002 \{published data only\}

Sanders K, Satyvavolu A. Improving blood pressure control in diabetes: limitations of a clinical reminder in influencing physician behaviour. The Journal of Continuing Education in the Health Professions 2002;22:23-32. [MedLine: 2963].

Soghikian 1992 \{published data only\} Soghikian K, Casper SM, Fireman BH, Hunkeler EM, Hurley LB, Tekawa, IS, Vogt TM. Home blood pressure monitoring. Effect on use of medical services and medical care costs. Medical Care 1992;30 (9):855-865.

Solomon 2002 \{published data only\} Solomon D, Portner T, Bass G, Gourley D, Gourley G, Holt J, Wicke W, Braden R, Eberle T, Self T, Lawrence B. Part 2. Clinical and economic outcomes in the hypertension and COPD arms of a mulitcenter outcomes study. Journal of the American Pharmaceutical Association 2002; Vol. 38:574-84.

Takala 1979 \{published data only\}

Takala J, Niemela N, Rosti J, Sievers K. Improving compliance with therapeutic regimens in hypertensive patients in a community health center. Circulation 1979;59(3):540-543.

Takala 1983 \{published data only\}

Takala J. Screening, treatment and adherence to treatment for hypertension. Scandinavian Journal of Primary Health Care 1983;1(34):114-119.

Tanner 1981 \{published data only\} Tanner GA, Noury DJ. The effect of instruction on control of blood pressure in individuals with essential hypertension. Journal of Advanced Nursing 1981;6(2):99-106.

Tobe 2006 \{unpublished data only\}

Tobe SW. Diabetes risk evaluation and microalbuminuria in first nations people with Diabetes (DREAM 3): a randomised controlled trial of nurse administered blood pressure managment. Journal of the Canadian Medical Association 2006.

Vetter 2000 \{published data only\}

Vetter W, Brignoli R. Influence of self-measurement of blood pressure on the responder rate in hypertensive patients treated with losartan: results of the SVATCH study. Journal of Human Hypertension 2000; 14:235-241. 
Watkins 1987 \{published data only\}

Watkins CJ, Papacosta AO, Chinn S, Martin J. A randomized controlled trial of an information booklet for hypertensive patients in general practice. Journal of the Royal College of General Practitioners 1987;37(305):548-550.

Webb 1980 \{published data only\}

Webb PA. Effectiveness of patient education and psychosocial counseling in promoting compliance and control among hypertensive patients. Journal of Family Practice 1980;10(6):1047-1055.

Zarnke 1997 \{published data only\} Zarnke K, Feagan B, Mahon J, Feldman R. A randomized study comparing a patient-directed hypertension management strategy with usual office-based care. American Journal of Hypertension 1997;10: $58-67$.

Zismer 1982 \{published data only\}

Zismer DK, Gillum RF, Johnson CA, Becerra J, Johnson TH. Improving hypertension control in a private medical practice. Archives of Internal Medicine 1982;142(2):297-299.

\section{References to studies excluded from this review \\ Andrejak 2000}

Andrejak M, Genes N, Vaur L, Poncelet P, Clerson P, Carre A. Electronic Pill-Boxes in the Evaluation of Antihypertensive Treatment Compliance: Comparison of Once Daily Versus Twice Daily Regimen. American Journal of Hypertension 2000;13:184-190. [MedLine: 1365].

Bachman 2002

Bachman L, Steurer J, Holm D, Vetter W. To what extent can we trust home blood pressure measurement? A randomized controlled trial. The Journal of Clinical Hypertension 2002;4:405-407. [MedLine: 2962].

\section{Barron-Rivera 1998}

Barron-Rivera AJ, Torreblaca-Roldan FL, Sanchez-Casanova LI, Martinez-Beltran M. Effect of an educational intervention on the quality of life of the hypertense patient. Salud Publica de Mexico YR: 1998 Vol. 40, issue 6:503-9. [MedLine: 1362].

Ben Said

Ben Said M, Consoli SM, Jean J. A comparative study between a computer-aided education (ISIS) and habitual education techniques for hypertensive patients. Proceedings - the Annual Symposium on Computer Applications in Medical Care YR:1994 [MedLine: 1373].

Binstock 1988

Binstock ML, Franklin KL. A comparison of compliance techniques on the control of high blood pressure. Am J Hypertens 1988;1:192S1944 S.

Birtwhistle 2004

Birtwhistle RV, Godwin MS, Delva MD, Casson RI, Lam M, MacDonald SE, Seguin R, Ruhland L. Randomised equivalence trial comparing three month and six month follow up of patients with hypertension by family practitioners. BMJ 2004;328(7433):204-0.

Blenkinsopp 2000

Blenkinsopp A, Phelan M, Bourne J, Dakhil N. Extended adherence support by community pharmacists for patients with hypertension: a randomised controlled trial. The International Journal of Pharmacy Practice 2000;8:165-175.

\section{Bond 1984}

Bond CA, Monson R. Sustained improvement in drug documentation, compliance, and disease control. A four-year analysis of an ambulatory care model. Archives of Internal Medicine 1984;144(6): 1159-1162. [MedLine: 906].

Broege 2001

Broege P, James GD, Pickering TG. Management of hypertension in the elderly using home blood pressures. Blood Pressure Monitoring 2001;6:139-144.

\section{Cappuccio 2004}

Cappuccio FP, Kerry SM, Forbes L, Donald A. Blood pressure control by home monitoring: meta-analysis of randomised trials. BMJ 2004 bmj.

\section{Caro 1998}

Caro JJ, Speckman JL. Existing treatment strategies: does nocompliance make a difference?. Journal of Hypertension 1998;16(Supplement 7):S31-S34. [MedLine: 1358].

\section{Celis 1998}

Celis H, Staessen JA, Buntinz F, Fagard R, Leeman M, Thijs L, Van Hedent T. Antihypertensive treatment based on home or office blood pressure measurement: protocol of the randomized controlled THOP trial. Blood Pressure Monitoring 1998;3(Supplement 1):S29S35. [MedLine: 1356].

\section{Charlesworth 1984}

Charlesworth EA, Williams BJ, Baer PE. Stress management at the worksite for hypertension: compliance, cost-benefit, health care and hypertension-related variables. Psychosomatic Medicine 1984;46(5): 387-397. [MedLine: 827].

\section{Consoli}

Consoli SM, Ben Said M, Jean J, Menard J, Plouin PF, Chatelier G. Interactive electronic teaching (ISIS); has the future started?. Journal of Human Hypertension YR:1996 Vol. 10, issue Supplement 1:S69S72. [MedLine: 1370].

\section{Consoli SM, Ben2}

Consoli SM, Ben Said M, Jean J, Menard J, Plouin PF, Chatellier G. Benefits of a computer-assisted education program for hypertensive patients compared with standard education tools. Patient Education \& Counselling YR:1995 Vol. 26, issue 1-3:343-7. [MedLine: 1371].

\section{Consoli SM, Ben3}

Consoli SM, Ben Said M, Jean J, Menard J, Plouin PF, Chatelier G. Evaluation of a computer assisted training program for hypertensive patients. Archives des Maladies du Coeur et des Vaisseaux YR:1994 Vol. 87, issue 8:1093-6. [MedLine: 1372].

\section{Cranney 1999}

Cranney M, Barton S, Walley T. Addressing barriers to change: an RCT of practice-based education to improve the management of hypertension in the elderly. British Journal of General Practice 1999; 49:522-526. [MedLine: 1344].

\section{Denver 2003}

Denver E, Barnard M, Woolfson R, Earle K. Management of uncontrolled hypertension in a nurse-led clinic compared with conventional care for patients with Type 2 diabetes. Diabetic Care 2003;26 2256-2260. [MedLine: 2958]. 


\section{Djerassi 1990}

Djerassi L, Silverberg DS, Goldblatt H, Goldberg A, Porat V. Comparison of hypertension treatment on and off the worksite. Journal of Human Hypertension 1990;4(4):322-325. [MedLine: 610].

\section{Dusing 1998}

Dusing R, Weisser B, Mengden T, Vetter H. Changes in Antihypertensive Therapy - The Role of Adverse Effects and Compliance. Blood Pressure 1998;7:313-315. [MedLine: 1368].

Erickson 1997

Erickson SR, Slaughter R, Halapy H. Pharmacists' Ability to Influence Outcomes of Hypertension Therapy. Pharmacotherapy 1997;17 (1):140-147. [MedLine: 1389].

\section{Flack 1995}

Flack JM, Novikov SV, Ferrario CM. Benefits of adherence to anti-hypertensive drug therapy. European Heart Journal 1995;17 (Supplement A):16-20. [MedLine: 1387].

\section{Flack 2000}

Flack JM, Yunis C, Preisser J, Holmes CB, Mensah G, McLean B, Saunders E. The Rapidity of Drug Dose Escalation Influences Blood Pressure Responses and Adverse Effects Burden in Patients With Hypertension. The Quinapril Titration Interval Management Evaluation (ATIME) Study. Archives of Internal Medicine 26-6-2000;160 1842-1847. [MedLine: 1384].

\section{Foote 1983}

Foote A, Erfurt JC. Hypertension control at the work site. Comparison of screening and referral alone, referral and follow-up, and on-site treatment. New England Journal of Medicine 1983;308(14): 809-813. [MedLine: 292].

\section{Girvin 1999}

Girvin B, McDermott J, Johnston GD. A comparison of enalapril $20 \mathrm{mg}$ once daily versus $10 \mathrm{mg}$ twice daily in terms if blood pressure lowering patient compliance. Journal of Hypertension 1999;17:16271631. [MedLine: 1360].

Godley 2003

Godley P, Nguyen A, Yokoyama K, Rohack J, Woodward B, Chiang T. Improving hypertension care in a large group-model MCO. American Journal of Health-System Pharmacy 2003;60:554-563. [MedLine: 2964].

Gonzalez-Fernandez

Gonzalez-Fernandez RA, Rivera M, Torres D, Quiles J, Jackson A. Usefulness of a systemic hypertension in-hospital educational program. American Journal of Cardiology 1990;65(20):1384-1386.

Grimm

Grimm RH, Jr, Grandits GA, Cutler JA, Stewart AL, McDonald RH, Svendsen K, Prineas RJ, Liebson PR. Relationship of Qualityof-Life measures to Long-term Lifestyle and Drug Treatment in the Treatment of Mild Hypertension Study. Archives of Internal Medicine 1997;157:638-648. [MedLine: 1386].

\section{Hatcher 1986}

Hatcher ME, Green LW, Levine DM, Flagle CE. Validation of a decision model for triaging hypertensive patients to alternate health education interventions. Social Science \& Medicine 1986;22(8):813819. [MedLine: 836].

\section{Herbert 2004}

Herbert CP, Wright JM, Maclure M, Wakefield J, Dormuth C, BrettMacLean P, Legare J, Premi J. Better Prescribing Project: a random- ized controlled trial of the impact of case-based educational modules and personal prescribing feedback on prescribing for hypertension in primary care. Family Practice 2004;21(5):575-581. [MedLine: 2955].

Hyman

Hyman DJ, Pavlik VN. Self-reported Hypertension Treatment Practices Among Primary Care Physicians. Blood Pressure Thresholds, Drug Chocies, and the Role of Guidelines and EvidenceBased Medicine. Archives of Internal Medicine 2002;160:2281-2286. [MedLine: 1385].

\section{Inui 1976}

Inui TS, Yourtee EL, Williamson JW. Improved outcomes in hypertension after physician tutorials. A controlled trial. Annals of Internal Medicine 1976;84(6):646-651. [MedLine: 132].

Iso 1996

Iso H, Shimamoto T, Yokota K, Sankai T, Jacobs DR, Komachi Y. Community-Based Education classes for hypertension control. Hypertension 1996;27:968-974. [MedLine: 1342].

Iso $\mathbf{H}$,

Iso H, Shimamoto T, Yokota K, Sankai T, Jacobs DR. CommunityBased Education Classes for Hypertension Control. A 1.5-Year Randomized Controlled Trial. Hypertension 1996;27:968-974. [MedLine: 1367].

\section{Jennett 1986}

Jennett PA, Laxdal O, Hayton R, Klaassen D, Mainprize G, Spooner J, Swanson R, Wickett R, Wilson T. The effects of continuing medical education upon family physician performance in the office management of hypertension. A randomized controlled study. 1986;25: 145-150. [MedLine: 3250].

\section{Kawachi 1991}

Kawachi I, Malcolm LA. The cost-effectiveness of treatingmild-tomoderate hypertension: a reappraisal. Journal of Hypertension 1991; 9:199-208. [MedLine: 1382].

\section{Krishan 1979}

Krishan I, Brennan LA, Jr, Nobrega FT, Smoldt RK, Smutka LK, Labarthe, DR, McEnaney JA, Hunt JC. The Mayo Three-Community Hypertension Control Program. II. Outcome of intervention in entire communities. Mayo Clinic Proceedings 1979;54(5):299-306. [MedLine: 236].

\section{Levine 2003}

Levine DM, Bone LR, Hill MN, Stallings R, Gelber AC, Barker A, Harris EC, Zeger SL, Felix-Aaron KL, Clark JM. The effectiveness of a community/academic health center partnership in decreasing the level of blood pressure in an urban African-American population. [comment]. Ethnicity \& Disease 2003;13(3):354-361. [MedLine: 3903].

\section{Lewis 1967}

Lewis CE, Resnik BA. Nurse clinics and progressive ambulatory patient care. The New England Journal of Medicine 7-12-1967;277(23): 1236-1241. [MedLine: 1375].

\section{Linjer 1997}

Linjer E, Hansson L. Underestimation of the true benefits of antihypertensive treatment: an assessment of some important sources of error. Journal of Hypertension 1997;15:221-225. [MedLine: 1383]. 


\section{Littenberg 1990}

Littenberg B, Garber AM, Sox HC. Screening for Hypertension. Annals of Internal Medicine 1-2-1990;112(3):192-202. [MedLine: 1380].

\section{Marquez 2000}

Marquez Contreras E, Casado Martinez JJ, Celotto Gomez B, Gascon Vivo J, Martin de Pablos JL, Gil Rodriguez R, Lopez Molina V, Dominguez YR. Therapeutic compliance in hypertension. Trial of two-year health education intervention. Atencion Primaria YR:2000 Vol. 26, issue 1:5-10. [MedLine: 1363].

\section{Mashru 1997}

Mashru M, Lant A. Interpractice audit of diagnosis and management of hypertension in primary care: educational intervention and review of medical records. British Medical Journal 1997;314:942-946. [MedLine: 1351].

\section{McDowell 1989}

McDowell I, Newell C, Rosser W. A randomized trial of computerized reminders for blood pressure screening in primary care. Medical Care 1989;27(3):297-305. [MedLine: 645].

\section{McInnes 1995}

McInnes GT, McGhee SM. Delivery of care for hypertension. Journal of Human Hypertension 1995;9:429-433. [MedLine: 1369].

\section{McKenney 1973}

McKenney JM, Slining JM, Henderson HR, Devins D, Barr M. The effect of clinical pharmacy services on patients with essential hypertension. Circulation 1973;48(5):1104-1111. [MedLine: 1194].

\section{Murray 1988}

Murray DM, Kurth CL, Finnegan JR, Jr, Pirie PL, Admire JB, Luepker RV. Direct mail as a prompt for follow-up care among persons at risk for hypertension. American Journal of Preventive Medicine 1988; 4(6):331-335. [MedLine: 543].

\section{New 2003}

New J, Mason J, Freemantle N, Teasdale S, Wong L, Bruce N, Burns J, Gibson J. Specialist nurse-led intervention to treat and control hypertension and hyperlipidemia in Diabetes (SPLINT). Diabetic Care 2003;26:2250-2254. [MedLine: 2957].

Pheley 1995

Pheley AM, Terry P, Pietz L, Fowles J, McCoy CE, Smith H. Evaluation of a nurse-based hypertension managment program: Screening, management, and outcomes. The Journal of Cardiovascular Nursing 1995;9(2):54-61. [MedLine: 1355].

\section{Putnam 1989}

Putnam RW, Curry L. Physicians' participation in establishing criteria for hypertension management in the office: will patient outcomes be improved?. Canadian Medical Association Journal 1989;140(7):806809. [MedLine: 726].

Ramsay 1996

Ramsay LE, Haq IU, Yeo WW, Jackson PR. Interpretation of prospective trials in hypertension: do treatment guidelines accurately reflect current evidence?. Journal of Hypertension 1996;14(Supplement 5): S187-S194. [MedLine: 1381].

\section{Staessen 2004}

Staessen J, Den Hond E, Celis H, Fagard R, Keary L, Vandenhoven G, O’Brien ET. Antihypertensive treatment based on blood pressure measurement at home or in the physician's office. Journal of the American Medical Association 2004;291:955-964.

\section{Stahl 1984}

Stahl SM, Kelley CR, Neill PJ, Grim CE, Mamlin J. Effects of home blood pressure measurement on long-term BP control. American Journal of Public Health 1984;74(7):704-709. [MedLine: 713].

\section{Statson 1977}

Statson WB, Weinstein MC. Public-Health Rounds at the Harvard School of Public Health. allocation of Resources to Manage Hypertension. The New England Journal of Medicine 31-3-1977;296(13): 732-739. [MedLine: 1379].

Stephenson 1999

Stephenson J. Noncompliance May Cause Half of Antihypertensive Drug "Failures“. JAMA 28-6-1999;282(4):313-314. [MedLine: 1378].

\section{Trocha 1999}

Trocha AK, Schmidtke C, Didjurgeit U, Muhlhauser I, Bender R, Berger M, Sawicki PT. Effects of intensified antihypertensive treatment in diabetic nephropathy: mortality and morbidity results of a prospective controlled 10-year study. Journal of Hypertension 1999; 17:1497-1503. [MedLine: 1374].

Tu 1999

Tu M. The effect of health education on self-care behaviours and hypertension control in elderly hypertensive patients at a veterans home. Chinese Journal of Public Health 1999;18:54-65. [MedLine: 1405].

\section{UK PDS 1998}

UK Prospective Diabetes Study Group. Tight Blood pressure control and risk of macrovascular and microscular complications in type 2 diabetes: UKPDS 38. British Medical Journal 12-9-1998;317:703713. [MedLine: 1377].

\section{van den Hoogen 1990}

van den Hoogen JP, van Ree JW. Preventive cardiology in general practice: computer-assisted hypertension care. Journal of Human Hypertension 1990;4(4):365-367. [MedLine: 606].

\section{Waeber 1999}

Waeber B, Leonetti G, Kolloch R, McInnes GT. Compliance with asprin or placebo in the hypertension optimal treatment (HOT) study. Journal of Hypertension 1999;17:1041-1045. [MedLine: 1388].

\section{Weiner 1980}

Weiner EE. Nurse management of hypertension. American Journal of Nursing 1980;80(6):1129.

\section{Weir 2002}

Weir MR, Maibach EW, Bakris GL, Black HR, Chawla P, Messerli FH, Neutel JM, Weber MA. Implications of a health Lifestyle and Medication Analysis for Improving Hypertension Control. Archives of Internal Medicine 28-2-0002;160:481-490. [MedLine: 1359].

\section{Wollard 1995}

Wollard J, Beilin L, Lord T, Puddey I, MacAdam D, Rouse I. A controlled trial of nurse counselling on lifestyle change for hypertensives treated in general practice: preliminary results. Clinical and Experimental Pharmacology and Physiology 1995;22:466-468. [MedLine: 1366].

\section{Wyka-Fitzgerald 1984}

Wyka-Fitzgerald C, Levesque P, Panciera T, Vendettoli D, Mattea E. Long-term evaluation of group education for high blood pressure control. Cardiovascular Nursing 1984;20(3):13-18. [MedLine: 728]. 
Zernike 1998

Zernike W, Henderson A. Evaluating the effectiveness of two teaching strategies for patients diagnosed with hypertension. Journal of Clinical Nursing 1998;7:37-44. [MedLine: 1364].

\section{References to ongoing studies}

Coppola

Improving the primary prevention of stroke in older patients in general practice: a randomized controlled trial. Ongoing study Not known.

Krieger

SHIP Clinic-Based Program. Ongoing study Not known.

\section{McManus}

A randomised controlled trial of patient held targets and self monitoring in the control of hypertension: Targets And Self Monitoring IN Hypertension (TASMINH). Ongoing study September 2001, last patient randomised March 2002, final follow up March 2003.

Sullivan

HYPER Trial. Ongoing study August 1999.

Zarnke

Not known. Ongoing study Not known.

\section{Additional references}

\section{Berlowitz 1998}

Berlowitz D, Ash A, Hickey E, Friedman R, Glickman M, Kader $\mathrm{B}$, Moskowitz M. Inadequate management of blood pressure in a hypertensive population. The New England Journal of Medicine 1998; 339:1957-1963. [MedLine: 1364]

\section{Blood 2000}

Blood pressure lowering Treatment Trialists' Collaboration. Effects of ACE inhibitors, calcium antagonists, and other blood pressure lowering drugs: results of prospectively designed overviews of randomised trials. Lancet 2000;356:1955-1964. [MedLine: 1670].

Bobrie 2004

Bobrie G, Chatellier G, Genes N, Clerson P, Vaur L, Vaisse B, Menard J, Mallion JM. Cardiovascular prognosis of "masked hypertension" detected by blood pressure self-measurement in elderly treated hypertensive patients. Journal of the American Medical Association 2004; 291:1342-1349.

Burnier 2002

Burnier M. Blood pressure control and the implementation of guidelines in clinical practice: can we fill the gap?. Journal of Hypertension 2002;20:1251-1253. [MedLine: 1997].

\section{Campbell 2000}

Campbell M, Fitzpatrick R, Haines A, Kinmonth AL, Sandercock P, Spiegelhalter D, Tyrer P. Framework for design and evaluation of complex interventions to improve health. British Medical Journal 2000;321:694-696. [MedLine: 1643].

\section{Cappuccio 2004}

Cappuccio FP, Kerry SM, Forbes L, Donald A. Blood pressure control by home monitoring: meta-analysis of randomised trials. BMJ 2004 bmj. [MedLine: 2870].

\section{Chobanian 2001}

Chobanian AV. Control of hypertension - an important national priority. The New England Journal of Medicine 16-8-2001;345(7): 534-535. [MedLine: 1927].

\section{Clarke 2000}

Clarke M, Oxman AD. Assessment of study quality. The Cochrane Library, Cochrane reviewer's handbook 4.1 [updated June 2000]. Issue 2. 2000

Collins 1994

Collins R, Peto R. Antihypertensive drug therapy: effects on stroke and coronary heart disease. In: SwalesJ editor(s). Textbook of Hypertension. Oxford: Blackwell Scientific Publications, 1994.

Davis 2001

Davis B, Ford C. The Hypertension Detection and Follow up Program. In: BlackHR editor(s). Clinical trials in Hypertension. New York: Marcel Dekker Inc, 2001.

Du 1997

Du X, Cruickshank JK, McNamee R, Saraee M, Sourbutts J, Summers A, Roberts N, Walton E, Holmes S. Case-control study of stroke and the quality of hypertension control in north west England. British Medical Journal 1997;314:272-276. [MedLine: 1000].

\section{Ebrahim 1998}

Ebrahim S. Detection, adherence and control of hypertension for the prevention of stroke: a systematic review. Health Technology Assessment 1998;2:11. [MedLine: 2164].

\section{Follman 1992}

Follman D, Elliott P, Suh I, Cutler J. Variance imputations for overviews of clinical trials with continuous response. Journal of Clinical Epidemiology 1992;45:769-773. [MedLine: 1408].

\section{Frijling 2001}

Frijling B, Spies T, Lobo C, Hulscher M, van Drenth B, Braspenning G, Prins A, van der Woulden J, Grol R. Blood pressure control in treated hypertensive patients: clinical performance of general practitioners. British Journal of General Practice 2001;51:9-14. [MedLine: 1626].

\section{Gueyffier 1999}

Gueyffier F, Bulpitt C, Boissel JP, Schron E, Ekbom T, Fagard R, Casiglia E, Kerlikowske K, Coope J. Antihypertensive drugs in very old people: a subgroup meta-analysis of randomised controlled trials. Lancet 1999;353:793-796. [MedLine: 2161].

\section{Hansson 1999}

Hansson L, Zanchetti A, Carruthers S, Dahlof B, Elmfeldt D, Julius S, Menard J, Rahn K, Wedel H, Westerling S. Effects of intensive blood pressure lowering and low dose aspirin in patients with hypertension: principal results of the Hypertension Optimal Treatment (HOT) randomised trial. Lancet 1999;351:1755-1762. [MedLine: 1478].

Hart 1991

Hart JT, Thomas C, Gibbons B, Edwards C, Hart M, Jones J, Jones $\mathrm{M}$, Walton $\mathrm{P}$. Twenty five years of case finding and audit in a socially deprived community [see comments]. BMJ 1991;302(6791):15091513. [MedLine: 1220].

\section{Hyman 2001}

Hyman DJ, Pavlik VN. Characteristics of patients with uncontrolled hypertension in the United States. [see comments.]. New England Journal of Medicine 2001;345(7):479-486. [MedLine: 2157]. 


\section{Keeler 1985}

Keeler EB, Brook RH, Goldberg GA, Kamberg CJ, Newhouse JP. How free care reduced hypertension in the health insurance experiment. JAMA 1985;254(14):1926-1931. [MedLine: 864].

\section{Oakeshott 2003}

Oakeshott P, Kerry S, Austin A, Cappuccio F. Is there a role for nurseled blood pressure management in primary care?. 2003;20(4):469473. [MedLine: 2816].

\section{Oliveria 2002}

Oliveria SA, Lapuerta P, McCarthy BD, L'Italien GJ, Berlowitz DR, Asch SM. Physician-Related Barriers to the Effective Management of Uncontrolled Hypertension. Annals of Internal Medicine 2002;162: 413-420. [MedLine: 2142].

Payne 1993

Payne JN, Milner PC, Saul C, Bowns I, Hannay DR, Ramsay LE. Local confidential inquiry into avoidable factors in deaths from stroke and hypertensive disease. British Medical Journal 1993;307:10271030. [MedLine: 196].

Phillips 2001

Phillips L, Branch W, Cook C, Doyle J, El-Kebbi I, Gallina D, Miller C, Ziemer D, Barnes C. Clinical inertia. Annals of Internal Medicine 2001;135:825-834. [MedLine: 1919].

Ramsay 1999

Ramsay LE, Williams B, Johnston G, MacGregor GA, Poston L, Potter JF, Poulter NR, Russell G. Guidelines for the management of hypertension: report of the third working party of the British Hypertension Society. Journal of Human Hypertension 1999;13:569592. [MedLine: 1500].

\section{Shea 1992}

Shea S, Misra D, Ehrlich M, Field L, Francis C. Predisposing factors for severe, uncontrolled hypertension in an inner-city minority population. The New England Journal of Medicine 1992;327:776-781. [MedLine: 100].

\section{Smith 1990}

Smith WCS, Lee AJ, Crombie IK, Tunstall-Pedoe H. Control of blood pressure in Scotland: the rule of halves. British Medical Journal 1990;300:981-983. [MedLine: 2163].

\section{Staessen 1997}

Staessen JA, Byttebier G, Buntinx F, Celis H, O’Brien ET, Fagard R. Antihypertensive Treatment Based on Conventional or Ambulatory Blood Pressure Measurement A randomised controlled trial. Journal of the American Medical Association 1997;278 No 13:1065-1072. [MedLine: 1208].

\section{Staessen 2001}

Staessen JA, Wang J-G, Thijs L. Cardiovascular protection and blood pressure reduction: a meta analysis. The Lancet 20-10-2001;358: 1305-1315. [MedLine: 1922].

\section{Staessen 2004}

Staessen JA, Den Hond E, Celis H, Fagard R, Keary L, Vandenhoven G, O'Brien E. Antihypertensive treatment based on blood pressure measurement at home or in the physician's office. JAMA 2004;291 955-964.

Warsi 2004

Warsi A, Wang P, LaValley M, Avorn J, Solomon D. Self-management eduction programs in chronic disease. Archives of Internal Medicine 2004;164:1641-1649. [MedLine: 2961].

Weingarten 2002

Weingarten SR, Henning JM, Badamgarav E, Knight K, Hasselblad $\mathrm{V}$, Gano A, Jr, Ofman JJ. Interventions used in disease management programmes for patients with chronic illness---which ones work? Meta-analysis of published reports. BMJ 26-10-2002;325(7370): 925. [MedLine: 2200].

Wilber 1972

Wilber J, Barrow J. Hypertension: a community problem. The American Journal of Medicine 1972;52:653-663. [MedLine: 2162].

\section{Williams 2004}

Williams B, Poulter NR, Brown MJ, McInnes GT, Potter J, Sever P, McG Thom S. Guidelines for management of hypertension: report of the fourth working party of the British Hypertension Society, 2004- BHS IV. Journal of Human Hypertension 2004;18:139-185. [MedLine: 2972].

* Indicates the major publication for the study

T A B L E S

\section{Characteristics of included studies}

\begin{tabular}{ll} 
Study & Ahluwalia $\mathbf{1 9 9 6}$ \\
\hline Methods & Parallel, individuals, hospital outpatients in a single hospital clinic, USA \\
\hline Participants & $\begin{array}{l}\text { Hypertensive (SBP } 180 \mathrm{mmHg} \text { and/or DBP } 110 \mathrm{mmHg}), 95 \% \text { African American, } 49 \% \text { uninsured, mean age } \\
56\end{array}$ \\
\hline Interventions & $\begin{array}{l}\text { (1) Mailed reminder- postcard addressed in the presence of the patient and mailed next day as a reminder to } \\
\text { attend clinic in a week's time } \\
\text { (2) No reminder card, given routine clinic appointment }\end{array}$ \\
\hline Interventions used to improve control of blood pressure in patients with hypertension (Review) \\
Copyright @ 2006 The Cochrane Collaboration. Published by John Wiley \& Sons, Ltd
\end{tabular}


Duration of FU 6 months

\begin{tabular}{ll}
\hline Notes & No blood pressure data collected at outcome \\
\hline Allocation concealment & $\mathrm{B}$ - Unclear \\
\hline
\end{tabular}

\begin{tabular}{ll} 
Study & Artinian 2001 \\
\hline Methods & Pilot RCT \\
\hline Participants & Age $>18$ years, SBP $>140 \mathrm{mmHg}$ or $>90 \mathrm{mmHg}$ or for diabetic patients ?130mmHg or ?85mmHg \\
\hline Interventions & $\begin{array}{l}\text { (1) Home BP telemonitoring- self monitoring at home and transmitting BP readings over telephone line } \\
\text { to care providers in order to "facilitate telecounselling and treatment planning“. BP readings transmitted } 3 \\
\text { times per week for } 12 \text { weeks. }(2) \text { Nurse-managed community based BP monitoring. (3) Usual care }\end{array}$ \\
\hline Outcomes & $\begin{array}{l}\text { (1) Blood pressure- mean change SBP } 25 \mathrm{mmHg} \text {, mean change DBP } 14 \mathrm{mmHg}(\mathrm{E}) \text { versus mean change SBP } \\
+1 \text { mmHg, mean change DBP } 2 \mathrm{mmHgDuration} \text { of FU } 3 \text { months }\end{array}$ \\
\hline Notes & Small pilot study with short follow up period \\
\hline Allocation concealment & B - Unclear \\
\hline
\end{tabular}

\begin{tabular}{|c|c|}
\hline Study & Bailey 1998 \\
\hline Methods & Parallel, individuals based in general practitioner surgeries, Australia \\
\hline Participants & $\begin{array}{l}\text { Patients who were about to start BP lowering treatment who did not practice self-measurement, }<7 \% \text { previ- } \\
\text { ously untreated, mean age } 53.5 \text { years. }\end{array}$ \\
\hline Interventions & $\begin{array}{l}\text { (1) Self monitoring- use of an OMRON HEM706 monitor. Asked to record BP twice daily for } 8 \text { weeks } \\
\text { (2) Usual care- no self recording }\end{array}$ \\
\hline \multirow[t]{2}{*}{ Outcomes } & 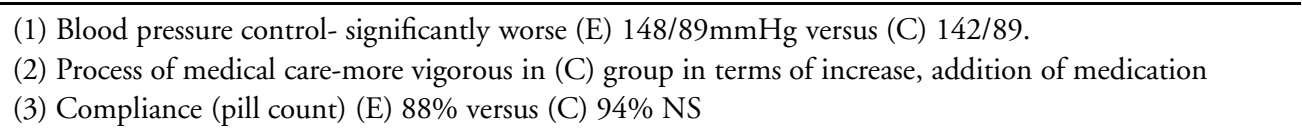 \\
\hline & Duration of FU 8 weeks \\
\hline Notes & $\begin{array}{l}23 \% \text { patients were not interested in future self-measurement } \\
\text { Outcome assessment: } 24 \text { hour ambulatory monitoring } \\
\text { Physicians not instructed to achieve a treatment goal or protocol } \\
\text { Significant disagreement between self monitoring and office measurement found by } 19 \% \text { physicians and } \\
16 \% \text { patients. In (E) group negative finding most likely due to the fact that physicians were less likely to alter } \\
\text { drug regimen when self-measurement readings were lower than office BP measurement. Finding most likely } \\
\text { to due different responses to process of care } \\
\text { no protocol concerning treatment intensification was provided in this RCT. No adjustment to the lower self } \\
\text { monitor readings were made and no intensification was associated with the intervention }\end{array}$ \\
\hline Allocation concealment & B - Unclear \\
\hline
\end{tabular}

\begin{tabular}{ll} 
Study & Barnett $\mathbf{1 9 8 3}$ \\
\hline Methods & Parallel, individuals based in one community-based health centre in USA. \\
\hline Participants & $\begin{array}{l}\text { Physicians } \\
\text { nurse-practitioners } \\
\text { (numbers not stated). Patients }(\mathrm{n}=115) \text { with sustained hypertension and/or diagnosis of hypertension and } \\
\text { placed on therapy, }<2 \text { repeat BP measurements after initial visit. } 49 \% \text { female, mean age } 43 \text { years (42\% older } \\
\text { than 45 years), 17\% black }\end{array}$ \\
\hline
\end{tabular}




\section{Characteristics of included studies (Continued)}

mean initial BP 150/102mm $\mathrm{mg}$, 7\% with history of hypertension, $4 \%$ with history of cardiovascular disease, $15 \%$ with family history of hypertension, $34 \%$ diagnosed obese

Interventions (1) Computer reminder to GP-automated surveillance system utilizing computer-based medical record system, generated automatic reminder to GP to check BP of patients. "No attempt was made to monitor the quality of care as to the degree of BP control“".

(2) Usual care.

Outcomes (1) Evaluate extent BP FU was attempted or achieved, (E) 62/63 (98\%) versus (C) 24/52 (46\%).

(2) Repeat BP recorded (E) 44/63 (70\%) versus (C) 27/52 (52\%).

(3) Degree of DBP control achieved (DBP <100mmHg) (E) 44/63 (70\%) versus (C) 27/52 (52\%).

Duration of FU 24 months.

Notes $\quad$ Intervention improved follow up of patients and in those who were followed up DBP was significantly improved.

Stratified according to age ( 45$)$ and DBP $(100 \mathrm{mmHg})$

Allocation concealment $\mathrm{B}$ - Unclear

\begin{tabular}{|c|c|}
\hline Study & Billault 1995 \\
\hline Methods & Parallel, individuals in a single outpatient clinic, Paris, France. \\
\hline Participants & $\begin{array}{l}\text { Individuals who attended hypertension clinic, no entry SBP/DBP defined, } 88 \% \text { (C) 83\% (E) on BP lowering } \\
\text { drugs. } 63 \% \text { male }\end{array}$ \\
\hline Interventions & $\begin{array}{l}\text { (1) Booklet with personalised standardised medical information explained to patient and their family doctor. } \\
\text { Ten items included on the basis of usefulness of managing hypertension. Patients asked to complete with } \\
\text { family doctor and mail carbon copy to outpatient clinic for entry into computerised record.(2) Usual care } \\
\text { Patients in both groups encouraged to visit family doctor 1-3 times per trimester according to severity of } \\
\text { hypertension }\end{array}$ \\
\hline Outcomes & $\begin{array}{l}\text { (1) Process of care in terms of use of services. (2) SBP/DBP- (E) } 145.1 / 88.2 \mathrm{mmHg} \text { versus (C) } 146.2 / 86.8 \text {; no } \\
\text { difference between groups (3) Other cardiovascular risk factors (smoking, exercise, body weight- no difference } \\
\text { between groups.Duration of FU } 1 \text { year }\end{array}$ \\
\hline Notes & 44/82 (54\%) of intervention group who were followed up completed personal medical record. \\
\hline Allocation concealment & B - Unclear \\
\hline Study & Bloom 1979 \\
\hline Methods & Parallel, individuals based after a work-site screening programme US \\
\hline 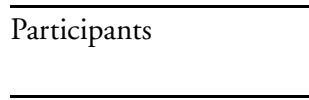 & $\begin{array}{l}\text { Patients with elevated blood pressure } 140 / 90 \mathrm{mmHg} \text {. } \\
\text { Average age } 40 \text {, white, male } 82 \% \text {, well educated } 60 \% \text { with a masters degree or higher }\end{array}$ \\
\hline Interventions & $\begin{array}{l}\text { (1) Educational material about hypertension, reinforced by a hypertension counsellor one week later, designed } \\
\text { to improve appointment keeping and knowledge } \\
\text { (2) No educational material or counsellor follow up. }\end{array}$ \\
\hline \multirow[t]{2}{*}{ Outcomes } & $\begin{array}{l}\text { (1) Number seeking medical care/appointment- significantly improved } 15 / 27 \text { (E- 55.5\%), 7/27 (C- 25.9\%) } \\
\text { (2) Knowledge about hypertension- increased in (E) } 3.22 \text { versus } \\
\text { (C) } 2.26\end{array}$ \\
\hline & Duration of FU 3 months \\
\hline Notes & $\begin{array}{l}\text { RCT concerned with initial follow up of patients identified as having sustained hypertension after screening } \\
\text { programme }\end{array}$ \\
\hline Allocation concealment & B - Unclear \\
\hline
\end{tabular}

Study $\quad$ Bogden 1998

Methods Parallel, individuals in a single OPD clinic in US 


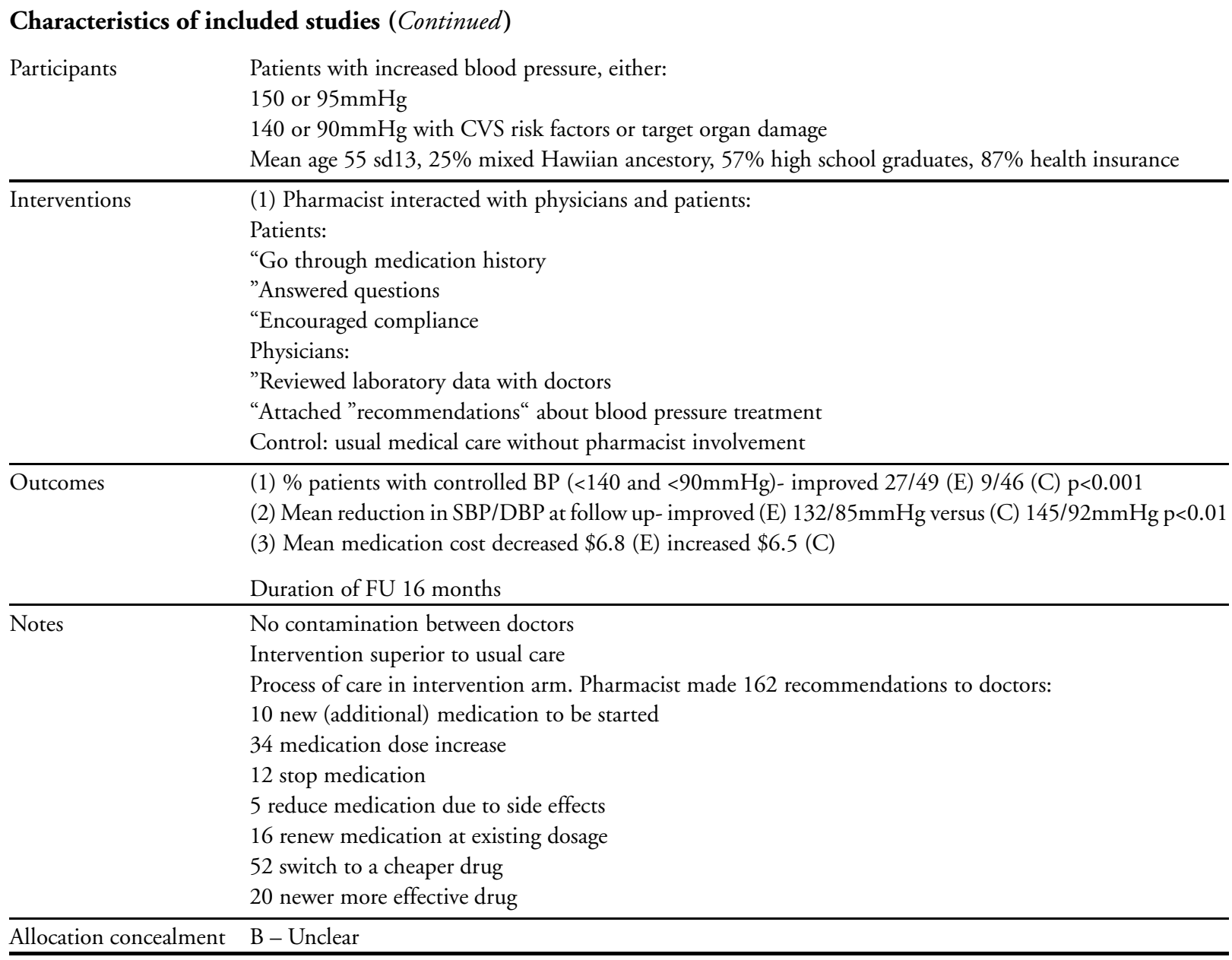

\begin{tabular}{|c|c|}
\hline Study & Brook 1983 \\
\hline Methods & Cluster RCT, families unit of randomisation \\
\hline Participants & $\begin{array}{l}2005 \text { Families living in six US cities ( } 47 \% \text { men, } 18 \% \text { non white, mean age } 33.4 \text {, range } 14-61) \text { Results are } \\
\text { reported for subset of hypertensive subjects, } 24.7 \%(n=294) \text { full health insurance, } 24.5 \%(n=562) \text { partial } \\
\text { health insurance. }\end{array}$ \\
\hline Interventions & $\begin{array}{l}\text { (1) Full health insurance-(2) Partial health insurance (three groups at different levels of re-imbusement:(a) } \\
\text { Individual - 95\% OPD to ceiling of } \$ 150 \text {, all inpatient(b) Intermediate- } 25-50 \% \text { both OPD and inpatient } \\
\text { up to } \$ 1000 \text { (c) Catastrophic- } 95 \% \text { both OPD and inpatient up to } \$ 1000\end{array}$ \\
\hline Outcomes & $\begin{array}{l}\text { (1) Mean DBP- improved by }-1.9 \mathrm{mmHg}(2) \text { Mean SBP- improved by }-1.8 \mathrm{mmHg}(3) \text { General health(4) } \\
\text { Health habits(5) Risk of dyingDuration of } \mathrm{FU}: 3 \text { years }\end{array}$ \\
\hline Notes & $\begin{array}{l}\text { SBP/DBP reported but baseline DBP lower than follow up (see tables } 3 \text { and } 5 \text { in original report). Subsequent } \\
\text { report suggested lower SBP/DBP at follow up adjusted for blood pressure at baseline (see table } 2 \text { and text). high } \\
\text { losses to FUNo details on process of BP care, but free care increased physician contacts and better lifestyle } \\
\text { changesSubgroup analysis: Low-income people with high BP had greater improvement than high-income-- } \\
3.5 \mathrm{mmHg} \text { (low income) versus } 1.1 \mathrm{mmHg} \text { (high-income) }\end{array}$ \\
\hline Allocation concealment & B - Unclear \\
\hline
\end{tabular}

\begin{tabular}{ll} 
Study & Bulpitt $\mathbf{1 9 7 6}$ \\
\hline Methods $\quad$ Parallel, individuals based in 3 hospital hypertension clinics in UK \\
\hline $\begin{array}{l}\text { Interventions used to improve control of blood pressure in patients with hypertension (Review) } \\
\text { Copyright @ 2006 The Cochrane Collaboration. Published by John Wiley \& Sons, Ltd }\end{array}$
\end{tabular}




\section{Characteristics of included studies (Continued)}

Participants Intervention directed at hospital physicians (number not stated).

278 patients with diagnosed hypertension referred to clinics. Characteristics of patients: computer group: 56\% female, mean age 51years, mean lying BP 178/105mmHg; control group: 53\% female, mean age 48 years, mean lying BP 177/106mmHg

\begin{tabular}{ll}
\hline Interventions & (1) Computer-held records- allowed doctor to record clinical information in structured format. \\
& (2) Standard hospital notes \\
\hline Outcomes & (1) Content of patient record 15 items- overall better recording in computer group \\
& (2) Length of time of consultation- longer in E (39.9 mins) than C (31.4 mins) at initial consultation, \\
& subsequent consultations no difference. \\
& (3) Patient investigations during RCT- no difference \\
& (4) Drop outs- $25 / 136$ (E- $18 \%) 36 / 142$ (C- $25 \%)$ \\
& (4) Average SBP and DBP- no difference (E) $149 / 96 \mathrm{mmHg}$ (C) $149 / 97 \mathrm{mmHg}$ \\
& Duration of FU 12 months. \\
\hline Notes & \\
\hline Allocation concealment & B - Unclear \\
\hline
\end{tabular}

\begin{tabular}{|c|c|}
\hline Study & Burrelle 1986 \\
\hline Methods & Parallel, individuals, hospital outpatients and primary care, USA \\
\hline Participants & 16 treated and non-adherent elderly hypertensive patients, $75 \%$ black, $75 \%$ women, mean age 69. \\
\hline Interventions & $\begin{array}{l}\text { (1) Home visits, education and special dosing devices; addressed psycho-social problems and compliance } \\
\text { problems by means of: medication planners; special dosing devices; individualized instruction on disease } \\
\text { states and treatments- Treatment Information on Medications for the Elderly (TIME) } \\
\text { (2) Usual care }\end{array}$ \\
\hline \multirow[t]{2}{*}{ Outcomes } & $\begin{array}{l}\text { (1) Blood pressure control- no difference between groups, (E) } 167.8 / 89.2 \mathrm{mmHg} \text { versus (C) } \\
165.8 / 86.8 \mathrm{mmHg} \\
\text { (2) Compliance (Pill counts and direct questioning, taking }>80 \% \text { of medication)- Percent of pills taken: } 92 \% \\
\text { (E) versus } 71 \%(\mathrm{C})(\mathrm{p}<0.001) \\
\text { (3) \% with controlled hypertension, no difference, (E) } 1 / 8,13 \% \text { versus } \\
\text { (C) } 1 / 8,13 \%\end{array}$ \\
\hline & Duration of FU 8 weeks \\
\hline Notes & Very small and underpowered study \\
\hline Allocation concealment & B - Unclear \\
\hline
\end{tabular}

Study

Carnahan 1975

\begin{tabular}{ll}
\hline Methods & $\begin{array}{l}\text { Parallel } \\
\text { Individuals }\end{array}$ \\
\hline Participants & V A outpatient clinic US, starting treatment, $\mathrm{n}=100$ (male 98), mean age 54 (E) 57 (C) \\
\hline Interventions & $\begin{array}{l}\text { (1) Self Monitoring, Instructed to use own sphygmomanometer twice a day. Readings recorded and delivered } \\
\text { to the clinic when visiting. (2) usual care }\end{array}$ \\
\hline Outcomes & $\begin{array}{l}\text { (1) Mean SBP/DBP- SBP lower at } 6 \text { months FU in (E), 7.5mmHg difference } \\
\text { DBP no difference at FU }\end{array}$ \\
\hline Notes & No SDs available, estimated to be 20mmHg SBP, 10mmHg DBP \\
\hline Allocation concealment & B - Unclear \\
\hline Study & Coe 1977 \\
\hline Methods & Parallel, individuals based in 2 hospital hypertension clinics in US \\
\hline Interventions used to improve control of blood pressure in patients with hypertension (Review) \\
Copyright @ 2006 The Cochrane Collaboration. Published by John Wiley \& Sons, Ltd
\end{tabular}




\section{Characteristics of included studies (Continued)}

Participants

Hospital physicians

(number not stated)

116 patients, $90.5 \%$ female, mean age 52 years, all black

unselected, consecutive referrals to clinics during 6-month period. Characteristics:

(1) Mean of 3 separate pretreatment BP measurements $>140 / 95 \mathrm{mmHg}$

(2)Three return visits while on treatment

(3).BP medication taken as prescribed

Interventions

(1) Computer-generated treatment recommendations by algorithm; generated drug type and dose recommendations to physician

(2) Usual physician care

Outcomes

(1) Blood pressure- reported in three strata of DBP, <95, 95-105, >105 but no differences between (E)

$152.5 / 99.6 \mathrm{mmHg}$ versus (C) $148.7 / 96.5 \mathrm{mmHg}$

(2) Compliance- self report, no difference

(3) Drugs prescribed- patterns of drug use the same.

Duration of FU months uncertain but weeks of treatment varied within a range of 21 to 40 weeks

Notes

Difficult to interpret as trial reported on all outcomes by means of initial DBP strata.

Mean SBP/DBP was non significantly better in (C) versus (E).

Overall conclusion computer generated treatment (E) and usual care by physicians (C) was equivalent.

Allocation concealment $\mathrm{B}-$ Unclear

\begin{tabular}{ll} 
Study & Cummings 1985 \\
\hline Methods & Hypertensive patients attending in a single urban family practice \\
\hline Participants & $\begin{array}{l}\text { Patients, aged } 19 \text { to } 96, \text { mean age } 60.62 \% \text { female, } 91 \% \text { black, } 11 \% \text { newly diagnosed, } 75 \% \mathrm{SBP}<140 \mathrm{mmHg} \\
\text { and DBP }>90 \mathrm{mmHg}\end{array}$ \\
\hline Interventions & $\begin{array}{l}\text { (1) Appointment reminder- reminder card sent one week in advance of appointment and telephone patients } \\
\text { who missed appointments to schedule new ones }(2) \text { Usual care }\end{array}$ \\
\hline Outcomes & $\begin{array}{l}\text { (1) Appointment keeping rate-appointments improved in }(\mathrm{E}-87 \%) \text { versus }(\mathrm{C}-79 \%) .(2) \text { Dropouts from } \\
\text { treatment- drop outs less at } 4 \text { months in experimental group (E- } 87 / 486,18 \%) \text { versus }(\mathrm{C}-150 / 487,31 \%)(3)\end{array}$ \\
& $\begin{array}{l}\text { Blood pressure control- average SBP/DBP improved in experimental group }(\mathrm{SBP}-2 \mathrm{mmHg}, \mathrm{p}=0.18 \text { and } \mathrm{DBP} \\
\text {-1mmHg, p=0.75)(4) Proportion of patients with controlled hypertension }(<140 / 90)-31 \%(\mathrm{E}) \text { versus } 25 \% \\
\text { (C)Duration FU } 8 \text { months }\end{array}$ \\
\hline Notes & \\
\hline Allocation concealment & B - Unclear \\
\hline
\end{tabular}

Study

Dickinson 1981

Methods

Factorial, Cluster, RCT

Participants

Four clinical teams in Family Medicine Centre in USA, 4 faculty physicians37 residents. Each team received on of the interventions. 250 Patients, $69.9 \%$ female, mean age 49.6 years, $70.4 \%$ whitemean weight $78.9 \mathrm{~kg}$, mean baseline BP $159 / 89 \mathrm{mmHg}$. Inclusion criteria:(1) Hypertensive patients visiting practice during 4month baseline period(2) Elevated systolic or diastolic pressure at last baseline visit(3) At least one visit during 7-month intervention period

Interventions

(1) Computer-generated feedback-monthly feedback reports on individual patients for physician, containing identification, age, date of last visit and latest BP in those with uncontrolled hypertension (age 18-44 $>/=140 / 90 ; 45-64>/=150 / 95 ;$ age $>64>/=160 / 95)$ or overdue appointments

(2) Education programme- designed to increase physician awareness about non-compliance, plan long term management based on periodic assessment, encourage family, behavioural and drug therapies. Three separate self instructions

Interventions used to improve control of blood pressure in patients with hypertension (Review) 


\section{Characteristics of included studies (Continued)}

(3) Both

(4) Neither

Outcomes

1) Follow up appointments increased in interventions-feedback 3.4, education 3.3, both 3.2, control 2.6 NS.(2) Knowledge-significantly improved in physicians who received education only, feedback 76, education 84, both 78, control 74(3) Blood pressure control- no difference - feedback $145 / 86 \mathrm{mmHg}$, education $149 / 85 \mathrm{mmHg}$, both $149 / 84 \mathrm{mmHg}$, control $148 / 83(4) \%$ with controlled hypertension- non significant differences, feeback $65 \%$, education $63 \%$, both $57 \%$, control $58 \%$ Duration of FU 7 months.

\begin{tabular}{ll}
\hline Notes & $\begin{array}{l}\text { Intervention randomised by, directed at physicians, analysis by patient No account taken of clustering. } \\
\text { Explains uneven patient numbers per arm of RCT }\end{array}$ \\
\hline Allocation concealment & B - Unclear \\
\hline
\end{tabular}

Study

Earp 1982

Methods

ParallelIndividuals

Participants

Hypertension, taking BP medication that had been initiated, altered or re-started. Based in outpatient hypertension clinic or family practice clinic

$\mathrm{n}=218$, mean age $48,59 \%$ female, $77 \%$ black

Interventions

(1) Home visits- over 18 months by nurse or pharmacist. Provided a "test of how effectively home-visiting health practitioners could motivate and/or reinforce positive health behaviours, including medication compliance"(2) Home visits plus involvement of "significant other"- involved daily/several times a week BP monitoring (3) Usual care

Outcomes

(1) Home visit group versus usual care: proportion of patients in each group with uncontrolled hypertension (DBP >l=95mmHg)- significant effect at year 2 (E) $21 \%$ versus (C) $42 \%$, not significant at year 1 (E) $34 \%$ versus (C) $34 \%$.

(2) Home visit and involvement of significant other versus usual care; proportion of patients in each group with uncontrolled hypertension (DBP $95 \mathrm{mmHg}$ )- non significant effect at year 2 (E) 25\% versus (C) 42\%, not significant at year 1 (E) 39\% versus (C) 34\%.

Duration of FU: 1 year

Notes Large proportions lost to follow up at year 2, hence follow up at 1 year when pooling data.

Mean number of BP medication taken declined in the two intervention group (1.7 to 1.5 Group 1 and 1.5 to 1.4 Group 2) but increased in control group (Group 31.6 to 1.8); between group differences non significant.

Allocation concealment $\mathrm{B}-$ Unclear

\begin{tabular}{|c|c|}
\hline Study & Evans 1986 \\
\hline Methods & Cluster- physicians stratified to solo or group practice and randomly allocated within strata \\
\hline Participants & $\begin{array}{l}\text { Canadian family physicians. Eligible patients, age } 30 \text { to } 69 \text { years, either DBP }>90 \mathrm{mmHg} \text { at one home visit } \\
\text { and taking BP medication or no BP medication and DBP }>90 \mathrm{mmHg} \text { on } 3 \text { times at home visits }\end{array}$ \\
\hline Interventions & $\begin{array}{l}\text { (1) Mailed CME to physicians } 14 \text { weekly instalments of information, chart and fu appointment system to } \\
\text { encourage detection and recall of patients(2) Usual care }\end{array}$ \\
\hline Outcomes & $\begin{array}{l}\text { (1) Blood pressure- }(\mathrm{DBP}<90 \mathrm{mmHg} \text {, (E) } 67 \% \text { versus }(\mathrm{C}) 67 \% \text {, non significant. }(2) \text { \# visits for BP check- } \\
\text { no difference( } 3 \text { ) \# patients told BP elevated- no difference( } 4 \text { ) \# patients on BP medication- no difference }(5) \\
\text { Mean } \% \text { compliance rate- no difference(6) } \% \text { patients with controlled blood pressure- no differenceDuration } \\
\text { FU } 1 \text { year }\end{array}$ \\
\hline Notes & $\begin{array}{l}\text { Cluster RCT- BP data aggregated at cluster level. } \\
\text { No difference found between intervention and usual care, } 76 \% \text { (E) and } 79 \%(C) \text { patients on BP medication. }\end{array}$ \\
\hline Allocation concealment & B - Unclear \\
\hline
\end{tabular}




\section{Characteristics of included studies (Continued)}

Study $\quad$ Fielding 1994

\begin{tabular}{|c|c|}
\hline Methods & Parallel, individuals at four work sites in the US \\
\hline Participants & $\begin{array}{l}\text { Patients with increased blood pressure, either: } \\
\text { SBP } 140 \text { and/or DBP } 90 \mathrm{mmHg} \text { identified during work-site screening. 16\%female, } 30.5 \% \text { taking BP lowering } \\
\text { durgs }\end{array}$ \\
\hline Interventions & $\begin{array}{l}\text { (1) IMPACT consisted of monthly } 10 \text { minute individual sessions for patients with counsellor at work site } \\
\text { that included: } \\
\text { "Assessment of current behaviours } \\
\text { "Discussion re: treatment goals } \\
\text { "Compliance } \\
\text { "Mailed monthly package including personalised blood pressure information } \\
\text { "Incentives offered e.g. coupons for free sports equipment } \\
\text { "Sites were requested to offer at least six classes or demonstrations related to BP control during the year } \\
\text { (2) Usual care }\end{array}$ \\
\hline Outcomes & $\begin{array}{l}\text { (1) Mean SBP/DBP changes- } \\
\text { SBP: significantly improved } 138.1 \mathrm{mmHg}(\mathrm{E}) \text { versus } 144.5 \mathrm{mmHg}(\mathrm{C}) \\
\text { DBP: -no difference } 86 \mathrm{mmHg}(\mathrm{E}) \text { versus } 86.5 \mathrm{mmHg}(\mathrm{C}) \\
\text { Adjusted difference: } \\
\text { SBP } 7.6 \mathrm{mmHg}, \mathrm{p}<0.05 \\
\text { DBP } 2.4 \mathrm{mmHg} \text {, NS } \\
\text { Duration of FU } 1 \text { year }\end{array}$ \\
\hline Notes & $\begin{array}{l}\text { Statistically significant change for SBP (but not DBP) after adjustment for age, sex and baseline blood pressure } \\
\text { A significantly higher proportion of intervention group started BP lowering drugs (E) } 13 / 49,26.5 \% \text { (C) } \\
5 / 52,9.6 \%\end{array}$ \\
\hline location concealment & B - Unclear \\
\hline
\end{tabular}

\begin{tabular}{ll} 
Study & Fletcher $\mathbf{1 9 7 5}$ \\
\hline Methods & Parallel, individuals based in single emergency room in US \\
\hline Participants & $\begin{array}{l}\text { Patients who attended emergency department with DBP 100mmHg and who had been given a follow up } \\
\text { appointment for a medical clinic }\end{array}$ \\
\hline Interventions & $\begin{array}{l}\text { (1) Reminder (letter or phone) to attend follow up appointment at clinic, offer of assistance if problems } \\
\text { arose, followed up until attended clinic or missed two consecutive appointments } \\
\text { (2) Usual care }\end{array}$ \\
\hline Outcomes & $\begin{array}{l}\text { (1) Returned to initial medical clinic appointment significantly improved 62/74 (E- } 84 \%), 44 / 70 \text { (C- } 63 \%) . \\
\text { (2) Blood pressure control the same at FU 38/74 (E- 51\%), 37/70 (C- 53\%) }\end{array}$ \\
& Duration of FU 5 months \\
\hline Notes & $\begin{array}{l}\text { Improved initial attendance but blood pressure control in both groups the same. Process of care the more } \\
\text { vigorous in (E) group but (E- 38\%), (C- 33\%) said that they were on BP lowering drugs. } \\
\text { Blood pressure control defined in age-specific categories } \\
20-39<140 / 90 \\
40-59<150 / 95 \\
>60<160 / 100\end{array}$ \\
\hline Allocation concealment & B - Unclear
\end{tabular}

\section{Study}

Friedman 1996

Methods Parallel, individuals from 29 different communities, Boston, USA




\section{Characteristics of included studies (Continued)}

Participants Under care of physician for hypertension on BP lowering drugs, $\mathrm{SBP}>/=160 \mathrm{mmHg}$ or DBP $>/=90 \mathrm{mmHg}$ on average two readings. $90 \%$ white, $77 \%$ female, mean age 76 years

Interventions (1) Home monitoring and telecommunication system

"Weekly automated home blood pressure recording.

"Telephone-linked computer system (TLC)- computer-based telecommunications system that converses with patients in their homes, patients contacted weekly. Provides advice concerning their blood pressure, understanding of BP lowering medication, adherence to medication, symptoms that might relate to side effects of therapy. Information directed to patient's physician

(2) Usual care

Outcomes

(1) Adherence to medication- improved by $18 \%$ (E) vs $12 \%(\mathrm{C}), \mathrm{p}=0.03$.

(2) Mean change in SBP/DBP- no difference for SBP, (E) $158.5 \mathrm{mmHg}$ versus (C) $156.4 \mathrm{mmHg}, \mathrm{p}=0.2$; significant difference for DBP, (E) $80.9 \mathrm{mmHg}$ versus (C) $83.2 \mathrm{mmHg}, \mathrm{p}=0.02$;

(3) Cost effectiveness- most cost effective for non-adherent patients

Duration of FU 6 months.

Notes Cost effectiveness measured all computer and telecommunication costs, facilities charges, supplies and support personnel for start-up and maintenance of the system. Cost effectiveness ratios were computed for medication adherence improvement and DBP decrease using regression analysis

Allocation concealment $\mathrm{B}-$ Unclear

\begin{tabular}{|c|c|}
\hline Study & Garcia-Pena 2001 \\
\hline Methods & $\begin{array}{l}\text { Parallel, individuals, elderly ( 60) age-stratified sample recruited from } 12 \text { family medical centres, Mexico city, } \\
\text { Mexico }\end{array}$ \\
\hline Participants & $\begin{array}{l}\text { Hypertension, mean SBP } 160 \text { or/both DBP } 90 \text { in untreated patients or treated hypertension patients Mean } \\
\text { BP level } 161.9 / 90.8 \text { (C) } 162.1 / 90.9 \text { (E) average age } 70.6 \text { years }\end{array}$ \\
\hline Interventions & $\begin{array}{l}\text { (1) Nurse-based intervention } \\
\text { Nurses trained in aging and clinical aspects of hypertension including: } \\
\text { "Personal interviews } \\
\text { "Health behaviour change models } \\
\text { "Process of negotiation } \\
\text { "Ethical aspects of home visits } \\
\text { On each visit nurse did the following: } \\
\text { "Measured BP } \\
\text { "Discussed baseline health check and discussed lifestyle changes } \\
\text { "Guided patients in healthier lifestyle and negotiated specific targets } \\
\text { "Revised pharmacological treatment } \\
\text { "Adherence encouraged } \\
\text { Frequency of visits 2-4 weeks } \\
\text { (2) Usual care from insitute's clinic and mailed pamphlet about hypertension }\end{array}$ \\
\hline Outcomes & $\begin{array}{l}\text { (1) Blood pressure- mean change SBP } 3.31 \mathrm{mmHg} p=0.03 \text {, mean change DBP } 3.67 \mathrm{mmHg} p<0.001 \\
\text { (2) Weight }-1.1 \mathrm{~kg} \text { significantly reduced } \\
\text { (3) Sodium excretion }-5.8 \mathrm{~ns} \\
\text { (4) Control BP }<160 / 90 \mathrm{mmHg} \text { improved } 36.5 \% \text { (E) versus } 6.8 \% \text { (C) } \\
\text { (5) Exercise- slow walking exercise increased (E) } 9.1 \% \text { versus decreased }(\mathrm{C}) 0.7 \% \\
\text { (6) Not taking antihypertensive drugs (E) } 15.9 \% \text { versus } \\
\text { (C) } 26.9 \% \\
\text { (7) Antihypertensive drug usage- increased in (E) change from baseline } 12.5 \% \text { versus }(\mathrm{C}) 5.3 \% \text {, difference } \\
7.2 \% \mathrm{p}=0.02\end{array}$ \\
\hline & Duration of FU 6 months \\
\hline Notes & $\begin{array}{l}\text { Well conducted RCT. Nurse intervention aimed at both pharmacological and non-pharmacological man- } \\
\text { agement of hypertension. Had positive effect on mean SBP/DBP and BP control with increases in number }\end{array}$ \\
\hline
\end{tabular}




\section{Characteristics of included studies (Continued)}

taking antihypertensive medications. Non pharmacological treatment also effective at reducing weight, increasing exercise with non significant reduction in sodium excretion

\begin{tabular}{|c|c|}
\hline Allocation concealment & A - Adequate \\
\hline Study & Gullion 1987 \\
\hline Methods & $\begin{array}{l}\text { Factorial RCT, randomised by physician }(n=111) \text {, analysed by patient }(n=2583) \text {, San Francisco USA. Average } \\
\text { of } 23 \text { patients per practice }\end{array}$ \\
\hline Participants & $\begin{array}{l}\text { Hypertensive patients using anti-hypertensive medication, had a DBP }>90 \mathrm{mmHg} \text { at some stage of their care. } \\
\text { Age range } 20-80 \text { years }\end{array}$ \\
\hline Interventions & $\begin{array}{l}\text { (1) Medical education- } \\
\text { "Individualised feedback on medical record information, detailed peer-review } \\
\text { "Syllabus material } \\
\text { "Educational session by means of telephone call with faculty expert discussing feedback reports and syllabus } \\
\text { materials. } \\
\text { (2) Behavioural education- } \\
\text { "Individualised feedback on patient survey summaries, detailed peer-review } \\
\text { "Syllabus material } \\
\text { "Educational session, telephone call with faculty expert discussing feedback reports and syllabus materials } \\
\text { (3) Both interventions } \\
\text { (4) Neither intervention }\end{array}$ \\
\hline Outcomes & $\begin{array}{l}\text { (1) DBP- no difference between four groups either for mean DBP }(85.17,85.59,85.16,85.79 \mathrm{mmHg} \\
\text { respectively) or for \% with controlled DBP }(68.65 \%, 66.78 \%, 67.93 \%, 68.25 \% \text { respectively) at follow up. } \\
\text { (2) Lifestyle outcomes- no difference apart from decreased BMI in behavioural group. } \\
\text { (3) Health promotion advice given- more likely to be given advice re: medication regimen, side effects of } \\
\text { drugs, sodium intake in behavioural group. } \\
\text { Duration of FU } 1 \text { year }\end{array}$ \\
\hline Notes & $\begin{array}{l}\text { Negative RCT with regard to primary outcome of DBP. } \\
\text { Caution required with interpretation of lifestyle and health promotion outcomes. Multiple comparisons. } \\
\text { DBP reported but not usable because no baseline numbers randomised reported or standard deviations }\end{array}$ \\
\hline Allocation concealment & B - Unclear \\
\hline Study & Hamilton 1993 \\
\hline Methods & Parallel, individuals based in hypertension clinic in tertiary care teaching medical centre, US \\
\hline Participants & $\begin{array}{l}\text { Thirty four treated hypertensives DBP } 90 \mathrm{mmHg} \text { and/or SBP } 160 \mathrm{mmHg} \text {, participating in therapeutic } \\
\text { hypertension regimen. Mean age } 54 \text { years, white, married, high school educated. }\end{array}$ \\
\hline Interventions & $\begin{array}{l}\text { (1) Postcard reminder one week before the next regularly scheduled appointment, a } 30 \text { to } 40 \text { min interven- } \\
\text { tion with the nurse practitioner before the appointment with the physician (including tailored care plan, } \\
\text { information on hypertension, discussion of risk factors, max. } 45 \text { min total time), follow up phone call one } \\
\text { month after the intervention to evaluate the negotiated plan of care. } \\
\text { (2) Usual care- no self recording }\end{array}$ \\
\hline Outcomes & 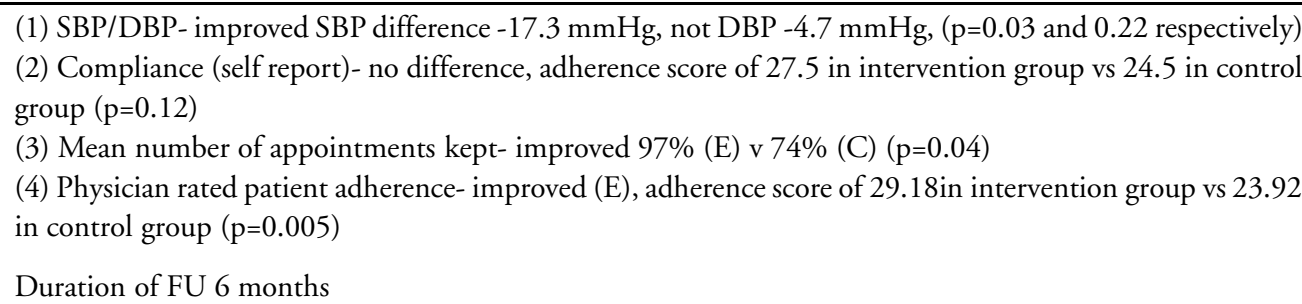 \\
\hline
\end{tabular}

Interventions used to improve control of blood pressure in patients with hypertension (Review) 


\section{Characteristics of included studies (Continued)}

Notes SBP improved, mean number of appointments kept improved in (E) group, adherence no difference on selfreport

Small RCT

Allocation concealment $\mathrm{B}-$ Unclear

Study

Hawkins 1979

Methods

Parallel

Individuals

Participants

Medical OPD clinic, San Antonio, US, patients fu for hypertension (42\% E) (49\% C) and diabetes or both (28\% E) (21\% C), mean age 61 (E) 60 (C), >90\% Mexican Americans, (female 76\% E, 78\% C)

Interventions (1) Clinical pharmacist- chronic disease management in OPD setting (medical care monitored by family practice faculty)

(2) Usual care by physician

Outcomes

(1) Kept-clinic appointments

(2) Compliance with medication (prescription record)-improved diuretic only: $60.5 \%$ adherent (E) vs $52.9 \%$

(C) $(\mathrm{p}<0.7)$, diuretic plus methyldopa: $84.6 \%(\mathrm{E})$ vs $65.4 \%(\mathrm{C})(\mathrm{p}=0.2)$

(3) Kept OPD appointments- $83.3 \%$ (E) vs $73.8 \%(\mathrm{C})(\mathrm{p}<0.0005)$

(4) Frequency of clinic visit- 6.69 (E) vs 5.38 (C) $(\mathrm{p}=<0.001)$

(4) Mean SBP (E) $147 \mathrm{mmHg}$ versus 141 (C); $\mathrm{p}<0.01$. Mean DBP $84 \mathrm{mHg}$ (E) versus $84 \mathrm{mHg}$ (C) non significant.

Duration FU 24-29 months

Notes

Improved for pharmacist led care(E) for:

(1) Kept OPD appointments

(2) Frequency of OPD appointments

(3) Mean SBP between group comparison- improved in (E) group but worse for DBP

Allocation concealment B-Unclear

\begin{tabular}{|c|c|}
\hline Study & Haynes 1976 \\
\hline \multirow[t]{2}{*}{ Methods } & Parallel \\
\hline & Individuals \\
\hline Participants & $\begin{array}{l}\text { Hypertensive males ( } \mathrm{n}=39 \text { ), not compliant (pill counts }<80 \%) \text { or at goal DBP }(90 \mathrm{mmHg}) \text { after } 6 \text { months } \\
\text { (previously enrolled in a separate RCT, see Sackett 1975) }\end{array}$ \\
\hline \multirow[t]{6}{*}{ Interventions } & (1) Patient self monitoring and education, includes: \\
\hline & "Home self-measurement of BP \\
\hline & "Home BP and medication charting \\
\hline & "Tailoring- patients interviewed to improved medication taking \\
\hline & "Increased supervision and reinforcement- fortnightly review including positive re-enforcement. \\
\hline & All interventions supervised and executed by non health professional programme coordinator \\
\hline \multirow{4}{*}{ Outcomes } & (1) Compliance- increased in experimental groun (F) 658 versus (C) $432 \mathrm{n}=0025$ \\
\hline & (2) Control of DBP- increased in experimental group, (E) $93.1 \mathrm{mmHg}$ versus $(C) 96.4 \mathrm{mmHg}, p=0.12$ \\
\hline & (3) Combined compliance and DBP targets- increased in experimental group \\
\hline & Duration of FU 1 year. \\
\hline \multirow[t]{3}{*}{$\overline{\text { Notes }}$} & (1) No data given- change in DBP and compliance reported \\
\hline & $\begin{array}{l}\text { (2) Experimental group patients received significantly more attention than control patients ( } 5 \text { hours over } 6 \\
\text { months) }\end{array}$ \\
\hline & (3) Physicians treating experimental patients prescribed more vigorously \\
\hline
\end{tabular}




\section{Characteristics of included studies (Continued)}

Allocation concealment B-Unclear

\begin{tabular}{ll} 
Study & Hetlevik 1998 \\
\hline Methods & $\begin{array}{l}\text { Cluster (29 health centres, } 53 \text { family practitioners), analysed by patient (2239 patients). Two regions in } \\
\text { Norway. }\end{array}$ \\
\hline Participants & Hypertensive patients (baseline BP level given), mean age 64 years, 57\% female. \\
\hline Interventions & $\begin{array}{l}\text { (1) Computer based decision support system (CDSS). Doctors and assistants trained and received a user } \\
\text { manual. Re-enforcement by means of telephone repetitions seminar on risk intervention and further demon- } \\
\text { stration of CDSS. } \\
\text { (2) Usual care }\end{array}$ \\
\hline Outcomes & $\begin{array}{l}\text { (1) SBP/DBP- SBP no difference (E) 156.8mmHg versus (C) 155.6mmHg NS, DBP (E) 88.8mmHg versus } \\
\text { outcomes no different between groups }(6) \text { Recording of risk factor data- improved slightly in (E) group for } \\
\text { cholesterol and family history.Duration of FU 24 months. }\end{array}$ \\
\hline Notes & Only 104 (11\%) patients had CDSS used on them during trial period. \\
\hline Allocation concealment & B - Unclear
\end{tabular}

\section{Study}

Methods

Participants

Interventions

\section{Hetlevik 1999}

Cluster (29 health centres, 53 family practitioners), analysed by patient (2239 patients). Two regions in Norway. Hypertensive patients (baseline BP level given), mean age 64 years, $57 \%$ female.

(1) Computer based decision support system (CDSS). Doctors and assistants trained and received a user manuel. Re-enforcement by means of telephone repetitions seminar on risk intervention and further demonstration of CDSS.(2) Usual care

\begin{tabular}{ll}
\hline Outcomes & (1) SBP/DBP- SBP (E) $156.8 \mathrm{mmHg}$ versus (C) $155.6 \mathrm{mmHg}$ NS, DBP (E) $88.8 \mathrm{mmHg}$ versus $89.8 \mathrm{mmHg}$, \\
& $\mathrm{p}<0.05$ \\
& (2) Cholesterol \\
& (3) \% smokers \\
& (4) BMI \\
& (5) Coronary heart disease risk score. \\
& All other outcomes no different between groups \\
& (6) Recording of risk factor data- improved slightly in (E) group for cholesterol and family history. \\
& Duration of FU 24 months. \\
\hline Notes & Only 104 (11\%) patients had CDSS used on them during trial period. \\
& No account for clustering reported in the analysis section \\
\hline Allocation concealment & B - Unclear
\end{tabular}

\section{Study Hypertension 1979}

Methods

Patients identified at 14 "HDFP centres throughout the US (13 by residential area- census tract, probability sample of larger areas, entire housing projects or in one centre by employment roll of industries). Randomisation at the patient level after initial screening. Initially screened for DBP, 2 stage process:(1) All 158,096 screened ( $89 \%$ of all age-eligible patients), if average DBP was $95 \mathrm{mmHg}$ invited for second screen at clinic, regardless of whether taking BP lowering drugs or not. (2) If mean DBP $90 \mathrm{mmHg}$, patient eligible and randomised. 10,940 agreed to randomisation Randomisation stratified according to entry DBP and HDFP centre:(1) Stratum i- 90-104 mmHg, $n=7,825$ (71.5\%)(2) Stratum ii- 105-114 mmHg, $n=2,052$ (18.8\%)(3) Stratum iii- $115 \mathrm{mmHg}, \mathrm{n}=1,063(9.7 \%)$ No SBP entry criteria and no upper limits of BP11,386 persons randomised but 446 subsequently excluded due to randomisation error that occurred at one clinic 


\section{Characteristics of included studies (Continued)}

Participants Inclusion criteria:(1) Men and women age 30 to 69 years(2) Average home screening $\mathrm{DBP} 95 \mathrm{mmHg}(3)$ Confirmed follow up DBP 90mmHgExclusion criteria:(1) Terminally ill(2) Institutionalised 10,940 randomised, 54\% male, 45\% blackAntihypertensive drugs taken at start of RCT: SC (26.3\%), RC (25.7\%)

\begin{tabular}{|c|c|}
\hline Interventions & $\begin{array}{l}\text { (1) Stepped care (SC), designed to provide rigorous, systematic, antihypertensive drug treatment by means } \\
\text { of: }\end{array}$ \\
\hline & "Free care- visits, drugs, investigations, transport \\
\hline & "Emphasis placed on clinic attendance and compliance- pill counts used \\
\hline & "Convenience- low waiting times, parmedical personnel, physician on call \\
\hline & "Stepped drug treatment according to BP response \\
\hline & $\begin{array}{l}\text { "Patients seen at intervals determined by their clinical status, at least every } 4 \text { months, and generally every } 2 \\
\text { months }\end{array}$ \\
\hline & (2) Referred care (RC): referred to their "primary sources of care, usually own physicians. \\
\hline & $\begin{array}{l}\text { All SC (E) and RC (C) participants seen at home at years 1, 2, } 4 \text { and } 5 \text { for health history and BP measurement } \\
\text { and at the clinic at years } 2 \text { and } 5 \text { for an examination. At each contact each RC participant was advised to } \\
\text { visit a physician. If severe hypertension (DBP } 115 \mathrm{mmHg} \text { or end organ damage) special steps were taken to } \\
\text { achieve contact with a physician. }\end{array}$ \\
\hline Outcomes & (1) \# (\%) on antihypertensive medication- higher for SC $81.2 \%$, compared to RC $64.2 \%$ by year 5 . \\
\hline & (2) SBP/DBP level- lower for SC $(130 / 84 \mathrm{mmHg})$ vs RC (140/89) at 5 year FU \\
\hline & (3) \% controlled blood pressure (HDFP goal)- improved SC versus RC. \\
\hline & (4) All cause mortality- significantly better $350 / 5485$ (6.38\%) vs 421/5455 (7.78\%) \\
\hline & All outcomes apply across 3 strata of entry DBP. Most of BP reduction occurred by end of year 1 \\
\hline & Duration FU 1 and 5 years (mortality) \\
\hline Notes & Data reported in 3 strata of entry DBP \\
\hline & At one year $84.4 \%$ (SC) versus $59.1 \%$ (RC) taking antihypertensive medication \\
\hline & Step $1-32.7 \%$ v $12.1 \%$ \\
\hline & Step $2-23.6 \%$ v $16 \%$ \\
\hline & Step $3-3.3 \%$ v $2.3 \%$ \\
\hline & Step $4-2 \%$ v $2 \%$ \\
\hline & Total drug status known at 1 year, $82.4 \%$ SC v $82.8 \%$ RC \\
\hline & $\begin{array}{l}\text { Intensity of BP medication in SC at } 5 \text { years: } 42 \% \text { taking single drug- step 1,27\% taking two drugs- step 2, } \\
9 \% \text { taking } 3 \text { drugs- step 3,11\% taking } 4 \text { or more drugs, step } 4 \text { and } 5 \text { at } 5 \text { years }\end{array}$ \\
\hline & $\begin{array}{l}\text { HDFP defined goal DBP as } 90 \mathrm{mmHg} \text { for those entering with DBP } 100 \mathrm{mmHg} \text { or receiving antihypertensive } \\
\text { therapy and a } 10 \mathrm{mmHg} \text { decrease for those entering with DBP of } 90-99 \mathrm{mmHg} \text {. }\end{array}$ \\
\hline & Mortality FU 5 years, mean BP data reported at 1 year and 5 years \\
\hline Allocation concealment & A - Adequate \\
\hline Study & Hypertension 1979a \\
\hline Methods & $\begin{array}{l}\text { Patients identified at } 14 \text { "HDFP centres throughout the US ( } 13 \text { by residential area- census tract, probability } \\
\text { sample of larger areas, entire housing projects or in one centre by employment roll of industries). Randomi- } \\
\text { sation at the patient level after initial screening. Initially screened for DBP, } 2 \text { stage process: } \\
\text { (1) All } 158,096 \text { screened ( } 89 \% \text { of all age-eligible patients), if average DBP was } 95 \mathrm{mmHg} \text { invited for second } \\
\text { screen at clinic, regardless of whether taking BP lowering drugs or not. } \\
\text { (2) If mean DBP } 90 \mathrm{mmHg} \text {, patient eligible and randomised. } 10,940 \text { agreed to randomisation Randomisation } \\
\text { stratified according to entry DBP and HDFP centre: } \\
\text { (1) Stratum i- } 90-104 \mathrm{mmHg}, \mathrm{n}=7,825(71.5 \%) \\
\text { (2) Stratum ii- } 105-114 \mathrm{mmHg}, \mathrm{n}=2,052(18.8 \%) \\
\text { (3) Stratum iii- } 115 \mathrm{mmHg}, \mathrm{n}=1,063(9.7 \%)\end{array}$ \\
\hline
\end{tabular}




\section{Characteristics of included studies (Continued)}

No SBP entry criteria and no upper limits of BP

11,386 persons randomised but 446 subsequently excluded due to randomisation error that occurred at one clinic

\begin{tabular}{ll}
\hline Participants & Inclusion criteria: \\
(1) Men and women age 30 to 69 years \\
(2) Average home screening DBP $95 \mathrm{mmHg}$ \\
(3) Confirmed follow up DBP $90 \mathrm{mmHg}$ \\
Exclusion criteria: \\
(1) Terminally ill \\
(2) Institutionalised \\
10,940 randomised, $54 \%$ male, $45 \%$ black \\
Antihypertensive drugs taken at start of RCT: SC $(26.3 \%)$ RC $(25.7 \%)$
\end{tabular}

$\begin{array}{ll}\text { Interventions } & \text { (1) Stepped care (SC), designed to provide rigorous, systematic, antihypertensive drug treatment by means }\end{array}$
of:

"Free care- visits, drugs, investigations, transport

"Emphasis placed on clinic attendance and compliance- pill counts used

"Convenience- low waiting times, parmedical personnel, physician on call

"Stepped drug treatment according to BP response

"Patients seen at intervals determined by their clinical status, at least every 4 months, and generally every 2 months

(2) Referred care (RC): referred to their "primary sources of care, usually own physicians.

All SC (E) and RC (C) participants seen at home at years 1, 2, 4 and 5 for health history and BP measurement and at the clinic at years 2 and 5 for an examination. At each contact each RC participant was advised to visit a physician. If severe hypertension (DBP $115 \mathrm{mmHg}$ or end organ damage) special steps were taken to achieve contact with a physician.

Outcomes

(1) \# (\%) on antihypertensive medication- higher for SC $81.2 \%$, compared to RC $64.2 \%$ by year 5 .

(2) SBP/DBP level- lower for SC $(130 / 84 \mathrm{mmHg})$ vs RC $(140 / 89)$ at 5 year FU

(3) $\%$ controlled blood pressure (HDFP goal)- improved SC versus RC.

(4) All cause mortality- significantly better $350 / 5485$ (6.38\%) vs $421 / 5455$ (7.78\%)

All outcomes apply across 3 strata of entry DBP. Most of BP reduction occurred by end of year 1

Duration FU 1 and 5 years (mortality)

Notes Data reported in 3 strata of entry DBP

At one year $84.4 \%$ (SC) versus $59.1 \%$ (RC) taking antihypertensive medication

Step $1-32.7 \%$ v $12.1 \%$

Step $2-23.6 \%$ v $16 \%$

Step $3-3.3 \%$ v $2.3 \%$

Step $4-2 \%$ v $2 \%$

Total drug status known at 1 year, $82.4 \%$ SC v $82.8 \%$ RC

Intensity of BP medication in SC at 5 years: $42 \%$ taking single drug- step 1, 27\% taking two drugs- step 2, $9 \%$ taking 3 drugs- step 3, 11\% taking 4 or more drugs, step 4 and 5 at 5 years

HDFP defined goal DBP as $90 \mathrm{mmHg}$ for those entering with DBP $100 \mathrm{mmHg}$ or receiving antihypertensive therapy and a $10 \mathrm{mmHg}$ decrease for those entering with DBP of $90-99 \mathrm{mmHg}$.

Mortality FU 5 years, mean BP data reported at 1 year and 5 years

Allocation concealment A-Adequate

Interventions used to improve control of blood pressure in patients with hypertension (Review)

Copyright @ 2006 The Cochrane Collaboration. Published by John Wiley \& Sons, Ltd 


\section{Characteristics of included studies (Continued)}

\section{Study}

Methods

\section{Hypertension 1982}

Patients identified at 14 "HDFP centres throughout the US (13 by residential area- census tract, probability sample of larger areas, entire housing projects or in one centre by employment roll of industries). Randomisation at the patient level after initial screening. Initially screened for DBP, 2 stage process:

(1) All 158,096 screened (89\% of all age-eligible patients), if average DBP was $95 \mathrm{mmHg}$ invited for second screen at clinic, regardless of whether taking BP lowering drugs or not.

(2) If mean DBP $90 \mathrm{mmHg}$, patient eligible and randomised. 10,940 agreed to randomisation Randomisation stratified according to entry DBP and HDFP centre:

(1) Stratum i- 90-104 mmHg, $\mathrm{n}=7,825$ (71.5\%)

(2) Stratum ii- $105-114 \mathrm{mmHg}, \mathrm{n}=2,052(18.8 \%)$

(3) Stratum iii- $115 \mathrm{mmHg}, \mathrm{n}=1,063(9.7 \%)$

No SBP entry criteria and no upper limits of BP

11,386 persons randomised but 446 subsequently excluded due to randomisation error that occurred at one clinic

Participants Inclusion criteria:

(1) Men and women age 30 to 69 years

(2) Average home screening DBP $95 \mathrm{mmHg}$

(3) Confirmed follow up DBP $90 \mathrm{mmHg}$

Exclusion criteria:

(1) Terminally ill

(2) Institutionalised

10,940 randomised, $54 \%$ male, $45 \%$ black

Antihypertensive drugs taken at start of RCT: SC (26.3\%), RC (25.7\%)

Interventions (1) Stepped care (SC), designed to provide rigorous, systematic, antihypertensive drug treatment by means of:

"Free care- visits, drugs, investigations, transport

"Emphasis placed on clinic attendance and compliance- pill counts used

"Convenience- low waiting times, parmedical personnel, physician on call

"Stepped drug treatment according to BP response

"Patients seen at intervals determined by their clinical status, at least every 4 months, and generally every 2 months

(2) Referred care (RC): referred to their "primary sources of care, usually own physicians.

All SC (E) and RC (C) participants seen at home at years 1, 2, 4 and 5 for health history and BP measurement and at the clinic at years 2 and 5 for an examination. At each contact each RC participant was advised to visit a physician. If severe hypertension (DBP $115 \mathrm{mmHg}$ or end organ damage) special steps were taken to achieve contact with a physician.

\begin{tabular}{|c|c|}
\hline \multirow[t]{3}{*}{ Outcomes } & $\begin{array}{l}\text { (1) \# (\%) on antihypertensive medication- higher for SC } 81.2 \% \text {, compared to R } \\
\text { (2) SBP/DBP level- lower for SC }(130 / 84 \mathrm{mmHg}) \text { vs RC }(140 / 89) \text { at } 5 \text { year FU } \\
\text { (3) \% controlled blood pressure (HDFP goal)- improved SC versus RC. } \\
\text { (4) All cause mortality- significantly better } 350 / 5485(6.38 \%) \text { vs } 421 / 5455(7.7\end{array}$ \\
\hline & All outcomes apply across 3 strata of entry DBP. Most of BP reduction occurred \\
\hline & Duration FU 1 and 5 years (mortality) \\
\hline \multirow[t]{5}{*}{ Notes } & Data reported in 3 strata of entry DBP \\
\hline & At one year $84.4 \%$ (SC) versus $59.1 \%(\mathrm{RC})$ taking antihypertensive medication \\
\hline & Step $1-32.7 \%$ v $12.1 \%$ \\
\hline & Step $2-23.6 \%$ v $16 \%$ \\
\hline & Step $3-3.3 \%$ v $2.3 \%$ \\
\hline
\end{tabular}

Interventions used to improve control of blood pressure in patients with hypertension (Review)

Copyright $\odot 2006$ The Cochrane Collaboration. Published by John Wiley \& Sons, Ltd 


\section{Characteristics of included studies (Continued)}

Step $4-2 \%$ v $2 \%$

Total drug status known at 1 year, $82.4 \%$ SC v $82.8 \%$ RC

Intensity of BP medication in SC at 5 years: $42 \%$ taking single drug- step 1, 27\% taking two drugs- step 2, $9 \%$ taking 3 drugs- step 3, 11\% taking 4 or more drugs, step 4 and 5 at 5 years

HDFP defined goal DBP as $90 \mathrm{mmHg}$ for those entering with DBP $100 \mathrm{mmHg}$ or receiving antihypertensive therapy and a $10 \mathrm{mmHg}$ decrease for those entering with DBP of $90-99 \mathrm{mmHg}$.

Mortality FU 5 years, mean BP data reported at 1 year and 5 years

Allocation concealment A-Adequate

Study Hypertension 1986

Methods Patients identified at 14 "HDFP centres throughout the US (13 by residential area- census tract, probability sample of larger areas, entire housing projects or in one centre by employment roll of industries). Randomisation at the patient level after initial screening. Initially screened for DBP, 2 stage process:

(1) All 158,096 screened (89\% of all age-eligible patients), if average DBP was $95 \mathrm{mmHg}$ invited for second screen at clinic, regardless of whether taking BP lowering drugs or not.

(2) If mean DBP 90mmHg, patient eligible and randomised. 10,940 agreed to randomisation Randomisation stratified according to entry DBP and HDFP centre:

(1) Stratum i- 90-104 $\mathrm{mmHg}, \mathrm{n}=7,825(71.5 \%)$

(2) Stratum ii- $105-114 \mathrm{mmHg}, \mathrm{n}=2,052(18.8 \%)$

(3) Stratum iii- $115 \mathrm{mmHg}, \mathrm{n}=1,063(9.7 \%)$

No SBP entry criteria and no upper limits of BP

11,386 persons randomised but 446 subsequently excluded due to randomisation error that occurred at one clinic

Participants Inclusion criteria:

(1) Men and women age 30 to 69 years

(2) Average home screening DBP $95 \mathrm{mmHg}$

(3) Confirmed follow up DBP $90 \mathrm{mmHg}$

Exclusion criteria:

(1) Terminally ill

(2) Institutionalised

10,940 randomised, 54\% male, 45\% black

Antihypertensive drugs taken at start of RCT: SC (26.3\%), RC (25.7\%)

Interventions

(1) Stepped care (SC), designed to provide rigorous, systematic, antihypertensive drug treatment by means of:

"Free care- visits, drugs, investigations, transport

"Emphasis placed on clinic attendance and compliance- pill counts used

"Convenience- low waiting times, parmedical personnel, physician on call

"Stepped drug treatment according to BP response

"Patients seen at intervals determined by their clinical status, at least every 4 months, and generally every 2 months

(2) Referred care (RC): referred to their "primary sources of care, usually own physicians.

All SC (E) and RC (C) participants seen at home at years 1, 2, 4 and 5 for health history and BP measurement and at the clinic at years 2 and 5 for an examination. At each contact each RC participant was advised to visit a physician. If severe hypertension (DBP $115 \mathrm{mmHg}$ or end organ damage) special steps were taken to achieve contact with a physician. 


\section{Characteristics of included studies (Continued)}

(2) SBP/DBP level- lower for SC $(130 / 84 \mathrm{mmHg})$ vs RC (140/89) at 5 year FU

(3) \% controlled blood pressure (HDFP goal)- improved SC versus RC.

(4) All cause mortality- significantly better $350 / 5485$ (6.38\%) vs $421 / 5455$ (7.78\%)

All outcomes apply across 3 strata of entry DBP. Most of BP reduction occurred by end of year 1

Duration FU 1 and 5 years (mortality)

\begin{tabular}{|c|c|}
\hline \multirow[t]{10}{*}{ Notes } & Data reported in 3 strata of entry DBP \\
\hline & At one year $84.4 \%$ (SC) versus $59.1 \%$ (RC) taking antihypertensive medication \\
\hline & Step $1-32.7 \%$ v $12.1 \%$ \\
\hline & Step $2-23.6 \%$ v $16 \%$ \\
\hline & Step $3-3.3 \%$ v $2.3 \%$ \\
\hline & Step $4-2 \%$ v $2 \%$ \\
\hline & Total drug status known at 1 year, $82.4 \%$ SC v $82.8 \%$ RC \\
\hline & $\begin{array}{l}\text { Intensity of BP medication in SC at } 5 \text { years: } 42 \% \text { taking single drug- step } 1,27 \% \text { taking two drugs- step } 2 \text {, } \\
9 \% \text { taking } 3 \text { drugs- step } 3,11 \% \text { taking } 4 \text { or more drugs, step } 4 \text { and } 5 \text { at } 5 \text { years }\end{array}$ \\
\hline & $\begin{array}{l}\text { HDFP defined goal DBP as } 90 \mathrm{mmHg} \text { for those entering with DBP } 100 \mathrm{mmHg} \text { or receiving antihypertensive } \\
\text { therapy and a } 10 \mathrm{mmHg} \text { decrease for those entering with DBP of } 90-99 \mathrm{mmHg} \text {. }\end{array}$ \\
\hline & Mortality FU 5 years, mean BP data reported at 1 year and 5 years \\
\hline Allocation concealment & A - Adequate \\
\hline Study & Jewell 1988 \\
\hline Methods & Hypertensive patients in a single practice in the UK \\
\hline \multirow[t]{3}{*}{ Participants } & Patients aged 30-64 years. \\
\hline & Newly diagnosed: raised DBP $>100 \mathrm{mmHg}$ aged $30-39,>105 \mathrm{mmHg}$ aged $>40$ \\
\hline & Previously diagnosed: $\mathrm{DBP}>95 \mathrm{mmHg}$ on 3 measurements at a single visit \\
\hline \multirow[t]{4}{*}{ Interventions } & (1) Nurse-led clinic. Agreed protocol determined treatment and frequency of attendance in both groups. \\
\hline & Target was to reduce $\mathrm{DBP}<90 \mathrm{mmHg}, 15$ minute consultation. \\
\hline & Note: both nurse led and doctor led care was by means of identical protocol. \\
\hline & (2) Usual care-general practitioner 10 minute consultation \\
\hline \multirow[t]{10}{*}{ Outcomes } & $\begin{array}{l}\text { (1) Mean SBP/DBP- between group difference in mean SBP }-0.8 \mathrm{mmHg}(-8.7 \text { to } 24.7) \mathrm{NS} \text {, DBP - } 0.4 \mathrm{mmHg} \\
(-6.2 \text { to } 7) \mathrm{NS} \text {. }\end{array}$ \\
\hline & (2) Proportion with DBP $<90 \mathrm{mmHg}$ \\
\hline & $10 / 15(\mathrm{E}-67 \%)$ \\
\hline & $12 / 19(\mathrm{C}-63 \%)$ \\
\hline & (3) Quality of data recording (better in nurse group for pulse, weight, urine testing) \\
\hline & (4) Frequency of attendance (no difference, mean annual rates 5.7 (C) \\
\hline & $6(\mathrm{E})$ groups. \\
\hline & (5) Knowledge of medication (no difference) \\
\hline & (6) Reactions to the service (no difference) \\
\hline & Duration FU 1 year \\
\hline \multicolumn{2}{|l|}{ Notes } \\
\hline Allocation concealment & B - Unclear \\
\hline
\end{tabular}

\begin{tabular}{ll} 
Study & Johnson $\mathbf{1 9 7 8}$ \\
\hline Methods & $\begin{array}{l}\text { Factorial RCT, } \\
\text { randomised at individual level, stratified by age and sex. }\end{array}$ \\
\hline
\end{tabular}




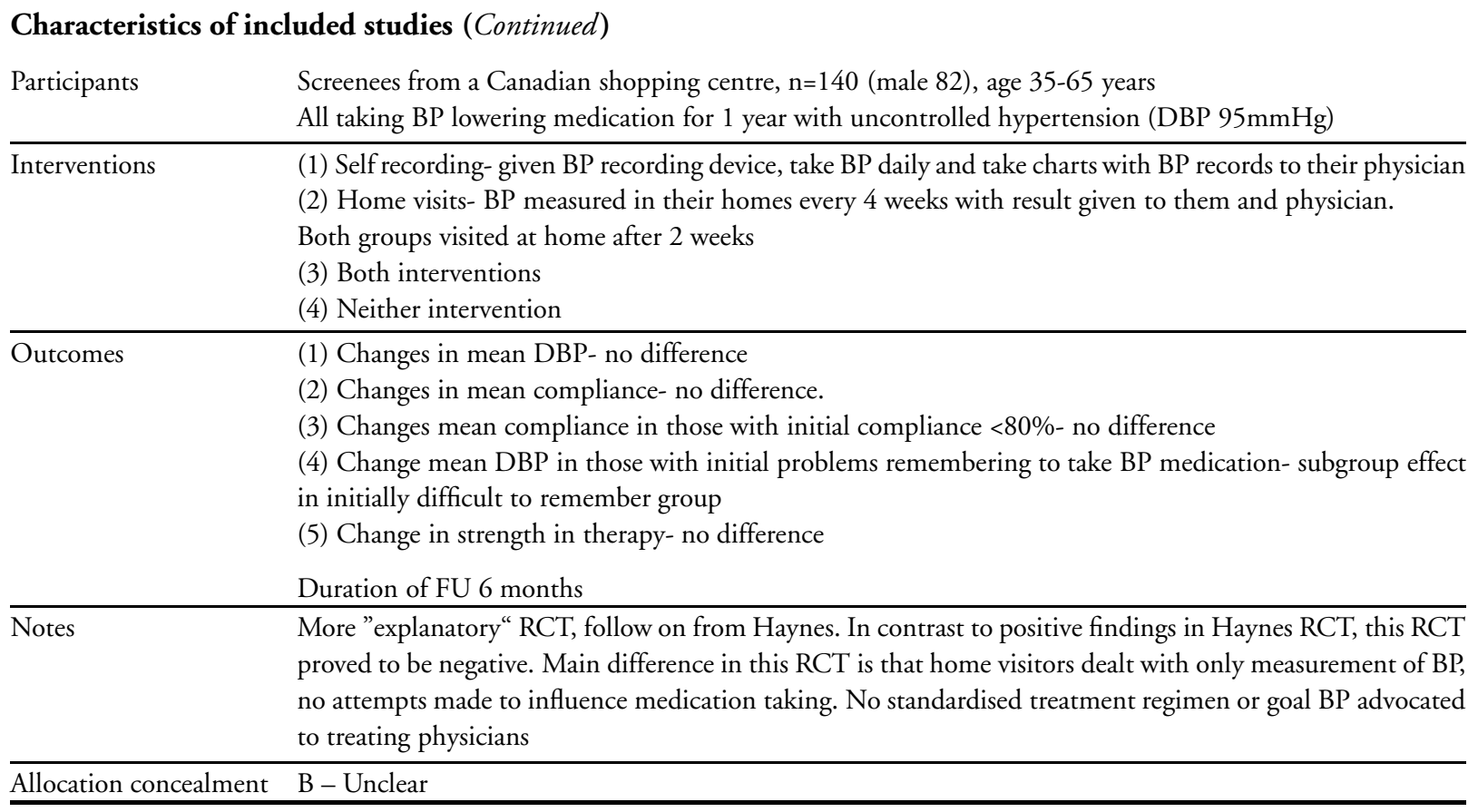

\begin{tabular}{|c|c|}
\hline Study & Krieger 1999 \\
\hline Methods & Parallel, individuals in a single "low income" area of Seattle, USA \\
\hline Participants & $\begin{array}{l}\text { Hypertensive patients (entry SBP } 140 \mathrm{mmHg} \text { or DBP } 90 \mathrm{mmHg}) .4761 \text { had BP measured, } 759(15.9 \%) \\
\text { eligible, } 421(55.5 \%) \text { participated. Overall, } 40 \% \text { taking BP lowering medication, } 79 \% \text { black, } 66 \% \text { below } \\
\text { federal poverty level, } 33 \% \text { BP } 160 / 100 \mathrm{mmHg} \text {. All participants paid } \$ 25 \text { for completing study }\end{array}$ \\
\hline Interventions & $\begin{array}{l}\text { (1) Outreach and tracking by community health worker. Provided: referral to medical care and assistance } \\
\text { with finding a provider; ensure appointment with health worker; appointment reminder letter; follow up } \\
\text { patient (up to } 3 \text { times) to see if appointment kept; new appointment if one missed (up to } 3 \text { times); assistance } \\
\text { to reduce barriers to care including transport, child care or other services } \\
\text { (2) Usual care }\end{array}$ \\
\hline Outcomes & $\begin{array}{l}\text { (1) Follow up appointment within } 90 \text { days- (E) } 95 / 146 \text { (65.1\%) versus (C) } 77 / 165 \text { (46.7\%). } \\
\text { (2) SBP/DBP-improved SBP (E) } 139.4 \mathrm{mmHg} \text { versus (C) } 141 \mathrm{mmHg} \text {, DBP no difference (E) } 84.6 \mathrm{mmHg} \\
\text { versus (C) } 84.3 \mathrm{mmHg} \\
\text { Duration of FU } 3 \text { months. }\end{array}$ \\
\hline Notes & $\begin{array}{l}\text { Study designed to assess follow up within } 30 \text { days. Large differential loss to follow up (greater in intervention } \\
\text { arm). } \\
\text { Mean SBP/DBP data provided by authors of study } \\
\text { No intention to treat analysis. }\end{array}$ \\
\hline Allocation concealment & B - Unclear \\
\hline
\end{tabular}

\begin{tabular}{ll} 
Study & Levine 1979 \\
\hline Methods & Factorial trial with 8 groups of various combinations of the 3 interventions and control individuals at two \\
& hypertension clinics in US \\
\hline Participants & $91 \%$ black, median age 54 years, $70 \%$ female, low income ( $\$ 45250$ median yearly income). \\
& BP ( $\mathrm{mmHg})$ entry criteria based on age: \\
& $20-39:>140 / 90$ \\
& $40-59:>150 / 95$ \\
$60: 160 / 100$
\end{tabular}




\section{Characteristics of included studies (Continued)}

Interventions

(1) Three interventions:

"Exit interview- individualised 5-10 minute counselling session, explaining and re-inforcing instructions to the patient

"Instructional session with adult at home concerning adherence and follow up care

"Group sessions- three, one hour sessions led by social worker

"Seven experimental groups and one control group

(2) Usual care with none of above interventions

Outcomes

(1) Deviation in weight from ideal weight- significantly better in patients who received all 3 interventions compared to those who received none

(2) Appointment keeping (ratio of kept/scheduled)- improved in group who received all 3 interventions versus control at 2 yrs (E) .68 versus (C) .63 ; no difference at 5 yrs (E) .95 versus (C) .83

(3) Adherence to drug therapy- all improved, greatest in 3 intervention arm versus control (53\% vs $40 \%)$

(4) \% patients with controlled BP - increased at 2 years (E) 52\% versus (C) $42 \%$; 5 years (E) $66 \%$ versus

(C) $56 \%$. Significantly better in four intervention groups compared to control at 5 years

(5) All cause mortality- cumulative mortality better in all experimental groups combined (12.9) compared to control group (30.2)

(6) Cost effectiveness- multiple interventions appear more effective, not necessarily more cost effective. Authors feel that may be better to use single interventions depending on setting and financial constraints $\{821\}$

Duration of FU 2 and 5 years.

Notes

Multiple comparisons in results section: 7 intervention arms and one control group

In addition no a priori sub-group analysis

Blood pressure control age-specific categories

$<40<140 / 90$,

$40-59<150 / 95$

$60,<160 / 100$

Substantially greater numbers lost to follow up in (C) arm at 2 and 5 years

Allocation concealment $\mathrm{D}-$ Not used

\begin{tabular}{ll} 
Study & Logan 1979 \\
\hline Methods & Parallel \\
& Individuals \\
\hline Participants & $\begin{array}{l}\text { Volunteers from business settings with newly diagnosed hypertension (DBP 95mmHg, or DBP 91-94mmHg } \\
\text { and SBP }>140 \mathrm{mmHg})\end{array}$ \\
\hline
\end{tabular}

Interventions (1) Work-site care- nurse management according to a standard protocol- including drug regimen and regular review, once monthly if BP not controlled

(2) Usual care from their own family physicians

Outcomes

(1) \# patients taking BP treatment- increased in Experimental group (177/206, 86\% vs 108/204, 53\%)

(2) Mean DBP- improved in (E) $94.3 \mathrm{mmHg}$ versus (C) $90.3 \mathrm{mmHg}, \mathrm{p}<0.01$.

(3) Reach goal DBP- $50 \%$ (E) versus $28.9 \%$ (C).

(4) Compliance-better in experimental group $(67.6 \%$ vs $49.1 \%)$

Duration of FU 6 months

\begin{tabular}{ll}
\hline Notes & Goal DBP $<90 \mathrm{mmHg}$ if entry DBP $>95 \mathrm{mmHg}$; or $<6 \mathrm{mmHg}$ in those with entry DBP $95 \mathrm{mmHg}$ or less. \\
\hline Allocation concealment & B - Unclear \\
\hline \multirow{3}{*}{ Study } & Martinez-Amenos $\mathbf{1 9 9 0}$ \\
\hline Methods & $\begin{array}{l}\text { Parallel } \\
\text { Individuals }\end{array}$ \\
\hline
\end{tabular}

Interventions used to improve control of blood pressure in patients with hypertension (Review) 


\section{Characteristics of included studies (Continued)}

Participants Hypertension Registry from 19 primary care centres in Spain. Mean age 61 years, 59\% female Initial volunteers asked if they wished to participate; those agreeing were randomised and labelled "motivated" group; group who declined to participate also followed up "non motivated"

\begin{tabular}{|c|c|}
\hline Interventions & $\begin{array}{l}\text { (1) Individual education- comments and explanations to errors encountered in answers to baseline knowledge } \\
\text { questionnaire } \\
\text { (2) Team education- } 2 \text { talks given by nurses or doctors with AV material to 8-12 patients } \\
\text { (3) Control group }\end{array}$ \\
\hline Outcomes & $\begin{array}{l}\text { (1) Proportion of patients in each group with uncontrolled hypertension (SBP }<160 \text {, DBP }<95 \mathrm{mmHg} \text { )- } \\
\text { within group increase reported for both intervention arms, individual } 50.4 \% \text { to } 60.9 \% \text {, team, } 55.8 \% \text { to } \\
68.8 \% \text {, non significant within group change in control group, } 54.4 \% \text { to } 58.9 \% \\
\text { (2) Patient knowledge- no between group difference, individual } 19.79 \text {, Team } 20.58 \text {, control } 19.78 \\
\text { Duration of FU: } 2 \text { months }\end{array}$ \\
\hline Notes & $\begin{array}{l}\text { Knowledge increased within all } 3 \text { groups over time, between group comparison not statistically tested } \\
\text { No baseline numbers per arm of study reported } \\
\% \text { control BP not included in meta-analysis as no denominator data available at start of RCT }\end{array}$ \\
\hline Allocation & B - Unclear \\
\hline
\end{tabular}

\begin{tabular}{|c|c|}
\hline Study & McAlister 1986 \\
\hline Methods & Cluster (60 doctors initially, 10 dropped out), parallel, Toronto Canada \\
\hline Participants & $\begin{array}{l}\mathrm{N}=50 \text { general practitioners, } 1241 \text { (E) } 990 \text { (C), hypertensive patients with one of the following: } \\
\text { (1) DBP > } 90 \mathrm{mmHg} \text { on treatment } \\
\text { (2) DBP }>104 \mathrm{mmHg} \text { not on treatment } \\
\text { (3) DBP }>90 \text { or }<105 \mathrm{mmHg} \text { unless evidence of complications or risk factors } \\
\text { (4) Newly detected patients with "high blood pressure" detected during the trial }\end{array}$ \\
\hline Interventions & $\begin{array}{l}\text { (1) Computer generated feedback to physician: } \\
\text { "Cumulative chart of patient's DBP } \\
\text { "Inter and Intra practice DBP ranking } \\
\text { "Commentary on treatment by GP according to a "stepped care" approach } \\
\text { (2) Control group filled out same forms but no feedback given }\end{array}$ \\
\hline \multirow[t]{2}{*}{ Outcomes } & $\begin{array}{l}\text { 1) Workload: GPs in experimental group saw more patients } \\
\text { (2) Mean score on length of follow up: better in intervention } 199.3 \text { days (E) vs } 167 \text { days (C) } \\
\text { (3) Drop outs: } 37.5 \% \text { (E) vs } 42.1 \% \text { (C) } \\
\text { (4) In all patients DBP reading in those with initial DBP > } 104 \mathrm{mmHg}: 88.5 \mathrm{mmHg} \text { (E) vs } 93.3 \mathrm{mmHg}(\mathrm{C}) \text {, } \\
\text { net DBP change } 0.8 \mathrm{mmHg} \mathrm{P}<0.1 \\
\text { (5) \% patients with controlled DBP }(90 \mathrm{mmHg})-88.9 \% \text { (E) versus } 87.5 \% \text { (C) NS } \\
\text { (6) \# days with sustained DBP control } 323 \text { (E) vs } 259 \text { (C) } \\
\text { (7) \# times visited GP: } 13.3 \text { (E) vs }(17.4)\end{array}$ \\
\hline & Duration 16 months \\
\hline Notes & $\begin{array}{l}\text { Multiple outcomes reported, some favourable for experimental arm- saw more patients who were less likely } \\
\text { to drop out of care. Doesn't appear to have had an impact on overall DBP control but other measures of BP } \\
\text { control favoured intervention group such as number of days with sustained DBP control. This was achieved } \\
\text { with fewer visits in the intervention group }\end{array}$ \\
\hline Allocation concealment & B - Unclear \\
\hline
\end{tabular}

Study

Mehos 2000

Methods

Parallel, individuals in a single family medicine clinic, US

Interventions used to improve control of blood pressure in patients with hypertension (Review)

Copyright (c) 2006 The Cochrane Collaboration. Published by John Wiley \& Sons, Ltd 


\section{Characteristics of included studies (Continued)}

Participants 41 uncontrolled hypertensives, SBP $140-179 \mathrm{mmHg}$ and/or DBP $90-109 \mathrm{mmHg}$, currently on treatment, mean age 59 years, $70 \%$ women

Interventions (1) Home blood pressure monitoring, diary and instruction to measure blood pressure, information on hypertension and risk factors, subsequent evaluation by clinical pharmacist (2) Usual care

Outcomes (1) SBP, DBP and mean BP- all reduced in (E) group, SBP (E) $140.8 \mathrm{mmHg}$ versus (C) $146.9 \mathrm{mmHg}$ $(\mathrm{p}=0.069)$, DBP (E) $80.6 \mathrm{mmHg}$ versus (C) $85.6 \mathrm{mmHg}(\mathrm{p}=0.02)$,

(2) Compliance (self report)- mean adherence $82 \%$ (E) vs $89 \%$ (C) ( $\mathrm{p}=0.29)$

(3) Drug alteration (dosage increase, addition or switch)- $83 \%$ (E) vs 33\% (C) ( $\mathrm{p}=0.29)$

(4) Quality of life (SF36)- no difference between groups

Duration of FU 6 months

Notes

Allocation concealment $\mathrm{B}-$ Unclear

Study

Midanik 1991

Methods Parallel, individuals, from a single foundation health plan in California, US.

Participants 204 untreated hypertensive patients with "mild“ hypertension- SBP $<180 \mathrm{mmHg}$ and DBP $90-99 \mathrm{mmHg}$

Interventions

(1) Self monitoring- patients trained to take two consecutive readings twice a week. Sent in readings every 4 weeks for one year(2) Usual care

Outcomes (1) Blood pressure- mean change SBP -1 mmHg, mean change DBP - $1 \mathrm{mmHg}(\mathrm{E})$ versus mean change SBP $+1 \mathrm{mmHg}$, mean change DBP $-1 \mathrm{mmHgDuration}$ of FU 1 year

Notes $\quad$ Untreated subjects with $18 \%$ of $(\mathrm{E})$ and $17 \%$ of $(\mathrm{C})$ patients taking antihypertensive medication at the end of the RCT

Allocation concealment $\mathrm{B}$ - Unclear

Methods 27 general practice in UK, Cluster RCT, patients on register

Participants Hypertensive patients aged 60-80 taking BP lowering drugs.

Randomly selected from practice register

Interventions (1) Computer based decision support system (CDSS)

(2) Risk chart

Both interventions provided health professional (general practitioner or practice nurse) with explicit cardiovascular risk. Based on New Zealand hypertension guidelines.

(3) Usual care

Outcomes

(1) Cardiovascular risk- no change in CVD risk between 3 groups

(2) SBP/DBP- adjusted analysis, chart group had better mean SBP reading than usual care (difference $4.6 \mathrm{mmHg})$

(3) Proportion of patients with controlled hypertension $(<160 / 90)$ - no difference between two intervention groups chart $39.7 \%$, CDSS $47.5 \%$ and control $40.7 \%$

(4) Medication change- intensity of BP medication prescribing greater in chart group compared to usual care

Duration of FU 1 year

Notes

Study Morisky 1983

Methods Factorial trial with 8 groups of various combinations of the 3 interventions and control individuals at two hypertension clinics in US 


\section{Characteristics of included studies (Continued)}

Participants

$91 \%$ black, median age 54 years, $70 \%$ female, low income ( $\$ 45250$ median yearly income).

$\mathrm{BP}(\mathrm{mmHg})$ entry criteria based on age:

20-39: $>140 / 90$

40-59: $>150 / 95$

60: $160 / 100$

Intervention

(1) Three interventions:

"Exit interview- individualised 5-10 minute counselling session, explaining and re-inforcing instructions to the patient

"Instructional session with adult at home concerning adherence and follow up care

"Group sessions- three, one hour sessions led by social worker

"Seven experimental groups and one control group

(2) Usual care with none of above interventions

Outcomes

(1) Deviation in weight from ideal weight- significantly better in patients who received all 3 interventions compared to those who received none

(2) Appointment keeping (ratio of kept/scheduled)- improved in group who received all 3 interventions versus control at 2 yrs (E) .68 versus (C) .63; no difference at 5 yrs (E) .95 versus (C) .83

(3) Adherence to drug therapy- all improved, greatest in 3 intervention arm versus control (53\% vs 40\%)

(4) \% patients with controlled BP - increased at 2 years (E) 52\% versus (C) 42\%; 5 years (E) 66\% versus

(C) $56 \%$. Significantly better in four intervention groups compared to control at 5 years

(5) All cause mortality- cumulative mortality better in all experimental groups combined (12.9) compared to control group (30.2)

(6) Cost effectiveness- multiple interventions appear more effective, not necessarily more cost effective. Authors feel that may be better to use single interventions depending on setting and financial constraints $\{821\}$

Duration of FU 2 and 5 years.

Notes

Multiple comparisons in results section: 7 intervention arms and one control group

In addition no a priori sub-group analysis

Blood pressure control age-specific categories

$<40<140 / 90$,

$40-59<150 / 95$

$60,<160 / 100$

Substantially greater numbers lost to follow up in (C) arm at 2 and 5 years

Allocation concealment $\mathrm{B}$ - Unclear

Study

Methods

Participants

Interventions

\section{Muhlhauser 1993}

10 general practices Germany, 20 hypertensive patients randomly selected (age 30-60 years)

Hypertension (mean last 2 measurements 160 and/or 95). Taking BP medication (E 77\%, C 86\%)

(1) Hypertension treatment and teaching programme (HTTP) consisted of:

"Four consecutive meetings lasting 60-90 mins in groups of 4-6.

"Provided by physician assistants

"Responsibility including BP self monitoring

"Confirming diagnosis and treatment by using home BP measurements

"Emphasis on non-pharmacological treatment

Doctors ( 8 hours) and assistants (20 hours) in intervention practices attended preparatory course but RCT aimed principally at patients

(2) Usual care

Outcomes

(1) Change in SBP/DBP- significantly improved at follow up, difference SBP $5 \mathrm{mmHg}$, DBP $4 \mathrm{mmHg}$

(2) Proportion of patients with controlled hypertension (<140/90)- no difference (E) 14\% versus 15\% (C)

(3) \# BP drugs taken 


\section{Characteristics of included studies (Continued)}

\begin{tabular}{ll}
\hline Notes & Duration of FU 18 months \\
& $\begin{array}{l}\text { (1) Only } 46 \text { (46\%) in intervention group received intervention (2) Cluster RCT not accounted for design } \\
\text { or analysis. } \\
\text { (3) Well conducted RCT but differential losses to FU } \\
\text { (4) Less people in intervention group taking BP medication at end of RCT (mean \# (E)- 1.2, (C) 1.8) }\end{array}$ \\
\hline Allocation concealment & B - Unclear \\
\hline Study & New 2004 \\
\hline Methods & Cluster RCTGeneral practices \\
\hline Participants & 44 general practices, Salford, UK, 10303 participants \\
\hline Interventions & $\begin{array}{l}\text { (1) Educational outreach: specialist nurses arranged a schedule of visits with general practitioners and practice } \\
\text { nurses, reminding them of protocols and clinical targets; provided educational material and protocols used in } \\
\text { secondary care for nurse and doctor interventions including stepping up pharmacotherapy when necessary.(2) } \\
\text { usual care }\end{array}$ \\
\hline Outcomes & $\begin{array}{l}\text { (1) Proportion of participants reaching blood pressure target/OR: no difference between groups OR 1.01 } \\
\text { (95\% CI 0.8 to 1.3, p=0.93). }\end{array}$ \\
\hline Notes & Study funded by pharmaceutical company. \\
\hline Allocation concealment & B - Unclear \\
\hline
\end{tabular}

\section{Study}

Methods

Participants

\section{Ornstein 2004}

Cluster RCT, 20 community-based family or general internal medicine practices in 14 US states. 44 physicians, 17 "midlevel" providers and approximately 200 staff members

Of 87,291 patients from 20 practices, 7772 (8.9\%) with hypertension. At baseline 40\% (E) and 43.7\% (C) had "controlled" blood pressure $(<140 / 90)$.

21 study indicators included:

-Hypertension (5) including most recent BP measurement $<140 / 90$ for patients with a diagnosis of hypertension

-Hyperlipidemia (2)

-Coronary heart disease (6)

"Heart failure (1)

-Atrial fibrillation (1)

-Diabetes (6)

Interventions

(1) Multi-method quality improvement (QI)-

-Practice site visits (6-7, 1-2 day site visits in a two year period) involving physicians and pharmacist with expertise in academic detailing. Healthcare providers encouraged to use (QI) tools

-Two-day network meetings in each study year. Initial meeting directed at lead clinician with "best practice“ presentations made by participating clinicians who were performing well. Clinical and administrative staff attended second meeting

(2) Usual care- received copies of practice guidelines and quarterly performance reports

Outcomes

(1) Control BP <140/90mmHg improved 58.4\% (E) versus 51.9\% (C), adjusted difference 8.0 (0.0 to 16.0), $\mathrm{p}=0.047$

Duration of FU 2 years

Notes

General multi-method across 6 conditions and 21 quality indicators. Overall intervention practices improved

22.4 percentage points in terms of indicators at or above target, compared to 16.4 in control practices, difference 6.0 percentage points $(\mathrm{p}>0.2)$.

Patients in intervention practices had greater improvements than control practices for diagnosis of hypertension and blood pressure control 


\section{Characteristics of included studies (Continued)}

Allocation concealment $\mathrm{B}$ - Unclear

\begin{tabular}{|c|c|}
\hline Study & Park 1996 \\
\hline Methods & Parallel, individuals two pharmacies, US \\
\hline Participants & $\begin{array}{l}\text { Taking BP lowering treatment or had BP } 140 / 90 \mathrm{mmHg} \text {. mainly white treated hypertensives, } 50 \% \text { women } \\
\text { mean age } 60 \text { years }\end{array}$ \\
\hline Interventions & $\begin{array}{l}\text { (1) Pharmacist administered monthly patient management including education, medication changes, verba } \\
\text { counselling and written information on hypertension and risk factors } \\
\text { (2) Traditional pharmacy services }\end{array}$ \\
\hline Outcomes & $\begin{array}{l}\text { (1) SBP/DBP- improved SBP (E) } 143.2 \mathrm{mmHg} \text { versus }(\mathrm{C}) 148.6 \mathrm{mmHg} \text {, DBP (E) } 83.2 \mathrm{mmHg} \text { versus }(\mathrm{C} \text { ) } \\
83.7 \mathrm{mmHg} \text {, no between group p values reported } \\
\text { (2) Control of blood pressure (<140/90 mmHg)- improved } 52.2 \%(\mathrm{E}) \text { vs } 17.4 \%(\mathrm{C}), \mathrm{p}<0.02 \\
\text { (3) Compliance (pill counts, unaware)- mean adherence } 86.8 \%(\mathrm{E}) \text { vs } 89.1 \%(\mathrm{C}) \text { no p value reported } \\
\text { (4) Self reported quality of life- in general higher in (E) vs }(\mathrm{C}) \text { group } \\
\text { (5) Time spent with patient- higher in (E) group, particularly at first visit } \\
\text { Duration of FU } 4 \text { months }\end{array}$ \\
\hline Notes & \\
\hline Allocation concealment & B - Unclear \\
\hline
\end{tabular}

\section{Study}

Methods

Participants

Interventions

\section{Pierce 1984}

Factorial, individuals, single general practice clinic, Western Australia

Uncontrolled hypertensives (SBP 160 and/or DBP 95) taking BP medication, mean age 57 years, 60\% women,

(1) Self monitoring of blood pressure: 30 min briefing, monthly recording chart

(2) Health education programme promoting a healthy cardiovascular lifestyle: four meetings, 90 min duration, max 12 participants, encouraged to make action goals, information (risk factors for heart disease, stress, diet)

(3) Both interventions

(4) Usual care

Outcomes

(1) Blood pressure control- Education: $83 \%$ (E) vs 67\% (C) (p<0.05, effect size unclear) $\mathrm{p}<0.05$ Monitoring: $74 \%$ (E) vs $78 \%$ (C) NS

(2) Compliance (pill count, self report)- No significant difference between groups: Education: 27\% good adherers versus $24 \%$ in control group.

Monitoring: 30\% Both interventions: 26\%

(3) Patient Knowledge- no difference

Duration of FU 12 months

Notes

Health education appears more beneficial in controlled blood pressure than self monitoring.

Blood pressure reduction, target blood pressure level not defined

Allocation concealment $\mathrm{B}-$ Unclear

\begin{tabular}{ll} 
Study & Robson $\mathbf{1 9 8 9}$ \\
\hline Methods & Parallel, individuals based in a single family practice in UK \\
\hline Participants & $\begin{array}{l}\text { Patients registered in the practice. Age 30-64. Also concerned with recording and follow up of other cardio- } \\
\text { vascular risk factor data and cervical screening follow up }\end{array}$ \\
\hline
\end{tabular}

Interventions

(1) Recording and follow up of blood pressure and other cardiovascular risk factors with practice nurse or general practitioner aided by computer

Interventions used to improve control of blood pressure in patients with hypertension (Review) 


\section{Characteristics of included studies (Continued)}

(2) Usual general practitioners follow up

Outcomes

(1) Blood pressure recording in all patients- increased 1511/1620 (E- 93\%) 1160/1586 (C- 73\%)

(2) Blood pressure recording in hypertensive patients- increased 104/107 (E- 97\%) 90/116 (C- 69\%)

(3) Other cardiovascular risk factors- all increased recording in intervention group, smoking, family history and cholesterol

Duration of FU 2 years

\begin{tabular}{ll}
\hline Notes & Improved recording of blood pressure and other cardiovascular risk factors \\
\hline Allocation concealment & B - Unclear \\
\hline
\end{tabular}

Study

Roca-Cusachs 1991

Methods

Parallel, individual in a hypertension clinic, Spain

Participants

Newly diagnosed hypertensive patients (excluded age $>70$, illiterate and "high probability of non attendance") Entry SBP/DBP noted but no threshold required for eligibility. Mean values were:

(E) $156.3 / 95.8$

(C) $160.3 / 96.1$

Interventions

(1)Patient education-

"Booklet at initial entry into study

"Two educational talks. First educational talk given by pharmacist and doctor, covered information about hypertension, treatment adherence and appointments; second educational talk given by dieticians covered non-pharmacological treatments.

"Personal tutorial meeting one month later-solve problems, clarify misunderstandings and re-enforce knowledge.

(2) Usual care

Outcomes

(1) Weight- no difference

(2) Mean SBP/DBP- no difference

(3) Withdrawals-39\% (E) vs $26 \%$ (C) significant difference

(4) Knowledge questionnaire- improved knowledge in (E) group

(5) Number of BP pills taken- no difference

(6) Biochemical markers- no difference

Duration of FU 6 months

Notes

(1) Knowledge improved, other outcomes no difference, withdrawal from the programme greater in the (E) $39 \%$ versus (C) $25 \%$

(2) Large proportion of (E) failed to attend an educational session, 83/138 (60\%).

(3) Sub-group analysis showed that 55/138 (40\%) who attended one or more educational session did not have a different outcome in terms of all outcome measures at follow up, including SBP/DBP than those in intervention group who failed to attend sessions $83 / 138(60 \%)$, except that those who attended had significantly higher probability of not withdrawing overall $3.6 \%$ vs $63 \%$.

Allocation concealment $\mathrm{D}$ - Not used

\begin{tabular}{ll} 
Study & Rogers $\mathbf{2 0 0 1}$ \\
\hline Methods & Medical outpatients department, patients covered by insurance under care of 5 internists, New York state, \\
& US. \\
\hline Participants & Previous diagnosis of hypertension but were being considered for change in BP medication because: \\
& (1) SBP 140 or DBP 90 despite current antihypertensive therapy \\
& (2) Side effects from drugs \\
& (3) SBP $>180$ or DBP $>110$ without current antihypertensive therapy \\
\hline
\end{tabular}

Interventions

(1) Telecommunication service with 3 components:

"Automated BP at home with no self report 


\section{Characteristics of included studies (Continued)}

"Central processing of BP readings

"Weekly reports to both physician and patient. When physicians received report forms that indicated increased blood pressure they adjusted BP medication via telephone call, office visit or both. Readings minimum of 3 days each week for minimum 8 weeks

(2) Usual care

\begin{tabular}{ll}
\hline Outcomes & (1) Mean change in arterial blood pressure- improved $-2.8 \mathrm{mmHg}(\mathrm{E})$ versus $+1.3(\mathrm{C}) \mathrm{p}=0.013$ \\
& (2) Mean change in systolic blood pressure- improved $-4.9 \mathrm{mmHg}(\mathrm{E})$ versus $-0.1(\mathrm{C}) \mathrm{p}=0.047$ \\
& (3) Mean change in diastolic blood pressure- improved $-2 \mathrm{mmHg}(\mathrm{E})$ versus $+2.1(\mathrm{C}) \mathrm{p}=0.012$ \\
& Median duration of FU 11 weeks \\
\hline Notes & Change in mean arterial BP primary outcome via $24 \mathrm{hr}$ ambulatory reading \\
& Change in BP medication related to change in mean arterial BP and was more common in intervention \\
& group, 33\% (E) versus 7\% (C) group. \\
& No change in median number of office visits \\
& Difference in median length of FU (longer in intervention group, 79 vs 72 days) \\
& Satisfaction with care same in both groups \\
\hline Allocation concealment & A- Adequate
\end{tabular}

\begin{tabular}{|c|c|}
\hline Study & Rudd 2004 \\
\hline Methods & Parallel RCT, two medical clinics \\
\hline Participants & $\begin{array}{l}\text { Hypertension- SBP ? } 140 \mathrm{mmHg} \text { or DBP } ? 90 \mathrm{mmHg} \text { in previous six months or history of drug treatment. } \\
\text { Drug therapy for patients with } 150 \mathrm{mmHg} \text { or DBP } 95 \mathrm{mmHg} \text {. }\end{array}$ \\
\hline Interventions & $\begin{array}{l}\text { (1) Self measurement with nurse management based on algorithm. Twice daily measurement, after } 14 \text { mea- } \\
\text { surements mailed to nurse care manager who used this BP data to give management. Additional interventions } \\
\text { included tips on enhancing drug adherence and recognition of possible side effects; printed materials; follow } \\
\text { up calls at } 1 \text { week, } 1,2 \text { and } 4 \text { months. Nurse contacted physicians to initiate new drugs not did not contact } \\
\text { physicians when changing medication dosage. Increase in drug dose occurred when }<80 \% \text { measurements } \\
\text { met criterion of } 130 / 85 \mathrm{mmHg} \text { (1) }\end{array}$ \\
\hline Outcomes & Usual care \\
\hline Notes & $\begin{array}{l}\text { (1) Blood pressure- mean change DBP - } 6.5 \mathrm{mmHg}(\mathrm{E}) \text { versus mean change DBP } 3.4 \mathrm{mmHg}(\mathrm{C})(2) \text { Increase } \\
\text { in taking and intensification of antihypertensive drugs- } 22 \%(\mathrm{E}) \text { and } 30 \%(\mathrm{C}) \text { patients taking antihypertensive } \\
\text { medication, changed to } 96 \%(\mathrm{E}) \text { and } 78 \%(\mathrm{C}) \text {. Significant increase in number taking ?drugs } 70 \%(\mathrm{E}) \text { and } \\
46 \% \text { (C). (3) Improved adherence to mediation- } 80.5 \% \text { (E) versus } 69.2 \% \text { (C)Duration of FU } 6 \text { months }\end{array}$ \\
\hline Allocation concealment & B - Unclear \\
\hline
\end{tabular}

\begin{tabular}{ll} 
Study & Sackett $\mathbf{1 9 7 5}$ \\
\hline Methods & Factorial RCT \\
& Steel mill employees in Canada \\
\hline Participants & Hypertension $95 \mathrm{mmHg}$ on repeated measurement. Not currently treated. $\mathrm{n}=230$. \\
\hline Interventions & (1) Augmented convenience (AC) \\
& Saw on-site physicians during working hours and on full pay versus usual care of seeing their own GP \\
& (2) Mastery learning (ML) \\
& Educational programme designed to give them the facts about hypertension, including compliance advice \\
and reminders about pill-taking. Information supplied in audio-casette and booklet. Mastery learning re- \\
emphasised by a "patient educator" \\
(3) Both intervention \\
(4) Usual care
\end{tabular}

Outcomes

(1) Number men placed on BP medication increased in both groups AC $(87 / 114,76 \%$ vs $57 / 116,49 \%)$ 


\section{Characteristics of included studies (Continued)}

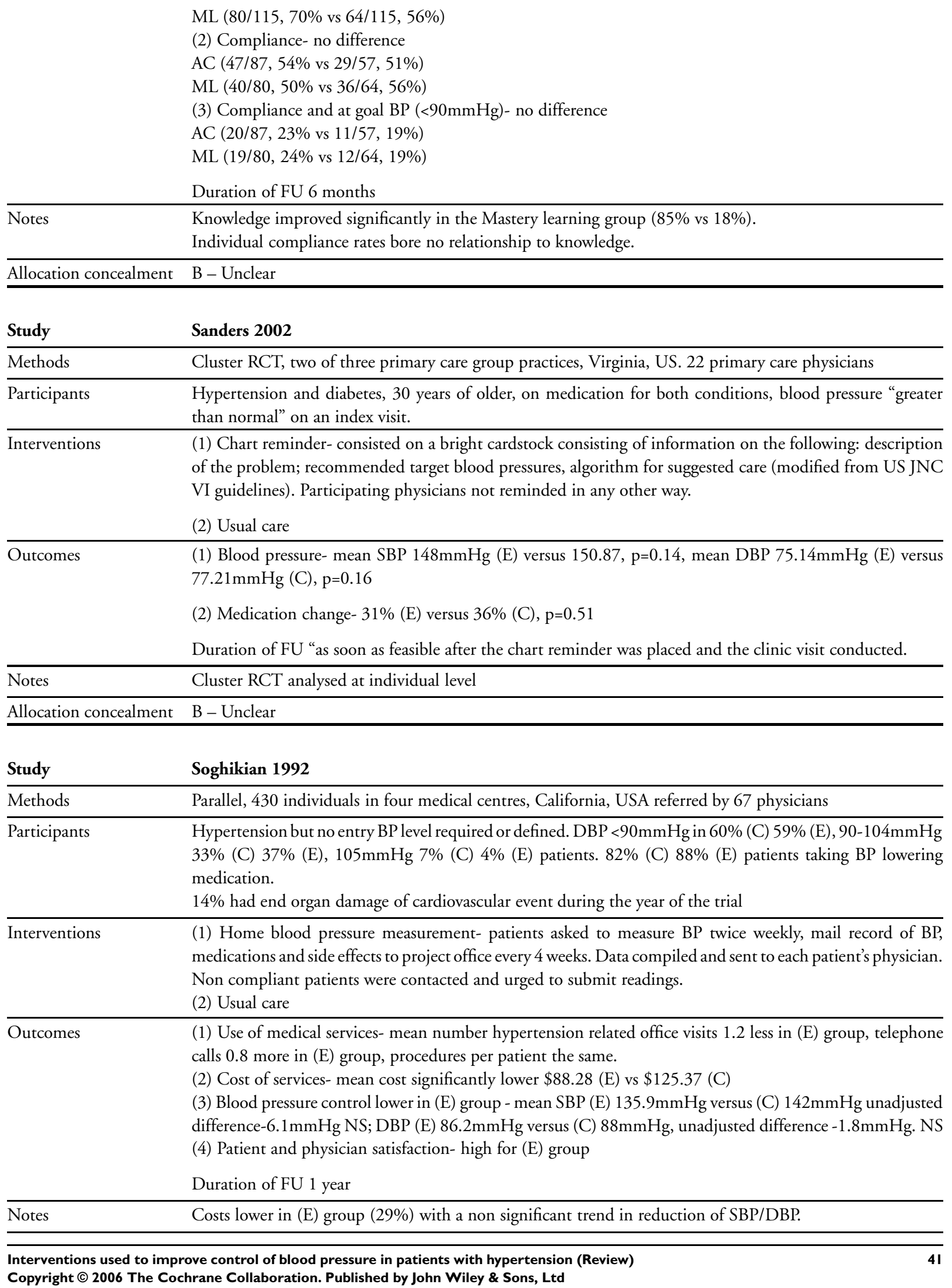


Characteristics of included studies (Continued)

Allocation concealment $\mathrm{B}$ - Unclear

\begin{tabular}{ll} 
Study & Solomon $\mathbf{2 0 0 2}$ \\
\hline Methods & Parallel, individuals from ten departments of Veterans Affairs medical centres and one academic medical \\
& centre, US \\
\hline Participants & Treated hypertensive patients (dihydropyridine and/or diuretic therapy) (n=133), 64\% caucasian, 28\% black, \\
& $96 \%$ men, mean age 67 years, \\
\hline Interventions & (1) Patient-centred pharmaceutical care model (employing standardised care) implemented by clinical phar- \\
& macy residents, scheduled visits at one-month intervals for a total of five visits \\
& (2) Usual care \\
\hline Outcomes & (1) Blood pressure control- SBP improved (E) 138.5mmHg versus (C) 144.9mmHg (p<0.05), DBP (E) \\
& 80.2mmHg versus (C) 83.2mmHg NS \\
& (2) Compliance (pill count, self report)- better compliance scores (0.23 vs 0.61) in (E) group (p<0.05) \\
& (3) Mean number of hospitalisations/other health care provider visits- significantly higher in $(\mathrm{C})$ group \\
& Duration of FU 6 months \\
\hline Notes & Losses to follow up not reported \\
\hline Allocation concealment & B - Unclear \\
\hline
\end{tabular}

\begin{tabular}{|c|c|}
\hline Study & Takala 1979 \\
\hline Methods & $\begin{array}{l}\text { Hypertensive patients identified through systematic screening of } 1245 \text { individuals. To be included had to } \\
\text { have two BP readings, six months apart with high blood pressure on not on BP treatment }\end{array}$ \\
\hline Participants & $\begin{array}{l}\text { Hypertensive patients in Finland, } \mathrm{n}=147 \text {, aged } 40-49 \text {, SBP } 160 \mathrm{mmHg} \text { or DBP } 95 \mathrm{mmHg} \text {; aged } 50-64 \text {, SBP } \\
170 \mathrm{mmHg} \text { or DBP } 105 \mathrm{mmHg} \text {. Drug treatment started in } 78 / 93(84 \%) \text { in intervention group and } 86 / 100 \\
(86 \%) \text { in control group }\end{array}$ \\
\hline Interventions & $\begin{array}{l}\text { (1) "Improved treatment system " included:Written treatment instructions.Card with details of BP readings, } \\
\text { drugs prescribed, time of next appointment.Appointments at one monthly intervals.Invitation for outpatient } \\
\text { review; appointment if defaulted on any appointment.(2) Usual care }\end{array}$ \\
\hline Outcomes & $\begin{array}{l}\text { (1) "Dropping out" of system- failing to keep outpatient follow up appointment. Improved in (E) 3/100 } \\
\text { versus (C) } 16 / 102(2) \text { Control of SBP/DBP reported separately in two age groups (aged 50)(3) \% patients in } \\
\text { each group who attained BP goal, } 31 \% \text { (E) vs } 17 \% \text { (C)Duration of FU } 1 \text { and } 2 \text { years. }\end{array}$ \\
\hline \multicolumn{2}{|l|}{ Notes } \\
\hline Allocation concealment & B - Unclear \\
\hline
\end{tabular}

\section{Study}

Methods

Participants

Interventions

\section{Takala 1983}

Hypertensive patients identified through systematic screening of 1245 individuals. To be included had to have two BP readings, six months apart with high blood pressure on not on BP treatment

Hypertensive patients in Finland, aged $40-49$, SBP $160 \mathrm{mmHg}$ or DBP $95 \mathrm{mmHg}$; aged 50-64, SBP $170 \mathrm{mmHg}$ or DBP $105 \mathrm{mmHg}$. Drug treatment started in 78/93 (84\%) in intervention group and 86/100 $(86 \%)$ in control group

(1) "Improved treatment system" included:Written treatment instructions.Card with details of BP readings, drugs prescribed, time of next appointment.Appointments at one monthly intervals.Invitation for outpatient review; appointment if defaulted on any appointment.(2) Usual care

Outcomes

(1) "Dropping out" of system- failing to keep outpatient follow up appointment. Improved in (E) 3/100 versus (C) 16/102(2) Control of SBP/DBP reported separately in two age groups (aged 50)(3) \% patients in each group who attained BP goal, 31\% (E) vs 17\% (C)Duration of FU 1 and 2 years.

Notes 


\section{Characteristics of included studies (Continued)}

Allocation concealment B-Unclear

\begin{tabular}{|c|c|}
\hline Study & Tanner 1981 \\
\hline \multirow[t]{2}{*}{ Methods } & Hypertensive patients attending in a single urban family practice. \\
\hline & Both groups visit family practice every 2 weeks for 4 months- total 8 appointments. \\
\hline Participants & $\begin{array}{l}\text { Diagnosis of hypertension from computer search with DBP } 90 \mathrm{mmHg} \text {, age } 18-65.50 \text { identified, } 30 \text { agreed } \\
\text { to participate, } 11 \text { males. } 14 \text { black }\end{array}$ \\
\hline Interventions & $\begin{array}{l}\text { (1) Intervention group given "Guide to essential hypertension" content included: hypertension; medication; } \\
\text { diet; stress; exercise; smoking; lifestyle; bp monitoring techniques. Encouraged to ask questions and discuss } \\
\text { problems when they at practice visits. } \\
\text { (2) Usual care }\end{array}$ \\
\hline \multirow[t]{5}{*}{ Outcomes } & (1) Knowledge- baseline and follow up-within group comparison knowledge \\
\hline & E-13.53 to 14.40 increase \\
\hline & C- 13.26 to 13.26 no change. \\
\hline & $\begin{array}{l}\text { Between group score significantly better in } \mathrm{E} \text { versus } \mathrm{C} \text { group. } \\
\text { (2) Control of DBP- no difference }\end{array}$ \\
\hline & Duration of FU 4 months \\
\hline \multicolumn{2}{|l|}{ Notes } \\
\hline Allocation concealment & B - Unclear \\
\hline Study & Tobe 2006 \\
\hline \multicolumn{2}{|l|}{ Methods } \\
\hline \multicolumn{2}{|l|}{ Participants } \\
\hline \multicolumn{2}{|l|}{ Interventions } \\
\hline \multicolumn{2}{|l|}{ Outcomes } \\
\hline \multicolumn{2}{|l|}{ Notes } \\
\hline Allocation concealment & D - Not used \\
\hline Study & Vetter 2000 \\
\hline Methods & Parallel, individuals 244 practitioners in Switzerland, 4 patients per practitioner recruited \\
\hline Participants & $\begin{array}{l}\text { Hypertension, SBP } 160-200 \mathrm{mmHg} \text { or DBP } 95-115 \mathrm{mmHg} \text { in untreated patients or uncontrolled patients } \\
\text { or who wished to change BP lowering drug because of low tolerance }\end{array}$ \\
\hline Interventions & $\begin{array}{l}\text { (1) Home measurement of blood pressure by patients } \\
\text { (2) Usual care }\end{array}$ \\
\hline \multirow[t]{2}{*}{ Outcomes } & $\begin{array}{l}\text { (1) Blood pressure control- SBP improved (E) } 145.1 \mathrm{mmHg} \text { versus }(\mathrm{C}) 147.6 \mathrm{mmHg}(\mathrm{p}=0.02) \text {, DBP improved } \\
\text { (E) } 88.7 \mathrm{mmHg} \text { versus (C) } 90.1 \mathrm{mmHg}(\mathrm{p}=0.038) \text {. (2) \% with controlled hypertension (DBP } 90 \mathrm{mmHg}) \\
66.2 \% \text { (E) vs } 59.8 \mathrm{mmHg} \text { (ns) }\end{array}$ \\
\hline & Duration of FU 8 weeks \\
\hline Notes & $\begin{array}{l}\text { All patients treated with same BP lowering drug, Losartan } 50 \mathrm{mg} \text { once daily. No compliance data so not } \\
\text { possible to say improved BP control due to improved compliance. Home BP measurement produced small } \\
\text { BP change at } 8 \text { weeks }\end{array}$ \\
\hline Allocation concealment & B - Unclear \\
\hline Study & Watkins 1987 \\
\hline Methods & $\begin{array}{l}6 \text { General practices UK } \\
\mathrm{n}=414,41 \% \text { male }\end{array}$ \\
\hline
\end{tabular}




\section{Characteristics of included studies (Continued)}

Participants Hypertension determined from medical records age range 35-64

\begin{tabular}{|c|c|}
\hline Interventions & $\begin{array}{l}\text { (1) Information booklet on hypertension sent out to patients } \\
\text { (2) Usual care }\end{array}$ \\
\hline Outcomes & $\begin{array}{l}\text { (1) (1) Systolic blood pressure- no difference } 149.2 \mathrm{mmHg}(\mathrm{C}) \text { versus } 149.8 \mathrm{mmHg}(\mathrm{E}) \\
\text { (2) Diastolic blood pressure- no difference } 94.9 \mathrm{mmHg}(\mathrm{C}) \text { versus } 95.3 \mathrm{mmHg}(\mathrm{E}) \\
\text { (2) Knowledge- slight increase in knowledge score in intervention group } \\
\text { Duration of FU } 1 \text { year }\end{array}$ \\
\hline Notes & Drop outs not reported in each arm \\
\hline Allocation concealment & B - Unclear \\
\hline Study & Webb 1980 \\
\hline Methods & Parallel, individuals who were patients of 14 family practice residents US \\
\hline Participants & $\begin{array}{l}\text { Patients had to have at least: one year history of hypertension; uncontrolled DBP } 90 \mathrm{mmHg} \text {; taking BP } \\
\text { lowering drugs }\end{array}$ \\
\hline Interventions & $\begin{array}{l}\text { (1) Education- three group education sessions by nurse-health educator (causes, nature, implications and } \\
\text { treatment of hypertension) } \\
\text { (2) Counselling-three "individualized" counselling sessions } \\
\text { (3) Usual care- three appointments with family physician }\end{array}$ \\
\hline Outcomes & $\begin{array}{l}\text { (1) DBP- no difference between either group and usual care- education (E1) } 88.9 \mathrm{mmHg} \text { versus (C) } \\
88.1 \mathrm{mmHg} \text {, counselling (E2) } 87.4 \mathrm{mmHg} \text { versus } 88.1 \mathrm{mmHg} \\
\text { (2) Compliance- no difference between either group and usual care } \\
\text { (3) Return for follow up appointment- no difference education (E1) } 10.1 \text { versus (C) } 10.2 \text {, counselling (E2) } \\
11.2 \text { versus } 10.2 \\
\text { Duration of FU } 6 \text { months }\end{array}$ \\
\hline Notes & Negative RCT, data pooled from education arm of trial \\
\hline Allocation concealment & B - Unclear \\
\hline
\end{tabular}

\begin{tabular}{ll} 
Study & Zarnke 1997 \\
\hline Methods & Parallel individuals from eleven family physicians and one tertiary hypertension research unit, Canada \\
\hline Participants & $\begin{array}{l}\text { Age } 52 \text { (E) } 56(\mathrm{C}), 13(42 \%) \text { male, average BP readings }<160 / 95, \text { taking BP lowering drugs or receiving } \\
\text { non-pharmacological advice }\end{array}$ \\
\hline
\end{tabular}

Interventions (1) Patient-directed group - instructed in home BP measurement, measured own BP twice daily and instructed by means of algorithm to change own BP medication, if still exceed goal to contact family doctor

(2) Office-based group- adjustments to BP medication made by family doctor

Outcomes (1) Change in daytime mean arterial BP adjusted for baseline measurement- decreased significantly in (E) group -0.95 versus $+1.9(\mathrm{C})$

(2) Compliance (doses missed per week- (E) 0.05 versus (C) $0.2 \mathrm{NS}$

(3) Quality of life scores- no difference

(4) Indices of health care resource use- total number of physician visits significantly greater in (E) group, no difference in total number of BP drugs used

Duration of FU 8 weeks

\begin{tabular}{ll}
\hline Notes & Small RCT ( $\mathrm{n}=31)$, short period of follow up \\
\hline Allocation concealment & $\mathrm{B}-$ Unclear \\
\hline Interventions used to improve control of blood pressure in patients with hypertension (Review)
\end{tabular}

Copyright @ 2006 The Cochrane Collaboration. Published by John Wiley \& Sons, Ltd 


\begin{tabular}{|c|c|}
\hline Study & Zismer 1982 \\
\hline Methods & $\begin{array}{l}\text { Hypertensive patients in a single urban family practice. } 176 \text { eligible, } 50 \text { randomly selected, } 39 \text { agreed to take } \\
\text { part. } \\
3 \text { groups- two separate intervention groups treated as the same in the analysis. }\end{array}$ \\
\hline Participants & $\begin{array}{l}\text { Diagnosis of hypertension or receiving BP lowering drugs or elevated BP for } 2 \text { consecutive visits } 140 \text { or } \\
90 \mathrm{mmHg} \text { within previous } 12 \text { months } \\
37 \text { black, } 21 \text { male, average age } 45 \text { (E) } 56 \text { (C), age range } 21 \text { to } 76 \text {. }\end{array}$ \\
\hline Interventions & $\begin{array}{l}\text { (1) Experimental group A- Educational "self-care“ intervention: pill taking; appointment keeping; dietary } \\
\text { sodium reduction } \\
\text { (2) Experimental group B-received additional support from family member. } \\
\text { (3) Usual care }\end{array}$ \\
\hline Outcomes & $\begin{array}{l}\text { (1) Systolic blood pressure- improved } 150.9 \mathrm{mmHg}(\mathrm{C}) \text { versus } 130.5 \mathrm{mmHg}(\mathrm{E}), \mathrm{p}<0.01 \text {. } \\
\text { (2) Diastolic blood pressure- improved } 92 \mathrm{mmHg}(\mathrm{C}) \text { versus } 85 \mathrm{mmHg}(\mathrm{E}), \mathrm{p}<0.001 \text {. } \\
\text { (3) Frequency of visits- no difference between groups in mean number of visits } \\
\text { Duration of FU } 6 \text { months }\end{array}$ \\
\hline Notes & $\begin{array}{l}\text { BP readings at baseline and FU were mean of last } 3 \text { readings } \\
\text { Control group was not similar to experimental group: } 10 \text { years older and diagnosed for longer }\end{array}$ \\
\hline Allocation concealment & B - Unclear \\
\hline
\end{tabular}

\section{Characteristics of excluded studies}

\begin{tabular}{|c|c|}
\hline Study & Reason for exclusion \\
\hline Andrejak 2000 & $\begin{array}{l}\text { Randomised trial of once daily versus twice daily ace inhibitor. Outcome compliance as judged by mem's } \\
\text { monitored. Once daily medication better than twice daily dosage. Included in adherence systematic review. } \\
\text { Excluded: adherence RCT }\end{array}$ \\
\hline Bachman 2002 & $\begin{array}{l}\text { Accuracy and quality of self-reported home blood pressure values assessed. } 48 \text { patients randomised to receive } \\
\text { information about storage capabilities of a home measuring device or not. Accuracy and interpretation of } \\
\text { home blood measurement increased in the informed group. Reason for exclusion: intervention not aimed } \\
\text { directly at improving blood pressure control; no blood pressure data reported. }\end{array}$ \\
\hline Barron-Rivera 1998 & $\begin{array}{l}\text { Randomised trial of education programmed to patients. Outcome was well-being and quality of life. Excluded: } \\
\text { no report on blood pressure control in the process of care. }\end{array}$ \\
\hline Ben Said & $\begin{array}{l}\text { Randomised trial of assessment education interventions - same trial as reported by Consoli. Excluded: no } \\
\text { outcome on blood pressure or process of care reported. }\end{array}$ \\
\hline Binstock 1988 & Excluded because no "usual care" group. \\
\hline Birtwhistle 2004 & $\begin{array}{l}\text { Equivalence RCT of three month versus six month follow up. } \\
\text { Reason for exclusion: } \\
\text { (1) Neither intervention met inclusion criteria of the review. No additional intervention directed at either } \\
\text { patient, health professional or organisation of care. } \\
\text { Finding that BP control was equivalent between three and six month follow up arms of the study. Both groups } \\
\text { saw health professional much more often than planned over the three years- mean (sd) visits per patient in } \\
\text { three month group } 18.8(8.06) \text { versus } 16.2(8.45) \text { in six month group. }\end{array}$ \\
\hline Blenkinsopp 2000 & $\begin{array}{l}\text { Parallel, cluster randomised, } 20 \text { community pharmacy sites, UK. } 180 \text { treated hypertensives, } 62 \% \text { age } 60 \text { or } \\
\text { over. (1) Pharmacist delivered, Structured, brief questioning protocol on medication problems; including } \\
\text { advice, information and referral to general practitioner versus usual care, delivered three times at two-month } \\
\text { intervals }\end{array}$ \\
\hline
\end{tabular}


(2) Usual care. (1) \% with controlled hypertension- of those patients with initially uncontrolled hypertension ( $160 / 90 \mathrm{mmHg}$ ) (E) $35.7 \%$ versus (C) $17.1 \%$ were controlled at follow up ( $<<0.05$ ), no difference in BP control in those who were controlled at start of study

(2) Compliance (self report)- 62\% (E) versus 50\% (C) $(\mathrm{p}<0.05)$

(3) Patient satisfaction- high level with service and no significant differences between groups. Duration of FU 6 months. Substantial losses to follow up. Subgroup analysis of \% controlled blood pressure, therefore not included in analysis. Reason for exclusion: no blood pressure data.

Bond $1984 \quad$ Non-randomised trial of clinical pharmacologist nurse clinician improving drug documentation, for blood pressure control and rheumatology/renal screening. Excluded: no BP outcome data

Broege 200140 hypertensive men and women randomly assigned to "home" self measurement with subsequent management and medication change compared to "clinic" group where medication adjusted based upon readings taken by project nurse.

Reasons for exclusion:

1. Includes treated and untreated hypertensive patients. Drug treatments adjusted downward or treatment initiated depending on BP reading and drug treatment status. Not possible to detect effect of self monitoring on treated blood pressure alone.

2. No usual care- both groups experienced monitoring- self monitoring at home or nurse monitoring in clinic.

Cappuccio $2004 \quad$ Systematic review of home monitoring. 18 RCTs included- several RCTs excluded from this review that Cappucion included. These are (with reasons why excluded from this review in brackets):

Binstock- no usual care group included.

Stahl- non randomised trial, patients allocated "sequentially".

Midanik-

Caro $1998 \quad$ Non-randomised trial. Observational study of compliance and persistance with therapy, excluded for these reasons.

Celis 1998 A randomised controlled trial protocol comparing self measurement of blood pressure against conventional blood pressure measurement. Protocol of trial. Excluded: no results reported.

Charlesworth 1984 Quasi randomised trial. Patients assigned random numbers and then rank ordered. The first 32 were given intervention, the next 22 were in the control group. Intervention was of stress management outcome SBP and DBP was significantly reduced in the stress management group. Excluded: intervention and wasn't properly randomised.

Consoli $\quad$ Randomised trial of computer assisted programme intervention was educational. Outcome knowledge increased at two months in intervention group compared to control. Excluded as no outcome on blood pressure or process of care reported.

Consoli SM, Ben2 Randomised trial of computer assisted programme intervention was educational. Outcome knowledge increased at two months in intervention group compared to control. Excluded as no outcome on blood pressure or process of care reported

Consoli SM, Ben3 Randomised trial of computer assisted programme intervention was educational. Outcome knowledge increased at two months in intervention group compared to control. Excluded as no outcome on blood pressure or process of care reported

Cranney $1999 \quad$ Non-randomised trial 9 pairs of practices matched by means of overall blood pressure control and then randomised to eductional intervention directed to health professionals in the practice. The outcome was a stated threshold for blood pressure control. Excluded because of non-randomised trial design.

Denver $2003 \quad 120$ Type 2 diabetic patients with uncontrolled hypertension (BP >140/90) randomised to usual GP care or nurse-led outpatient care. Nurse led care associated with improved systolic blood pressure. Reasons for exclusion: (1) patients allocated by means of alternation rather than randomisation (2) setting.

Djerassi $1990 \quad$ Non-randomised trial, before/after design. Intervention was based in factories program of follow-up treatment by planned doctor and nurse versus usual care by family doctor in other factories. Outcomes number of percentage of people treated with an intervention group was greater.

Dusing $1998 \quad$ Observational study of 1603 patients in 320 private practices in Germany. Investigated change in antihyperensive theapy within six months of start of study. Inadequate BP control most important reason for change 
in $48.4 \%$ of patients in the cohort, others include: adverse effects $30.1 \%$, patient dissatisfaction $20 \%$, noncompliance $16.8 \%$, cost $4.9 \%$.

Erickson 1997 A non-randomised trial of pharmacist care which involved reviewing medical records, taking drug history, assessing patients specific drug issues, concerns about taking drugs, lifestyle, compliance and knowledge all direct to the patient. Outcomes SBP and DBP were reduced in the group who received a pharmacist's care at 5 months. Quality of life measures were the same. Trial excluded because it was not randomised.

\begin{tabular}{ll}
\hline Flack 1995 & Observational study reporting adherence rates with different classes of anti-hypertensive agents. \\
\hline Flack 2000 & Randomised trial of slow versus fast titration of blood pressure lowering drugs. \\
\hline Foote 1983 & $\begin{array}{l}\text { Quasi randomised controlled trial. Four interventions, screening and referral to physician, referral to physician } \\
\text { and semi-annual follow-up, referral to physician and more frequent follow-up, and on-site treatment. Outcome } \\
\text { was the number of people under treatment, control and proved in the last three groups. }\end{array}$ \\
\hline Girvin 1999 & $\begin{array}{l}\text { A randomised trial cross-over design of single versus twice a day Enalapril. The outcomes were of compliance } \\
\text { which increased with the single dose medication and blood pressure control which is better in the twice a day } \\
\text { medication group. Reason for exclusion, adherence randomised trial, included in the adherence systematic } \\
\text { review. }\end{array}$
\end{tabular}

Godley $2003 \quad$ Evaluation of a quality improvement programmefor hypertension management. Intervention consisted of educating healthcare providers and recommending appropriate pharmacotherapy for compelling indications. 30,721 hypertensive patients identified from pharmacy claims, 417 patients randomly selected for note review. Overall level of blood pressure control stated to have improved from $37.2 \%$ to $49.2 \%$ at follow up. Reason for exclusion: not a randomised study; no comparison group.

Gonzalez-Fernandez $\quad$ Parallel, individuals, hospitalised for "non-hypertensive related diseases) in a single hospital, Puerto Rico. 60 treated hypertensives, $55 \%$ women, mean age 59 years. (1) In-hospital education- 4 educational interventions: "knowing high BP" by a physician; "diet and high BP" by a dietician; "exercise and high BP" by a health educator; "medications and compliance in high BP" by physician and pharmacy student. (2) Usual care. (1) Blood pressure control- SBP and DBP improved in (E) $137 \mathrm{mmHg}$ versus (C) $154 \mathrm{mmHg}$ ( $\mathrm{p}=0.005$ ), diastolic (E) $89 \mathrm{mmHg}$ versus $98 \mathrm{mmHg}(\mathrm{p}=0.006)$

(2) Compliance (direct questioning and pill count)- adherence improved by $66 \%$ in the intervention group compared to $16 \%$ in usual care group $(\mathrm{p}=0.04)$. Reason for exclusion: hospital-based RCT.

Duration of FU 8 weeks

Grimm A randomised trial of four different class of anti-hypertensive agents and quality of life. Excluded: no data on BP control, no interventions other than different classes of anti-hypertensive drugs.

Hatcher 1986 Factorial randomised trial of health education intervention. Three levels of intervention medication schedules, diet, appointment keeping, family member, reinforcements and small group meeting. Excluded as intervention was based on ? ? education and no outcomes on blood pressure control in the process of care.

Herbert $2004 \quad 2 \times 2$ factorial RCT of 28 peer learning groups involving 200 family physicians in British Columbia, Canada. Interventions: personalised prescribing feedback relating to hypertension; case-based educational module. Evidence-based prescribing improved in both groups (increase in thiazide prescribing as first line agents). Reason for exclusion: no blood pressure outcomes reported.

\begin{tabular}{|c|c|}
\hline Hyman & Questionnaire study self reported physician practice excluded for that reason. \\
\hline Inui 1976 & $\begin{array}{l}\text { Before/after study intervention with tutor physician educating patients regarding their hypertension. Excluded: } \\
\text { not a randomised trial. }\end{array}$ \\
\hline Iso 1996 & $\begin{array}{l}\text { Randomised trial of health education advice (non-pharmacological) follow-up was at } 6 \text { months and one and } \\
\text { half years. Excluded: intervention was based around health education/counselling advice. }\end{array}$ \\
\hline Iso $\mathrm{H}$, & $\begin{array}{l}\text { Randomised trial of health education classes to patients. Excluded as intervention was non-pharmacological } \\
\text { advice. }\end{array}$ \\
\hline Jennett 1986 & $\begin{array}{l}\text { RCT of continuing medical education in the context of treatment of hypertension. Intervention focussed on } \\
\text { three learning objectives: 1) physicians reschedule diagnosed hypertensive patients (aged } 50 \text { years or older) } \\
\text { not as yet in control, to be seen at least every month until controlled; 2) physicians take blood pressure of }\end{array}$ \\
\hline
\end{tabular}


hypertensive patients in the supine position and also within one minute after standing on every visit and the patient's position is recorded with their blood pressure record; 3) physicians ask patients who have not yet got controlled blood pressure about their compliance in taking prescribed medication and record the answer. Two educational formats used: 1) six to eight page educational newsletters; 2) small group discussion. Behaviour change improvement scores with the intervention group compared to control. Behaviour was sustained 12 months post education. Reason for exclusion: no blood pressure data reported.

\begin{tabular}{ll}
\hline Kawachi 1991 & Non-randomised trial. Cost effectiveness analysis. \\
\hline Krishan 1979 & $\begin{array}{l}\text { Non-randomised trial of nurse practitioner and integrated physician supervised management in community } \\
\text { hypertension clinics versus usual care. No difference in outcome of blood pressure control. }\end{array}$ \\
\hline Levine 2003 & $\begin{array}{l}\text { RCT of community health workers providing less intensive care (education, counselling and information } \\
\text { about gaining access to free ongoing care in the community) versus more intensive care (all components } \\
\text { of less intensive intervention plus additional home visits, further educational messages and social support } \\
\text { mobilization through family members). At } 40 \text { months follow up, both groups experienced improvement } \\
\text { in blood pressure control (signiticant within group difference from baseline blood pressure readings). Less } \\
\text { intensive group had greater blood pressure control compared to more intensive group but difference was not } \\
\text { significant. Reason for exclusion: no usual care group. }\end{array}$ \\
\hline Lewis 1967 & $\begin{array}{l}\text { Randomised trial of nurse clinics versus usual care in outpatient clinic. The population included patients } \\
\text { with Hypertension and Atherosclerotic Disease, Obesity, Arthritis and Psychophysiological Disorders. The } \\
\text { outcomes are preferences for care, costs and process of care in terms of examinations and investigations. } \\
\text { Excluded: no data on process or outcome of blood pressure care. }\end{array}$ \\
\hline Linjer 1997 & $\begin{array}{l}\text { Non-randomised trial. Discussion paper regarding percentage of patients eligible in randomised trials generally } \\
\text { at low risk in trial participants. }\end{array}$ \\
\hline Littenberg 1990 & Non-randomised trial. Cost effectiveness study of increased blood pressure. \\
\hline Marquez 2000 & $\begin{array}{l}\text { Randomised trial intervention being health education through group sessions with postal back-up. Outcomes } \\
\text { were compliance with blood pressure medication. Excluded as no outcome in terms of blood pressure control } \\
\text { reported }\end{array}$ \\
\hline
\end{tabular}

Mashru $1997 \quad$ Before after study of interpractice audit following educational programme concerning diagnosis and managment of hypertension. Six general practices in NW London, UK, 750 hypertensive patients. At two years follow up, two thirds of patients remained "uncontrolled" $(\mathrm{BP}<160 / 90)$.

\begin{tabular}{|c|c|}
\hline McDowell 1989 & $\begin{array}{l}\text { Non hypertensive patients registered with a large family practice (Canada). Interventions: computer reminder } \\
\text { to GP, letter to patient, nurse telephone call to patient. Outcome was whether blood pressure was checked or } \\
\text { not. Effect of reminders was "modest" }\end{array}$ \\
\hline McInnes 1995 & $\begin{array}{l}\text { Non-randomised trial two patients were matched and then randomised to it. Shared care or clinical care. } \\
\text { The intervention was computerised shared care versus hospital clinical care in outpatients departments. The } \\
\text { outcome showed there were less drop-outs for shared care and they were better adequately used in terms of } \\
\text { patient management in shared care compared to usual care. Shared care was more cost effective. Blood pressure } \\
\text { control was similar in both groups. }\end{array}$ \\
\hline McKenney 1973 & $\begin{array}{l}\text { A pharmacist intervention directly at patients improved knowledge compliance with medication and blood } \\
\text { pressure control, however not randomised properly. Patients assigned consecutive numbers then randomised } \\
\text { according whether they had odd or even numbers }\end{array}$ \\
\hline Murray 1988 & $\begin{array}{l}\text { Not hypertensive patients. Population: persons "at risk" of developing hypertension. Intervention: direct mail } \\
\text { to prompt attendance at clinic, either single, multiple or no mail. Outcome: number of patients who had a } \\
\text { blood pressure checked or discussed with their physician }\end{array}$ \\
\hline New 2003 & $\begin{array}{l}\text { Specialist nurse-led clinic in a single outpatient clinic in Salford, UK. Population: diabetic patients receiving } \\
\text { hospital-based care. Comparison group: usual hospital care. Outcome: improvement in blood pressure and } \\
\text { hyperlipidemia targets acheived with intervention. Reason for exclusion: hosptial-based, (2) diabetic patients. }\end{array}$ \\
\hline Pheley 1995 & Observational study of nurse based hypertension clinic with no comparison group. \\
\hline Putnam 1989 & $\begin{array}{l}40 \text { family physicians from the Dalhousie University Division of Continuing Medical Education separated into } \\
3 \text { groups according to extent of involvement in establishing essential criteria for hypertension managment. }\end{array}$ \\
\hline
\end{tabular}


No difference in control of blood pressure in these family physician's patients at 18 months follow up. Reason for exclusion: non randomised trial

\begin{tabular}{ll}
\hline Ramsay 1996 & Non-randomised trial. Discussion paper. \\
\hline Staessen 2004 & $\begin{array}{l}\text { Randomised trial of treatment based on (1) BP measured at home (3 consecutive measurements twice daily) } \\
\text { versus (2) BP measured at physician's office (average of } 3 \text { consecutive readings taken by physician during } \\
\text { practice hours). }\end{array}$
\end{tabular}

Reason for exclusion:

(1) Assessed self monitoring in the context "as guides to initiate and titrate antihypertensive drug treatment".

(2) Treated and untreated patients included.

At follow-up (median 350 days), more home BP than office BP patients had stopped antihypertensive drugs with no difference between groups of patients who had progressed to multiple drug treatment. Final office, home and 24-hour ambulatory BP measurements were higher in the home BP group than in the office BP group.

\begin{tabular}{ll}
\hline Stahl 1984 & $\begin{array}{l}\text { Non-randomised trial. Self and family read blood pressure monitoring groups plus nurse education. Excluded } \\
\text { because of non-randomised study. }\end{array}$ \\
\hline Statson 1977 & Non-randomised trial. Examining the cost effectiveness of treatment of hypertension \\
\hline Stephenson 1999 & Non-randomised trial. \\
\hline Trocha 1999 & 91 hypertensive type 1 diabetic patients with overt diabetic nephropathy followed for 10 years. Intensfied
\end{tabular}

Trocha $1999 \quad 91$ hypertensive type 1 diabetic patients with overt diabetic nephropathy followed for 10 years. Intensfied versus routine antihypertensive treatment. Blood pressure control and survival improved in the intensified group. Reason for exclusion: non randomised study

Tu $1999 \quad$ Parallel, individuals 222 attending a "health unit clinic", carried out in a veteran home in Taiwan, China. Hypertension, SBP 140 or DBP 90 in untreated patients or treated hypertension patients BP level not stated. Average age 74.6 years. (1) Medical education group (MEG)- monthly meeting concerning cognition, attitude self-care behaviours for hypertension

(2) Health education- same content but delivered every other month group (EOMG). Differences between groups not clearly reported. Stated that no difference in attitudes and behaviour between groups. Blood pressure no difference in SBP but higher DBP in EOMG. Between group differences not clearly stated. Table 3 , within group differences all improved for "cognition, behaviours and attitudes" scores and "blood pressure marking" changes. Duration of FU 6 months. Reason for exclusion: no BP data for both arms of study reported.

UK PDS $1998 \quad$ Randomised trial of tight less tight blood pressure control. Excluded because its not reporting on process and
organisational issues in hypertension care.

\begin{tabular}{ll}
\hline Waeber 1999 & Randomised trial of compliance in terms of aspirin versus placebo from the HOT randomised controlled trial \\
\hline Weiner 1980 & Cluster- six "industrial settings" randomised. Ohio county clinics US, SBP>140 or DBP $>90$ age 19-39,
\end{tabular}
SBP $>150$ or DBP $>90$ age 40-64. (1) Nurse management. Involved reinforcement to take medication, information about side effects of medications, diet instruction, BP checks, weight checks, education and counselling regarding "an understanding and acceptance of hypertension", (2) Usual care. Positive RCT reported. Experimental patients had better:

(1) Decreases in maximum SBP $(\mathrm{p}=0.02)$

(2) Average SBP $(\mathrm{p}=0.02)$

(3) \% overweight $(\mathrm{p}=0.01)$

(4) Improved knowledge ( $\mathrm{p}=0.002$ ). Duration FU 3 months. No difference found for maximum and average DBP between (E) and (C). Only very brief account of RCT with no details of baseline or follow up blood pressure. Reason for exclusion: no blood pressure data.

\begin{tabular}{ll}
\hline Weir 2002 & Questionnaire survey a combination of lifestyle medication taking in half outcomes \\
\hline Wollard 1995 & Randomised trial at two levels of intensity, lifestyle advice/counselling from practice nurses. Outcome was \\
& $\begin{array}{l}\text { lifestyle and non-pharmacological change in patients. Excluded because intervention was based on non- } \\
\text { pharmacological advice and outcomes included lifestyle changes. Of note intervention was more effective than } \\
\text { usual care. }\end{array}$ \\
\hline
\end{tabular}

Interventions used to improve control of blood pressure in patients with hypertension (Review) 


\section{Characteristics of excluded studies (Continued)}

Wyka-Fitzgerald 1984 Randomised trial of nurse education programme directed at patients intervention was non-pharmacological advice so excluded for this reason.

Zernike $1998 \quad$ Randomised trial of structured patient-centred education programme versus normal information. Outcome patient knowledge which was increased and structured intervention. Excluded as no outcomes reported on blood pressure control or process of care.

van den Hoogen 1990 Non randomised study. "Experimental" study but no mention of randomisation. 15 general practices in the Netherlands, newly detected patients with hypertension two years prior to start of study aged 36-55 years. Intervention: computer-assisted monitoring system, provides monthly feedback on treatment results, regular meetings at practices where surveys discussed. Outome: improved surveillance and control of blood pressure in computer group

\section{Characteristics of ongoing studies}

\begin{tabular}{|c|c|}
\hline Study & Coppola \\
\hline Trial name or title & Improving the primary prevention of stroke in older patients in general practice: a randomized controlled trial \\
\hline Participants & Elderly patients (aged between 60 to 75 years) registered in 20 general practices in London UK \\
\hline Interventions & Intervention directed at health professionals in general practices. One hour seminar \\
\hline Outcomes & Blood pressure control \\
\hline Starting date & Not known \\
\hline Contact information & pwhincup@sghms.ac.uk \\
\hline \multicolumn{2}{|l|}{ Notes } \\
\hline Study & Krieger \\
\hline Trial name or title & SHIP Clinic-Based Program \\
\hline Participants & $\begin{array}{l}\text { 1. Patients currently at a participating clinic with a diagnosis of hypertension. } \\
\text { 2. Low income. } \\
\text { 3. Caucasian or African American. } \\
\text { 4. Aged } 18 \text { or older }\end{array}$ \\
\hline Interventions & $\begin{array}{l}\text { 1. Patient care co-ordinator at each clinic. } \\
\text { 2. Computerised tracking system. } \\
\text { 3. Linkage with outreach workers. } \\
\text { 4. Linkage with community-based resources }\end{array}$ \\
\hline Outcomes & $\begin{array}{l}\text { 1. Mean systolic and diastolic blood pressure. } \\
\text { 2. Non-pharmacological behaviour change } \\
\text { 3. Control of blood pressure }\end{array}$ \\
\hline Starting date & Not known \\
\hline Contact information & $\begin{array}{l}\text { James Krieger } \\
\text { James.krieger@METROC.GOV }\end{array}$ \\
\hline Notes & RCT complete, anticipated publication in 2003 \\
\hline Study & McManus \\
\hline Trial name or title & $\begin{array}{l}\text { A randomised controlled trial of patient held targets and self monitoring in the control of hypertension: Targets } \\
\text { And Self Monitoring IN Hypertension (TASMINH) }\end{array}$ \\
\hline
\end{tabular}




\section{Characteristics of ongoing studies (Continued)}

Participants $\quad 441$ patients aged 35-75 with known hypertension (coded by own general practitioner), on antihypertensive drug treatment with a blood pressure greater than $140 / 85$ at randomisation drawn from eight practices in Birmingham UK, two practices each drawn from a quartile of Townsend (deprivation) score

Interventions $\quad$ All patients receive information on non pharmacological methods (British Hypertension Society self help leaflet). Intervenion group taught to check their own blood pressure using OMRON blood pressure monitor at their own surgery/practice. Patients asked to check monthly. Patients given British Hypertension Society targets (140/85 or $148 / 80$ for diabetic patients). Patients requested to attend their family doctor (general practitioner) to discuss treatment with antihypertensive drugs if their blood pressure reading exceeds target reading two months continuously. Control group receive usual care from their family doctors (general practitioners)

\begin{tabular}{|c|c|}
\hline Outcomes & 1. Blood pressure reading at 12 months follow up \\
\hline Starting date & September 2001, last patient randomised March 2002, final follow up March 2003 \\
\hline Contact information & $\begin{array}{l}\text { Dr Richard McManus r.j.mcmanus@bham.ac.uk } \\
01214142658\end{array}$ \\
\hline Notes & RCT nearly complete, anticipate publication late 2003/early 2004 \\
\hline Study & Sullivan \\
\hline Trial name or title & HYPER Trial \\
\hline Participants & $\begin{array}{l}\text { Elderly (aged 65-79) hypertensive patients majority of patients were taking antihypertensive medication at } \\
\text { baseline }\end{array}$ \\
\hline Interventions & $\begin{array}{l}\text { Aim to evaluate the provision of diferent levels of feedback developed from computerised GP data. } 52 \text { Scottish } \\
\text { general practices randomised to three groups: } \\
\text { 1. Usual care. } \\
\text { 2. Feedback of audit data (information about patients who need either screening, assessment or treatment). } \\
\text { 3. Strategic feedback prioritising patients by absolute risk of death from stroke }\end{array}$ \\
\hline Outcomes & $\begin{array}{l}\text { 1. Blood pressure measurement } \\
\text { 2. Mean systolic and diastolic blood pressure } \\
\text { 3. Blood pressure control }\end{array}$ \\
\hline Starting date & August 1999 \\
\hline Contact information & $\begin{array}{l}\text { Liz Mitchell } \\
\text { e.d.mitchell@dundee.ac.uk }\end{array}$ \\
\hline Notes & RCT complete, data being analysed and report should be in the public domain in 2003 \\
\hline Study & Zarnke \\
\hline Trial name or title & Not known \\
\hline Participants & Patients with uncontrolled hypertension \\
\hline Interventions & Patient-directed self measurement \\
\hline Outcomes & 1. Blood pressure measurement2. Mean systolic and diastolic blood pressure3. Blood pressure control \\
\hline Starting date & Not known \\
\hline Contact information & kelly.zarnke@lhsc.on.ca \\
\hline Notes & RCT complete, data being analysed \\
\hline
\end{tabular}


(Continued)

AD D I T I O AL TABLES

Table 01. Quality of included randomized trials

\begin{tabular}{|c|c|c|c|c|}
\hline Study ID & Randomization & Allocation concealed & Blinding & Losses to follow up \\
\hline Carnahan & Method not stated & Not stated & No & $\begin{array}{l}1 / 50(\mathrm{E}-2 \%) \\
2 / 50(\mathrm{C}-4 \%) \\
1 / 50(\mathrm{E}-2 \%) \\
2 / 50(\mathrm{C}-4 \%) \\
1 / 50(\mathrm{E}-2 \%) \\
2 / 50(\mathrm{C}-4 \%)\end{array}$ \\
\hline Hawkins & Method not stated & Not stated & No & $\begin{array}{l}225 / 574(\mathrm{E}-39.2 \%) \\
294 / 574(\mathrm{C}-51.2 \%)\end{array}$ \\
\hline Evans & Method not stated & Not stated & $\begin{array}{l}\text { Yes- BP check Staff } \\
\text { "blind" to allocation } \\
\text { group }\end{array}$ & $\begin{array}{l}5 / 107(\mathrm{E}-5 \%) \\
10 / 91(\mathrm{C}-11 \%)\end{array}$ \\
\hline $\begin{array}{l}\text { Hypertension Detection } \\
\text { and Follow up (HDFP) }\end{array}$ & $\begin{array}{l}\text { Randomisation done } \\
\text { centrally, stratified by } \\
\text { centre }(n=14) \text { and entry } \\
\text { DBP strata }(n=3)\end{array}$ & $\begin{array}{l}\text { Yes, coordinating centre } \\
\text { prepared sealed opaque } \\
\text { envelopes. An envelope } \\
\text { was drawn sequentially } \\
\text { and attached to } \\
\text { participant's data form } \\
\text { at the time of DBP } \\
\text { screening. Envelope } \\
\text { opened after baseline }\end{array}$ & $\begin{array}{l}\text { No- neither participant } \\
\text { or clinic blind to } \\
\text { randomisation. BP } \\
\text { outcome not blinded }\end{array}$ & $\begin{array}{l}\text { 967/5485 (E-17.6\%) } \\
938 / 5422 \text { (C- } \\
17.2 \% \text { ) status of } \\
\text { antihypertensive drug } \\
\text { treatment not known at } \\
1 \text { year } \\
\text { (includes lost to } \\
\text { FU/dead/missing data) }\end{array}$ \\
\hline Jewell & Method not stated & Not stated & No & $\begin{array}{l}15 / 17(\mathrm{E}-12 \\
19 / 19(\mathrm{C}-0 \%)\end{array}$ \\
\hline Cummings & "Randomisation list" & Not stated & Yes & $\begin{array}{l}446 \backslash 486(\mathrm{E}-8 \%) \\
420 \backslash 487(\mathrm{C}-14 \%)\end{array}$ \\
\hline Tanner & $\begin{array}{l}\text { "Randomly assigned } \\
\text { through a table of } \\
\text { random numbers" }\end{array}$ & Not stated & No & $\begin{array}{l}15 / 15(\mathrm{E}-0 \%) \\
15 / 15(\mathrm{C}-0 \%)\end{array}$ \\
\hline Zismer & Not stated & Not stated & No & $\begin{array}{l}26 / 26(\mathrm{E}-0 \%) \\
13 / 13(\mathrm{C}-0 \%)\end{array}$ \\
\hline Watkins & $\begin{array}{l}\text { Not stated but stratified } \\
\text { by age, sex, practice and } \\
\text { last recorded BP }\end{array}$ & Not stated & Yes & 414/565 (Overall- 27\%) \\
\hline Rogers & $\begin{array}{l}\text { Randomisation stratified } \\
\text { by \# prescription } \\
\text { medications }\end{array}$ & $\begin{array}{l}\text { Yes- to physicians and } \\
\text { clinical research staff but } \\
\text { once completed "open“" }\end{array}$ & No & $\begin{array}{l}56 / 60(\mathrm{E}-7 \%) \\
55 / 61(\mathrm{C}-10 \%)\end{array}$ \\
\hline Muhlhauser & $\begin{array}{l}\text { Randomisation process } \\
\text { for } 10 \text { participating } \\
\text { practices. } 20 \text { patients } \\
\text { per practice selected } \\
\text { by means of random } \\
\text { number chart }\end{array}$ & Not stated & No & $\begin{array}{l}86 / 100(\mathrm{E}-14 \%) \\
74 / 100(\mathrm{C}-26 \%)\end{array}$ \\
\hline Montgomery & $\begin{array}{l}\text { Randomisation by } \\
\text { means of random }\end{array}$ & Yes & No & $\begin{array}{l}202 / 229 \text { (E } 1 \text { 12\%) } \\
199 / 228 \text { (E } 2-13 \%)\end{array}$ \\
\hline
\end{tabular}


Table 01. Quality of included randomized trials (Continued)

\begin{tabular}{|c|c|c|c|c|}
\hline Study ID & $\begin{array}{l}\text { Randomization } \\
\text { number table by } \\
\text { a researcher not } \\
\text { involved in study. } \\
\text { Practices stratified by } \\
\text { computer system used } \\
\text { ( } 2 \text { alternative computer } \\
\text { systems) }\end{array}$ & Allocation concealed & Blinding & $\begin{array}{l}\text { Losses to follow up } \\
130 / 157 \text { (C- 17\%) }\end{array}$ \\
\hline Takala & Method not stated & Not stated & No & $\begin{array}{l}25 / 100(\mathrm{E}-25 \%) \\
32 / 102(\mathrm{C}-31 \%)\end{array}$ \\
\hline Sackett & Method not stated & Not stated & Yes & $\begin{array}{l}\text { Factorial RCT } \\
\text { (1) Convenience } \\
\text { Augmented 6/114 (E- } \\
5 \%) \\
\text { Normal 4/116 (C-3\%) } \\
\text { (2) Mastery learning } \\
\text { Yes 8/115 (E-7) } \\
\text { No 2/115 (C- } 2 \%)\end{array}$ \\
\hline Haynes & $\begin{array}{l}\text { Minimisation, method } \\
\text { not stated, patients } \\
\text { stratified according to } \\
\text { important prognostic } \\
\text { factors in previous RCT } \\
\text { by Sackett } 20\end{array}$ & Not stated & Yes & $\begin{array}{l}0 / 20(\mathrm{E}-0 \%) \\
1 / 19(\mathrm{C}-5 \%)\end{array}$ \\
\hline Logan & Method not stated & Not stated & Yes & $\begin{array}{l}26 / 232(\text { E- } 11 \%) \\
21 / 204(C-9 \%)\end{array}$ \\
\hline Johnson & Method not stated & Not stated & Yes & $\begin{array}{l}\text { Factorial RCT } \\
\text { (1) Self recording of } \\
\text { blood pressure } \\
(\text { E- 34/36- 6\%) } \\
\text { (2) Home visits } \\
\text { (C-34/36-6\%) }\end{array}$ \\
\hline Brook & $\begin{array}{l}\text { By means of "random } \\
\text { sampling techniques } \\
\text { that made the } \\
\text { distribution of family } \\
\text { characteristics in each as } \\
\text { similar as possible“ }\end{array}$ & Not stated & No & $\begin{array}{l}\text { Free care versus } 3 \text { forms } \\
\text { of cost-sharing plans. } \\
\text { Blood pressure outcome: } \\
\text { Free care (E- } 134 / 294 \text {, } \\
46 \% \text { ) } \\
\text { Cost share (C- }\end{array}$ \\
\hline Earp & Method not stated & Not stated & No & $\begin{array}{l}3 \text { arm RCT } \\
\text { Follow up at year } 1 \text { and } \\
2 \\
\text { Group } 1- \\
1 \text { year- } 74 / 99,25 \% \\
2 \text { year- } 55 / 99,44 \% \\
\text { Group } 2- \\
1 \text { year- } 41 / 56,27 \% \\
2 \text { year- } 39 \%\end{array}$ \\
\hline
\end{tabular}

Interventions used to improve control of blood pressure in patients with hypertension (Review) 
Table 01. Quality of included randomized trials (Continued)

\begin{tabular}{|c|c|c|c|c|}
\hline Study ID & Randomization & Allocation concealed & Blinding & $\begin{array}{l}\text { Losses to follow up } \\
\text { Group 3(control)- } \\
1 \text { year- } 47 / 63,25 \% \\
2 \text { year- 38/63, 40\% }\end{array}$ \\
\hline Martinez-Amenos & Method not stated & Not stated & No & $\begin{array}{l}\text { No details on losses to } \\
\text { FU provided }\end{array}$ \\
\hline McAllister & $\begin{array}{l}\text { Practice cluster stratified } \\
\text { by: } \\
\text { 1) partners } \\
\text { 2) Ethnicity } \\
\text { randomisation by } \\
\text { "shuffled deck of cards" }\end{array}$ & Not stated & No & $\begin{array}{l}5 / 30(\mathrm{E}-17 \%) \\
5 / 30(\mathrm{C}-17 \%)\end{array}$ \\
\hline Bogden & $\begin{array}{l}\text { Randomisation by last } \\
\text { digit of social security } \\
\text { number: } \\
\text { Odd \# (E) } \\
\text { Even \# (C) }\end{array}$ & Not stated & Yes & $\begin{array}{l}1 / 50(\mathrm{E}-2 \%) \\
4 / 50(\mathrm{C}-8 \%)\end{array}$ \\
\hline Fielding & $\begin{array}{l}\text { Randomisation by } \\
\text { means of random } \\
\text { numbers table }\end{array}$ & Not stated & No & $\begin{array}{l}6 / 80(\mathrm{E}-7 \%) \\
8 / 79(\mathrm{C}-10 \%)\end{array}$ \\
\hline Morisky and Levine & $\begin{array}{l}\text { Randomisation through } \\
\text { "simple random } \\
\text { sampling procedures" }\end{array}$ & Not stated & No & $\begin{array}{l}\text { Overall 64/400 (16\%) } \\
\text { Control of BP } \\
\text { (C) } \\
40 / 50(20 \%) 2 \text { yrs } \\
30 / 50(40 \%) 5 \text { yrs } \\
\text { (E) all } 3 \text { intervention } \\
44 / 50(12 \%) 2 \text { yrs } \\
42 / 50(16 \%) 5 \text { yrs }\end{array}$ \\
\hline Zarnke & $\begin{array}{l}\text { Randomisation by } \\
\text { means of computer } \\
\text { generated list in blocks } \\
\text { of six. Asymmetric } \\
\text { allocation scheme (2:1 } \\
\text { E:C) }\end{array}$ & Not stated & No & $\begin{array}{l}0 / 20(\mathrm{E}-0 \%) \\
1 / 11(\mathrm{C}-9 \%)\end{array}$ \\
\hline Roca-Cusachs & $\begin{array}{l}\text { Research nurse } \\
\text { "allocated every patient } \\
\text { to one of the two groups } \\
\text { using a random scale } \\
\text { balanced for age and } \\
\text { BP" }\end{array}$ & No & Yes & $\begin{array}{l}54 / 138(\text { E- 39\%) } \\
38 / 149(\mathrm{C}-26 \%)\end{array}$ \\
\hline Soghikian & Method not stated & Not stated & No & $\begin{array}{l}15 / 215(\mathrm{E}-7 \%) \\
25 / 215(\mathrm{C}-12 \%)\end{array}$ \\
\hline Billault & Method not stated & Not stated & No & $\begin{array}{l}82 / 101(\mathrm{E}-19 \%) \\
85 / 99(\mathrm{C}-14 \%)\end{array}$ \\
\hline Gullion & Method not stated, & Not stated & Yes & (1) Medical- 27 \\
\hline
\end{tabular}


Table 01. Quality of included randomized trials (Continued)

\begin{tabular}{|c|c|c|c|c|}
\hline Study ID & $\begin{array}{l}\text { Randomization } \\
\text { physicians stratified } \\
\text { according to four } \\
\text { criteria: } \\
\text { (1) \% patients whose } \\
\text { DBP controlled. } \\
\text { (2) \% patients } \\
\text { responding to the } \\
\text { survery } \\
\text { (3) Physician's ethnic } \\
\text { group } \\
\text { (4) Specialty }\end{array}$ & Allocation concealed & Blinding & $\begin{array}{l}\text { Losses to follow up } \\
\text { (2) Behavioural- } 28 \\
\text { (3) Both- } 30 \\
\text { (4) Neither- } 27\end{array}$ \\
\hline Friedman & $\begin{array}{l}\text { Randomized "using a } \\
\text { paired randomisation } \\
\text { protocol" }\end{array}$ & Not stated & Yes & $\begin{array}{l}23 / 133(\mathrm{E}-17 \%) \\
11 / 134(\mathrm{C}-8 \%)\end{array}$ \\
\hline Hetlevik & Method not stated & Not stated & No & $\begin{array}{l}816 / 984(\mathrm{E}-17.1 \%) \\
/ 1255(\mathrm{C}-18.5 \%)\end{array}$ \\
\hline Krieger & $\begin{array}{l}\text { Randomisation based } \\
\text { on computer-generated } \\
\text { random number table }\end{array}$ & $\begin{array}{l}\text { Sealed opaque } \\
\text { envelopes, sequentially } \\
\text { numbered. Not } \\
\text { clear who allocated } \\
\text { individuals to groups }\end{array}$ & No & $\begin{array}{l}146 / 209(\mathrm{E}-30.1 \%) \\
165 / 212(\mathrm{C}-22.2 \%)\end{array}$ \\
\hline Dickinson & Method not stated & Not stated & No & $\begin{array}{l}\text { 51/51(E feedback- } 0 \%) \\
78 / 78 \text { (E education- } \\
0 \%) \\
88 / 88 \text { (E both- } 0 \%) \\
33 / 33 \text { (C neither- } 0 \%)\end{array}$ \\
\hline Barnett & $\begin{array}{l}\text { Method not stated but } \\
\text { stratified by age and } \\
\text { intial DBP }(100 \mathrm{mmHg} \\
\text { or }<100 \mathrm{mmHg})\end{array}$ & Not stated & No & $\begin{array}{l}44 / 63(\mathrm{E}-30 \%) \\
27 / 52(\mathrm{C}-48 \%)\end{array}$ \\
\hline Bulpitt & Method not stated & Not stated & No & $\begin{array}{l}25 / 136(\mathrm{E}-18 \%) \\
36 / 142(\mathrm{C}-25 \%)\end{array}$ \\
\hline Coe & Method not stated & Not stated & Yes & $\begin{array}{l}56 / 56(\mathrm{E}-0 \%) \\
60 / 60(\mathrm{C}-0 \%)\end{array}$ \\
\hline Robson & Random number tables & Not stated & No & $\begin{array}{l}\text { ?/1620 (E- ?\%) } \\
\text { ?/1586 (C- ?\%) }\end{array}$ \\
\hline Bloom & Method not stated & Not stated & Yes & $\begin{array}{l}12 / 27(\mathrm{E}-44 \%) \\
19 / 27(\mathrm{C}-74 \%)\end{array}$ \\
\hline Fletcher & $\begin{array}{l}\text { Patients were "divided } \\
\text { by meams of a table of } \\
\text { random numbers" }\end{array}$ & Not stated & Uncertain & $\begin{array}{l}144 / 155(93 \%) \\
\text { followed up at five } \\
\text { months. Group losses to } \\
\text { FU not reported }\end{array}$ \\
\hline Bailey & Method not stated & Not stated & Yes & $\begin{array}{l}29 / 30(\mathrm{E}-3 \%) \\
31 / 32(\mathrm{C}-3 \%)\end{array}$ \\
\hline
\end{tabular}




\begin{tabular}{|c|c|c|c|c|}
\hline Webb & Method not stated & Not stated & Yes & $\begin{array}{l}37 / 37 \text { (E1-0\%) } \\
31 / 31 \text { (E2-0\%) } \\
55 / 55 \text { (C-0\%) }\end{array}$ \\
\hline Hamilton & Method not stated & Not stated & No & $\begin{array}{l}0 / 17(\mathrm{E}-0 \%) \\
4 / 17(\mathrm{C}-24 \%)\end{array}$ \\
\hline Park & Method not stated & Not stated & No & $\begin{array}{l}5 / 32(\mathrm{E}-16 \%) \\
6 / 32(\mathrm{C}-19 \%)\end{array}$ \\
\hline Mehos & $\begin{array}{l}\text { Yes "randomized using a } \\
\text { deck of cards" }\end{array}$ & Not stated & No & $\begin{array}{l}2 / 20(\mathrm{E}-10 \%) \\
3 / 21(\mathrm{C}-14 \%)\end{array}$ \\
\hline Pierce & Yes "minimisation" & Not stated & Yes & $\begin{array}{l}59 / 59 \text { (E health } \\
\text { education)-0\%) } \\
54 / 57 \text { (E monitor- } \\
8.5 \%)\end{array}$ \\
\hline Solomon & $\begin{array}{l}\text { Yes, random number } \\
\text { tables }\end{array}$ & Not stated & No & $\begin{array}{l}63 / 63(\mathrm{E}-0 \%) \\
70 / 70(\mathrm{C}-0 \%) \\
63 / 63(\mathrm{E}-0 \%) \\
70 / 70(\mathrm{C}-0 \%)\end{array}$ \\
\hline Burelle & Not stated & Not stated & No & $\begin{array}{l}8 / 8(\mathrm{E}-0 \%) \\
8 / 8(\mathrm{C}-0 \%)\end{array}$ \\
\hline Ahluwalia & $\begin{array}{l}\text { Yes, computer generated } \\
\text { random number table }\end{array}$ & Not stated & No & $\begin{array}{l}8 / 8(\mathrm{E}-0 \%) \\
8 / 8(\mathrm{C}-0 \%)\end{array}$ \\
\hline Vetter & Not stated & Not stated & No & $\begin{array}{l}296 / 296(\mathrm{E}-0 \%) \\
326 / 326(\mathrm{C}-0 \%)\end{array}$ \\
\hline Garcia-Pena & $\begin{array}{l}\text { Randomisation by } \\
\text { computer }\end{array}$ & Yes & Yes & $\begin{array}{l}345 / 345(\mathrm{E}-0 \%) \\
338 / 338(\mathrm{C}-0 \%)\end{array}$ \\
\hline Artinian & Method not stated & Not stated & No & 6/6 (E), 9/9 (C) \\
\hline Midanik & Method not stated & Not stated & No & $\begin{array}{l}74 / 102(\mathrm{E}-28 \%) 72 / 102 \\
(\mathrm{C}-30 \%)\end{array}$ \\
\hline New & Method not stated & Not stated & No & $\begin{array}{l}99 / 506(19.6 \%) \text { in } \\
\text { intervention group } \\
\text { compared to } 132 / 508 \\
(26.0 \%) \text { in control } \\
\text { group }\end{array}$ \\
\hline Rudd & $\begin{array}{l}\text { Computer-generated } \\
\text { assignment }\end{array}$ & Not stated & $\begin{array}{l}\text { Blind outcome } \\
\text { assessment }\end{array}$ & $\begin{array}{l}74 / 74(\mathrm{E}-0 \%) 74 / 74 \\
(0 \%)\end{array}$ \\
\hline Ornstein & $\begin{array}{l}\text { "Balanced adaptive } \\
\text { randomisation scheme", } \\
3 \text { practice characteristics } \\
\text { were: practice specialty, } \\
\text { practice size and } \\
\text { geographical location }\end{array}$ & Not stated & No- open RCT & $\begin{array}{l}4446 / 4446(\mathrm{E}-0 \%) \\
3326 / 3326(\mathrm{C}-0 \%)\end{array}$ \\
\hline
\end{tabular}

Interventions used to improve control of blood pressure in patients with hypertension (Review) 


\section{A N A L Y S E S}

\section{Comparison 01. Active intervention versus control}

\begin{tabular}{|c|c|c|c|c|}
\hline Outcome title & $\begin{array}{l}\text { No. of } \\
\text { studies }\end{array}$ & $\begin{array}{c}\text { No. of } \\
\text { participants }\end{array}$ & Statistical method & Effect size \\
\hline $\begin{array}{l}01 \text { Self monitoring (systolic blood } \\
\text { pressure) }\end{array}$ & 10 & 1860 & Weighted Mean Difference (Fixed) 95\% CI & $-2.50[-3.87,-1.13]$ \\
\hline $\begin{array}{l}02 \text { Self monitoring (diastolic } \\
\text { blood pressure) }\end{array}$ & 12 & 1966 & Weighted Mean Difference (Fixed) 95\% CI & $-2.03[-2.69,-1.38]$ \\
\hline 03 Self monitoring (BP control) & 4 & 948 & Odds Ratio (Fixed) 95\% CI & $0.88[0.67,1.15]$ \\
\hline $\begin{array}{l}11 \text { Patient education (systolic } \\
\text { blood pressure) }\end{array}$ & 7 & 1136 & Weighted Mean Difference (Fixed) 95\% CI & $-2.54[-4.55,-0.53]$ \\
\hline $\begin{array}{l}12 \text { Patient education (diastolic } \\
\text { blood pressure) }\end{array}$ & 9 & 1258 & Weighted Mean Difference (Fixed) 95\% CI & $-0.81[-1.83,0.21]$ \\
\hline 13 Patient education (BP control) & 5 & 530 & Odds Ratio (Fixed) 95\% CI & $0.66[0.44,1.01]$ \\
\hline $\begin{array}{l}21 \text { Physician education (systolic } \\
\text { blood pressure) }\end{array}$ & 6 & 2839 & Weighted Mean Difference (Fixed) 95\% CI & $-2.03[-3.45,-0.62]$ \\
\hline $\begin{array}{l}22 \text { Physician education (diastolic } \\
\text { blood pressure) }\end{array}$ & 6 & 2839 & Weighted Mean Difference (Fixed) 95\% CI & $-0.43[-1.12,0.27]$ \\
\hline $\begin{array}{l}23 \text { Physician education (BP } \\
\text { control) }\end{array}$ & 6 & 13985 & Odds Ratio (Fixed) 95\% CI & $0.85[0.80,0.91]$ \\
\hline $\begin{array}{l}31 \text { Health professional led care } \\
\text { (systolic blood pressure) }\end{array}$ & 6 & 1685 & Weighted Mean Difference (Fixed) 95\% CI & $-2.37[-3.79,-0.95]$ \\
\hline $\begin{array}{l}32 \text { Health professional led care } \\
\text { (diastolic blood pressure) }\end{array}$ & 7 & 2095 & Weighted Mean Difference (Fixed) 95\% CI & $-1.53[-2.09,-0.97]$ \\
\hline $\begin{array}{l}33 \text { Health professional led care } \\
\text { (BP control) }\end{array}$ & 5 & 1271 & Odds Ratio (Fixed) 95\% CI & $0.24[0.18,0.32]$ \\
\hline $\begin{array}{l}41 \text { Organisation/protocol driven } \\
\text { care (systolic blood pressure) }\end{array}$ & 7 & 7072 & Weighted Mean Difference (Fixed) 95\% CI & $-8.55[-9.40,-7.70]$ \\
\hline $\begin{array}{l}42 \text { Organisation/protocol driven } \\
\text { care (diastolic blood pressure) }\end{array}$ & 7 & 7072 & Weighted Mean Difference (Fixed) 95\% CI & $-4.58[-4.98,-4.19]$ \\
\hline $\begin{array}{l}43 \text { Organisation/protocol driven } \\
\text { care }\end{array}$ & 5 & 11406 & Odds Ratio (Fixed) 95\% CI & $0.43[0.40,0.46]$ \\
\hline $\begin{array}{l}51 \text { Appointment reminder } \\
\text { (appointment interventions) } \\
\text { (outcome: lost to follow up at } \\
\text { clinic) }\end{array}$ & 6 & 1704 & Odds Ratio (Fixed) 95\% CI & $0.41[0.32,0.51]$ \\
\hline
\end{tabular}

\section{NDEX TERMS}

\section{Medical Subject Headings (MeSH)}

Antihypertensive Agents [*therapeutic use]; *Blood Pressure [drug effects]; Education, Medical, Continuing; Hypertension [drug therapy; ${ }^{*}$ therapy]; Patient Education; Randomized Controlled Trials

\section{MeSH check words}

Humans

\section{COVERSHEET}


Authors

\section{Contribution of author(s)}

Issue protocol first published

Review first published

Date of most recent amendment

Date of most recent

SUBSTANTIVE amendment

What's New

Date new studies sought but
none found

Date new studies found but not yet included/excluded

Date new studies found and included/excluded

Date authors' conclusions

section amended

\section{Contact address}

DOI

Cochrane Library number

Editorial group

Editorial group code
Fahey T, Schroeder K, Ebrahim S

All authors contributed to the design, data extraction, analysis and write up of the review

22 February 2006

16 February 2006

Information not supplied by author

Information not supplied by author

Information not supplied by author

Information not supplied by author

Information not supplied by author

Dr Tom Fahey

Professor of Primary Care Medicine

Tayside Centre for General Practice

University of Dundee

Kirsty Semple Way

Dundee

DD2 4AD

UK

E-mail: tpfahey@chs.dundee.ac.uk

Tel: +441382420018

Fax: +44 1382633839

10.1002/14651858.CD005182.pub2

CD005182

Cochrane Hypertension Group

Interventions used to improve control of blood pressure in patients with hypertension (Review)

Copyright $\odot 2006$ The Cochrane Collaboration. Published by John Wiley \& Sons, Ltd 
GRAPHS AND OTHER TABLES

Analysis 01.01. Comparison 0I Active intervention versus control, Outcome 0 I Self monitoring (systolic blood pressure)

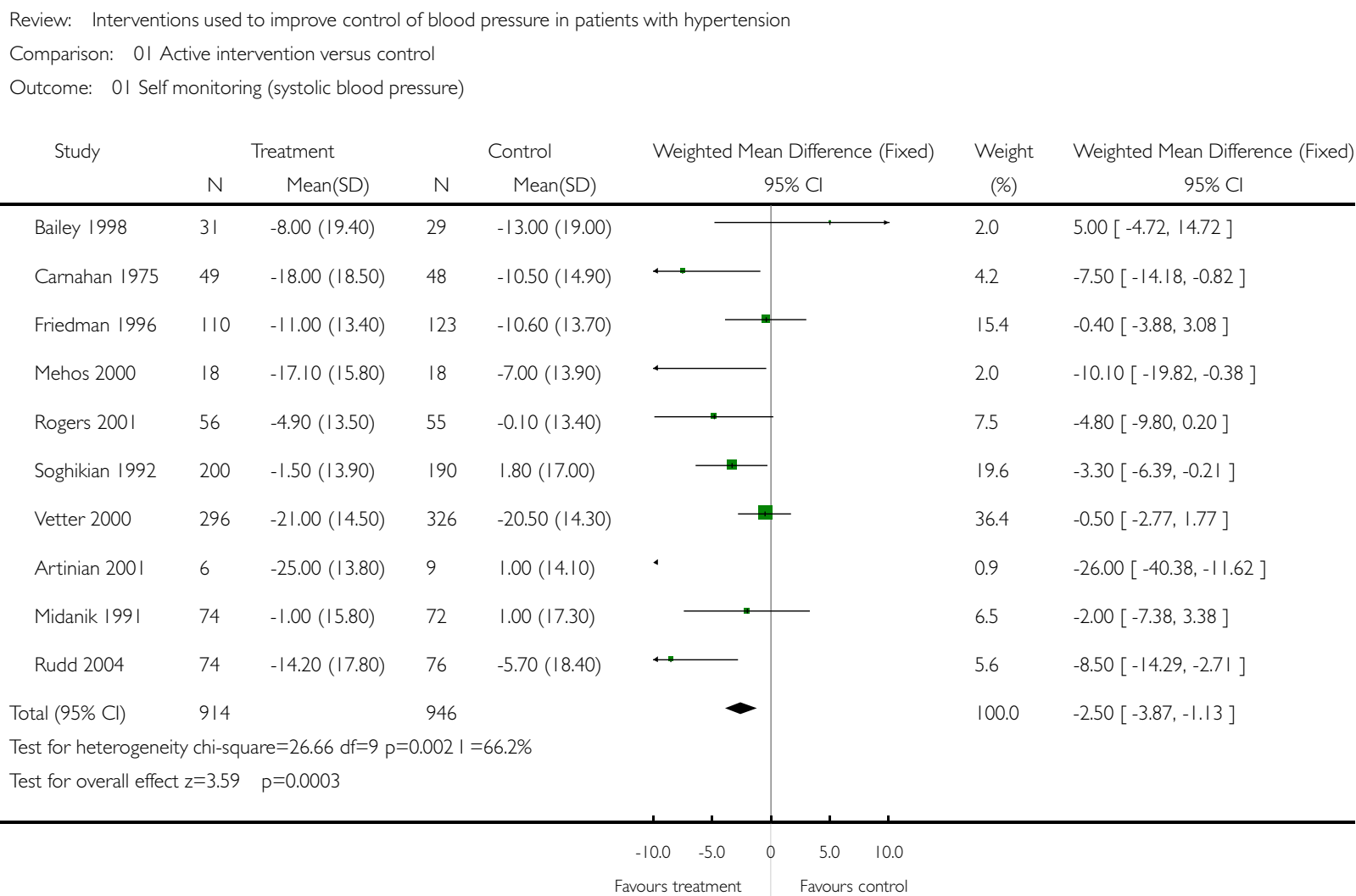




\section{Analysis 01.02. Comparison 01 Active intervention versus control, Outcome 02 Self monitoring (diastolic blood pressure)}

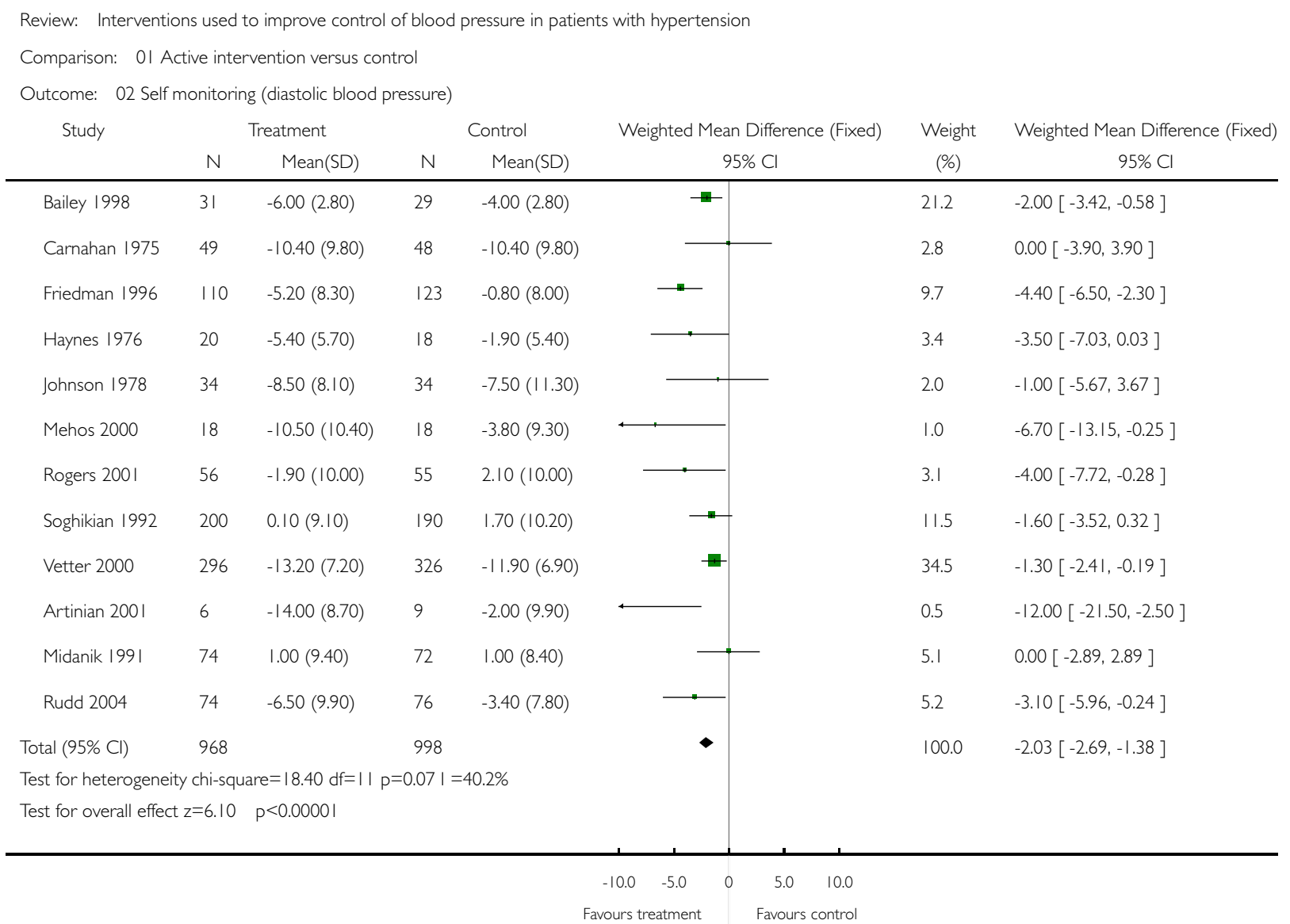




\section{Analysis 01.03. Comparison 0I Active intervention versus control, Outcome 03 Self monitoring (BP control)}

\begin{tabular}{|c|c|c|c|c|c|}
\hline \multicolumn{6}{|c|}{ Comparison: 0 I Active intervention versus control } \\
\hline Study & $\begin{array}{l}\text { Treatment } \\
\mathrm{n} / \mathrm{N}\end{array}$ & $\begin{array}{l}\text { Control } \\
\mathrm{n} / \mathrm{N}\end{array}$ & Odds Ratio (Fixed) & $\begin{array}{c}\text { Weight } \\
(\%)\end{array}$ & $\begin{array}{l}\text { Odds Ratio (Fixed) } \\
\qquad 95 \% \mathrm{Cl}\end{array}$ \\
\hline Pierce 1984 & $15 / 55$ & $7 / 29$ & $\cdot$ & 5.8 & $1.18[0.42,3.32]$ \\
\hline Rogers 2001 & $36 / 60$ & $35 / 61$ & & 12.1 & $1.11[0.54,2.30]$ \\
\hline Vetter 2000 & $100 / 296$ & $131 / 326$ & & 71.8 & $0.76[0.55,1.05]$ \\
\hline Earp 1982 & $29 / 74$ & $16 / 47$ & - & 10.3 & $1.25[0.58,2.68]$ \\
\hline Total $(95 \% \mathrm{Cl})$ & 485 & 463 & $<$ & 100.0 & $0.88[0.67,1.15]$ \\
\hline \multicolumn{6}{|c|}{ Total events: I 80 (Treatment), 189 (Control) } \\
\hline \multicolumn{6}{|c|}{ Test for heterogeneity chi-square $=2.30 \mathrm{df}=3 \mathrm{p}=0.5 \mathrm{I} \mathrm{I}=0.0 \%$} \\
\hline \multicolumn{6}{|c|}{ Test for overall effect $z=0.96 \quad p=0.3$} \\
\hline
\end{tabular}

\section{Analysis 0I.I I. Comparison 0 I Active intervention versus control, Outcome I I Patient education (systolic blood pressure)}

Review: Interventions used to improve control of blood pressure in patients with hypertension

Comparison: 0 I Active intervention versus contro

Outcome: II Patient education (systolic blood pressure)

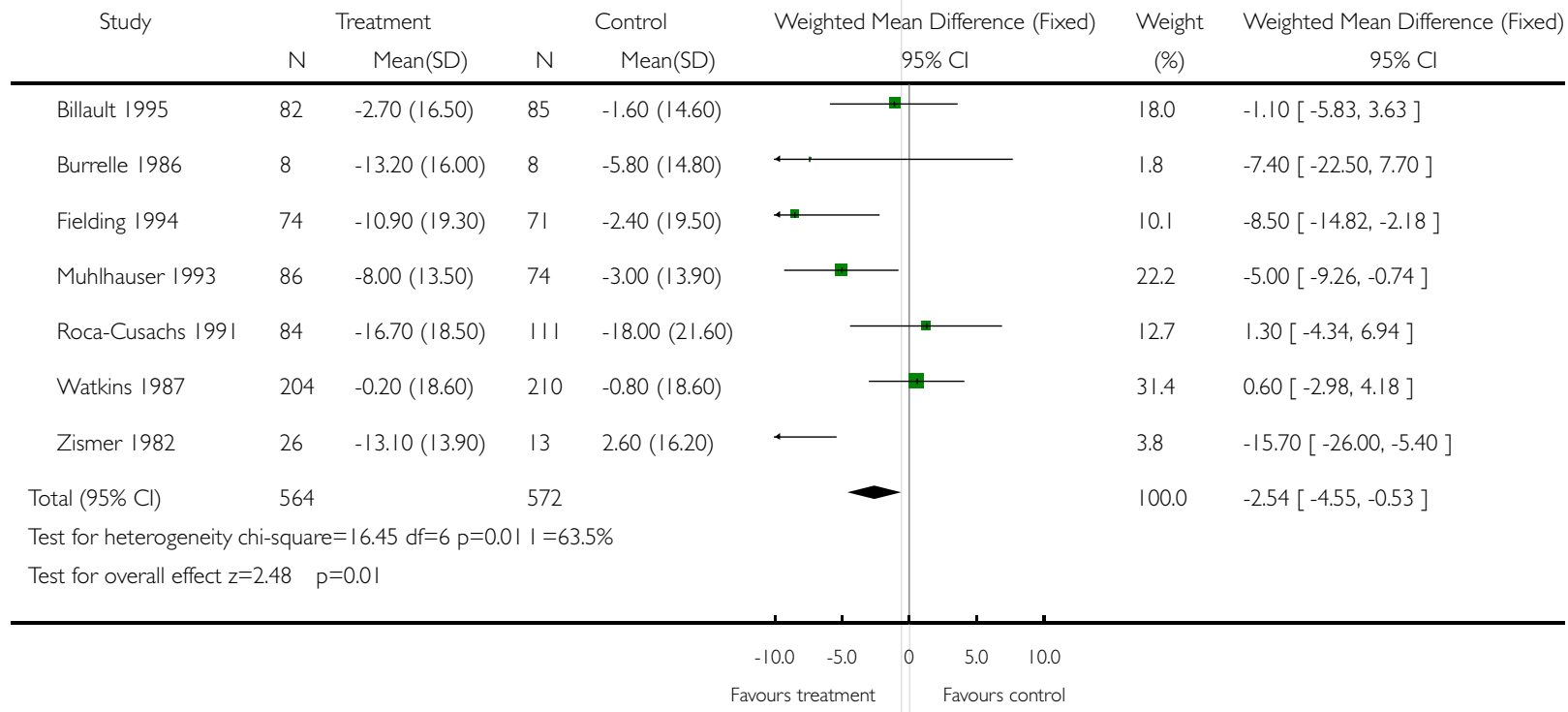




\section{Analysis 01.12. Comparison 0I Active intervention versus control, Outcome I2 Patient education (diastolic}

blood pressure)

\begin{tabular}{|c|c|c|c|c|c|c|c|}
\hline \multicolumn{8}{|c|}{ Comparison: $\quad 0$ I Active intervention versus control } \\
\hline \multirow[t]{2}{*}{ Study } & \multicolumn{2}{|r|}{ Treatment } & \multicolumn{2}{|r|}{ Control } & \multirow{2}{*}{$\begin{array}{l}\text { Weighted Mean Difference (Fixed) } \\
\qquad 95 \% \mathrm{Cl}\end{array}$} & \multirow{2}{*}{$\begin{array}{l}\text { Weight } \\
(\%)\end{array}$} & \multirow{2}{*}{$\begin{array}{l}\text { Weighted Mean Difference (Fixed } \\
\qquad 95 \% \mathrm{Cl}\end{array}$} \\
\hline & $\mathrm{N}$ & Mean(SD) & $\mathrm{N}$ & Mean(SD) & & & \\
\hline Billault 1995 & 82 & $1.30(7.80)$ & 85 & $-0.10(11.20)$ & $\longrightarrow$ & 12.3 & $1.40[-1.52,4.32]$ \\
\hline Burrelle 1986 & 8 & $-4.10(11.90)$ & 8 & $-11.20(13.10)$ & & 0.7 & $7.10[-5.16,19.36]$ \\
\hline Fielding 1994 & 74 & $-5.60(9.70)$ & 71 & $-1.70(9.80)$ & $\longrightarrow$ & 10.4 & $-3.90[-7.07,-0.73]$ \\
\hline Muhlhauser 1993 & 86 & $-5.00(7.30)$ & 74 & $-2.00(8.20)$ & $\longrightarrow$ & 17.8 & $-3.00[-5.42,-0.58]$ \\
\hline Roca-Cusachs 1991 & 84 & $-7.60(9.50)$ & 111 & $-9.50(11.70)$ & 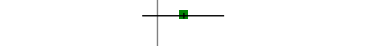 & 11.8 & $1.90[-1.08,4.88]$ \\
\hline Tanner 1981 & 15 & $-3.70(6.90)$ & 15 & $-3.90(6.90)$ & $\overline{ }$ & 4.3 & $0.20[-4.74,5.14]$ \\
\hline Watkins 1987 & 204 & $0.30(9.30)$ & 210 & $-0.10(9.30)$ & $\mp$ & 32.6 & $0.40[-1.39,2.19]$ \\
\hline Webb 1980 & 37 & $-6.80(9.00)$ & 55 & $-3.50(8.40)$ & & 7.8 & $-3.30[-6.95,0.35]$ \\
\hline Zismer 1982 & 26 & $-8.20(8.90)$ & 13 & $0.50(10.90)$ & - & 2.2 & $-8.70[-15.54,-1.86]$ \\
\hline Total $(95 \% \mathrm{Cl})$ & 616 & & 642 & & - & 100.0 & $-0.81[-1.83,0.21]$ \\
\hline \multicolumn{8}{|c|}{ Test for heterogeneity chi-square $=22.57 \mathrm{df}=8 \mathrm{p}=0.004 \mathrm{I}=64.5 \%$} \\
\hline \multicolumn{8}{|c|}{ Test for overall effect $z=1.55 \quad p=0.1$} \\
\hline
\end{tabular}

\section{Analysis 0I.13. Comparison 0I Active intervention versus control, Outcome I3 Patient education (BP control)}

Review: Interventions used to improve control of blood pressure in patients with hypertension

Comparison: 0 I Active intervention versus control

Outcome: 13 Patient education (BP control)

\begin{tabular}{|c|c|c|c|c|c|}
\hline Study & $\begin{array}{c}\text { Treatment } \\
n / N\end{array}$ & $\begin{array}{c}\text { Control } \\
n / N\end{array}$ & $\begin{array}{l}\text { Odds Ratio (Fixed) } \\
\qquad 95 \% \mathrm{Cl}\end{array}$ & $\begin{array}{c}\text { Weight } \\
(\%)\end{array}$ & $\begin{array}{l}\text { Odds Ratio (Fixed) } \\
\qquad 95 \% \mathrm{Cl}\end{array}$ \\
\hline Earp 1982 & $|4 / 4|$ & $16 / 47$ & $\longrightarrow$ & 17.9 & $1.00[0.42,2.43]$ \\
\hline Morisky 1983 & $15 / 44$ & $24 / 40$ & $\longrightarrow$ & 30.2 & $0.34[0.14,0.84]$ \\
\hline Muhlhauser 1993 & $74 / 86$ & $63 / 74$ & + & 17.2 & $1.08[0.44,2.61]$ \\
\hline Pierce 1984 & $10 / 59$ & $9 / 27$ & - & 18.7 & $0.41[0.14,1.17]$ \\
\hline Sackett 1975 & $61 / 80$ & $26 / 32$ & $\longrightarrow$ & 16.1 & $0.74[0.27,2.07]$ \\
\hline Total $(95 \% \mathrm{Cl})$ & 310 & 220 & & 100.0 & $0.66[0.44,1.01]$ \\
\hline \multicolumn{6}{|c|}{ Total events: 174 (Treatment), I38 (Control) } \\
\hline \multicolumn{6}{|c|}{ Test for heterogeneity chi-square $=4.95 \mathrm{df}=4 \mathrm{p}=0.29 \mathrm{I}=19.2 \%$} \\
\hline \multicolumn{6}{|c|}{ Test for overall effect $z=1.93 \quad p=0.05$} \\
\hline & & & $\begin{array}{llll}0.1 & 0.2 & 0.5 & \text { । }\end{array}$ & & \\
\hline \multicolumn{6}{|c|}{ Favours treatment Favours control } \\
\hline
\end{tabular}

Interventions used to improve control of blood pressure in patients with hypertension (Review) 


\section{Analysis 01.2I. Comparison 0I Active intervention versus control, Outcome 2I Physician education (systolic blood pressure)}

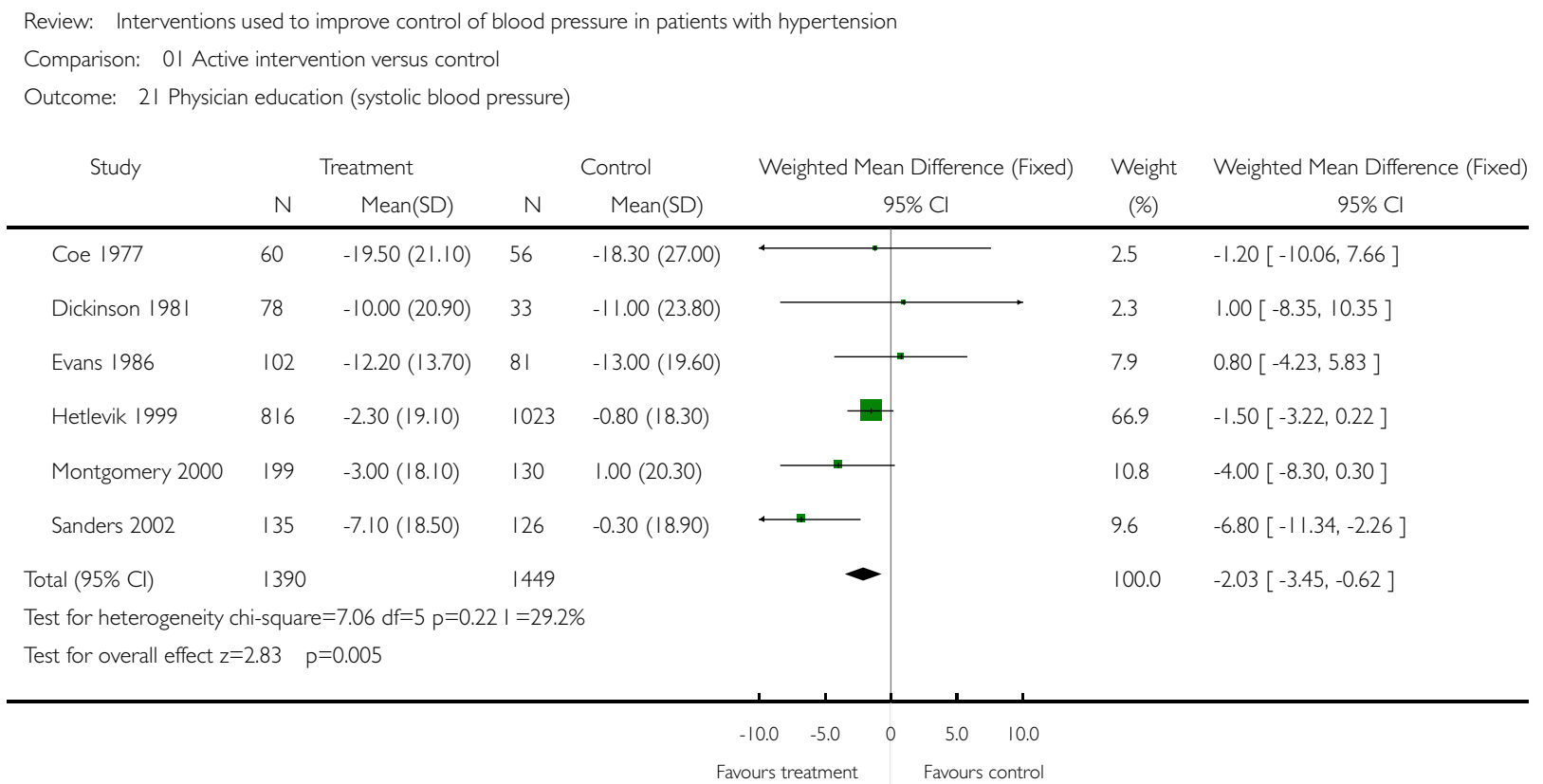

\section{Analysis 01.22. Comparison 0I Active intervention versus control, Outcome 22 Physician education (diastolic blood pressure)}

Review: Interventions used to improve control of blood pressure in patients with hypertension

Comparison: 01 Active intervention versus control

Outcome: 22 Physician education (diastolic blood pressure)

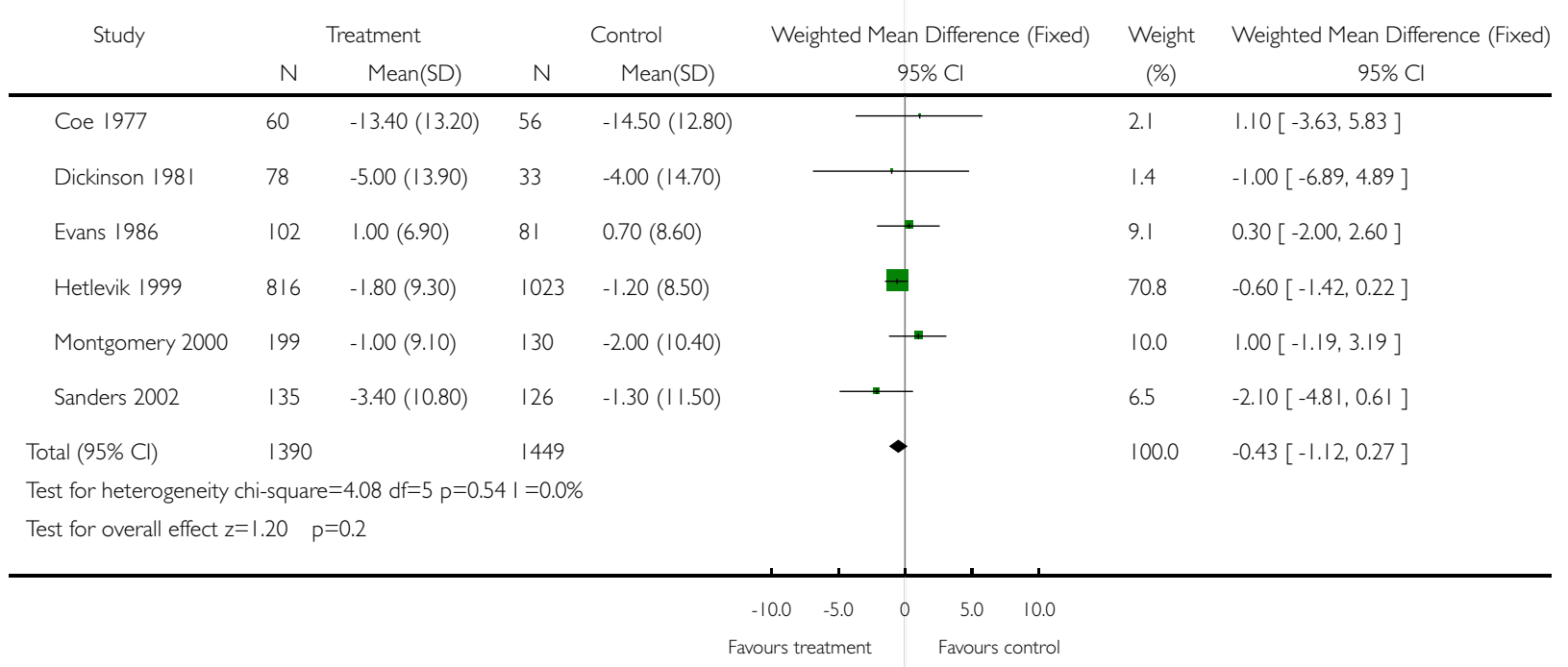

Interventions used to improve control of blood pressure in patients with hypertension (Review) 
Analysis 01.23. Comparison 0I Active intervention versus control, Outcome 23 Physician education (BP control)

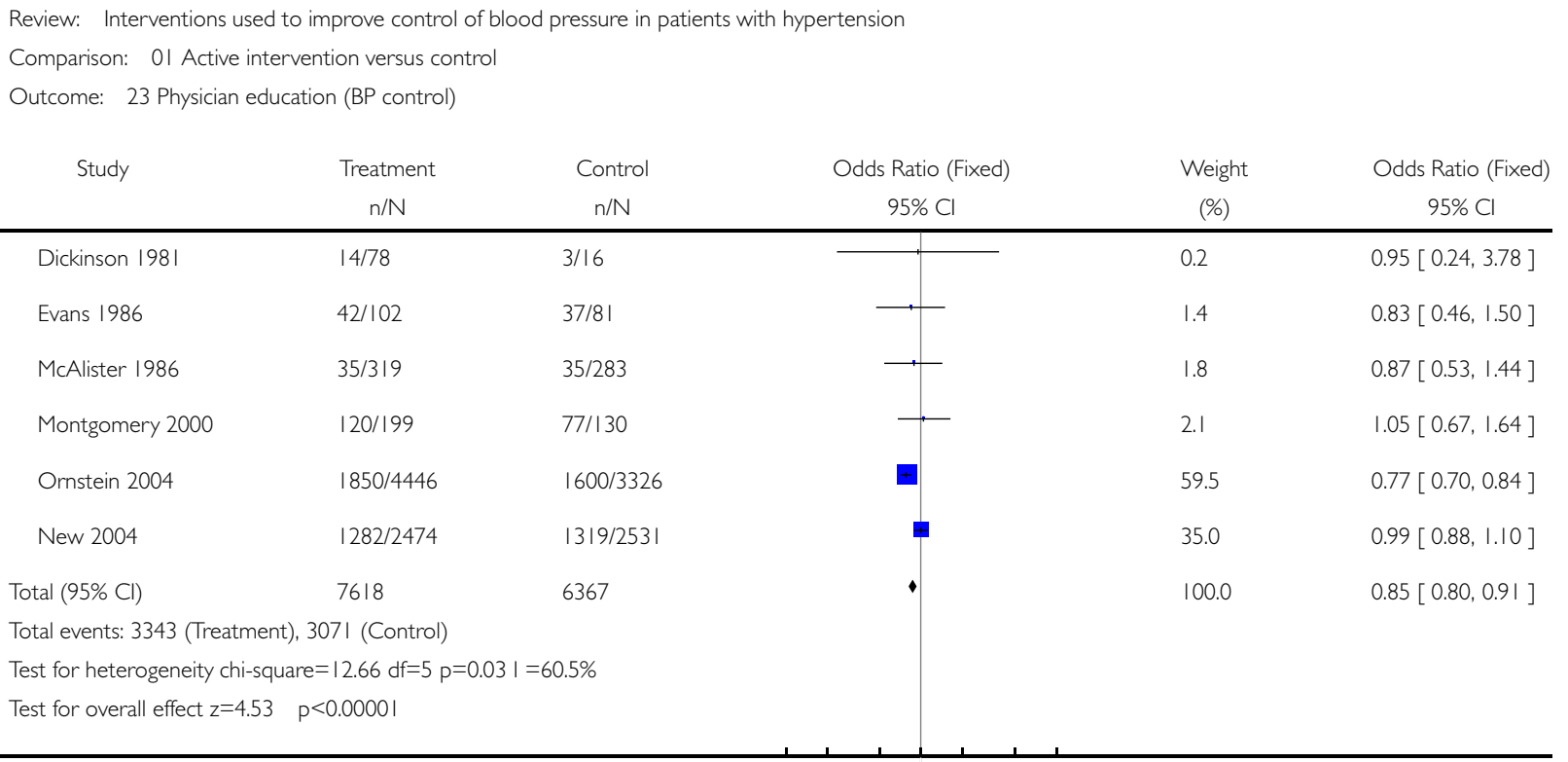

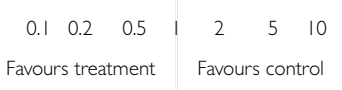

Analysis 01.31. Comparison 0I Active intervention versus control, Outcome 31 Health professional led care (systolic blood pressure)

Review: Interventions used to improve control of blood pressure in patients with hypertension

Comparison: 0 I Active intervention versus control

Outcome: 31 Health professional led care (systolic blood pressure)

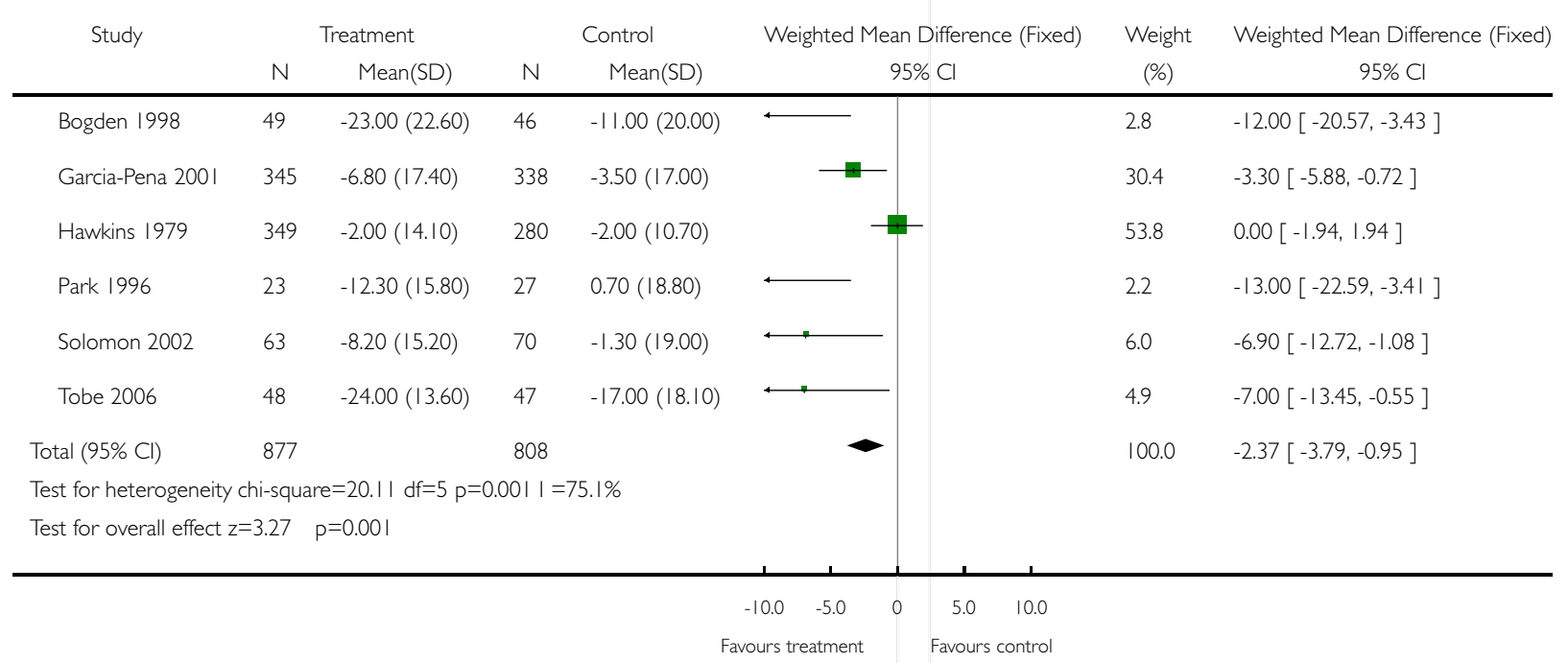


Analysis 01.32. Comparison 01 Active intervention versus control, Outcome 32 Health professional led care (diastolic blood pressure)

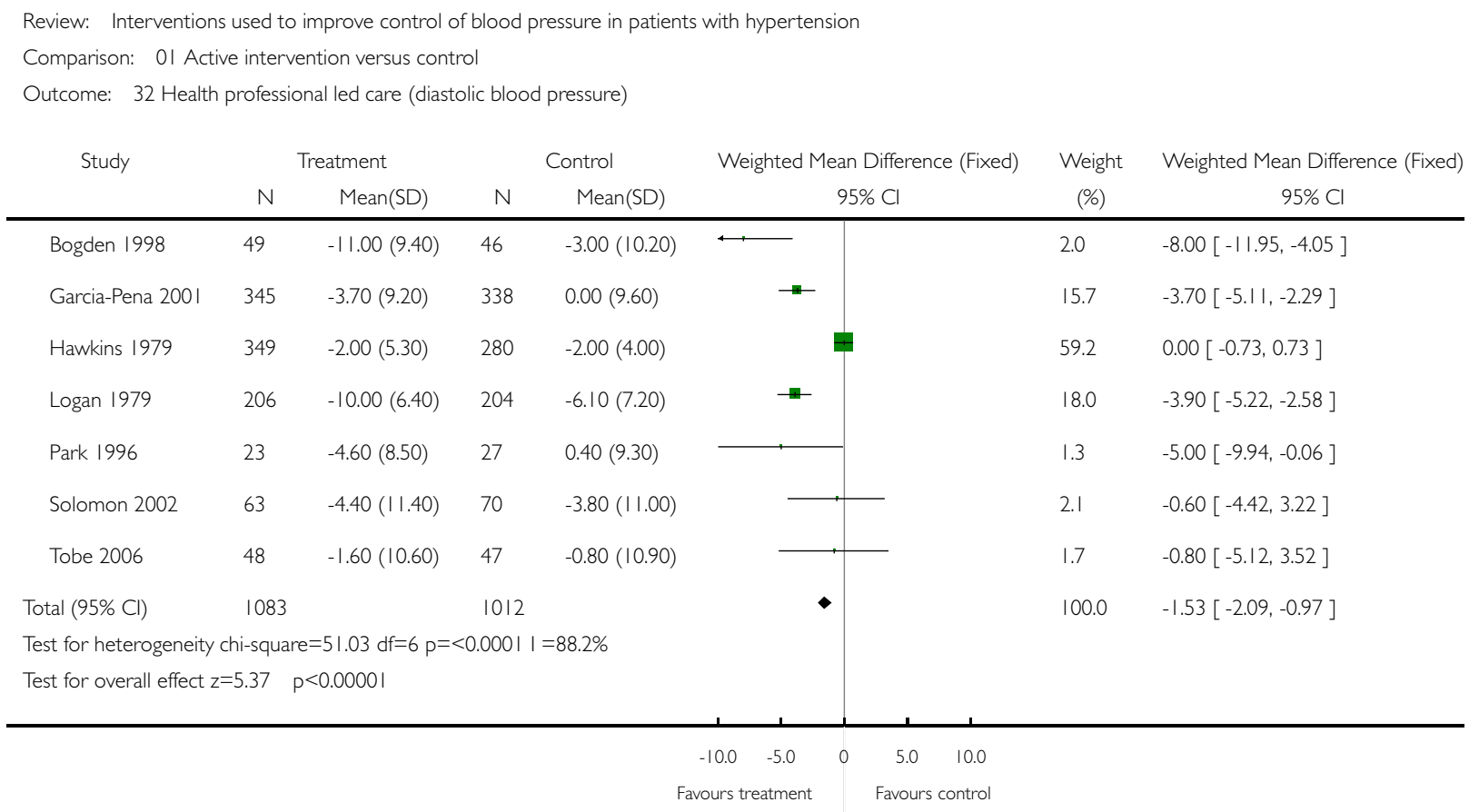

\section{Analysis 01.33. Comparison 01 Active intervention versus control, Outcome 33 Health professional led care} (BP control)

Review: Interventions used to improve control of blood pressure in patients with hypertension

Comparison: 0 I Active intervention versus control

Outcome: 33 Health professional led care (BP control)

\begin{tabular}{|c|c|c|c|c|c|}
\hline Study & $\begin{array}{l}\text { Treatment } \\
\mathrm{n} / \mathrm{N}\end{array}$ & $\begin{array}{l}\text { Control } \\
\mathrm{n} / \mathrm{N}\end{array}$ & $\begin{array}{l}\text { Odds Ratio (Fixed) } \\
\qquad 95 \% \mathrm{Cl}\end{array}$ & $\begin{array}{c}\text { Weight } \\
(\%)\end{array}$ & $\begin{array}{c}\text { Odds Ratio (Fixed) } \\
\qquad 95 \% \mathrm{Cl}\end{array}$ \\
\hline Bogden 1998 & $22 / 49$ & $37 / 46$ & $\longleftrightarrow$ & 9.4 & $0.20[0.08,0.50]$ \\
\hline Garcia-Pena 200। & $220 / 345$ & $316 / 338$ & - & 51.7 & $0.12[0.08,0.20]$ \\
\hline Jewell 1988 & $5 / 15$ & $7 / 19$ & \multirow[b]{2}{*}{-} & 1.8 & $0.86[0.21,3.55]$ \\
\hline Logan 1979 & $102 / 204$ & 146/206 & & 32.5 & $0.41[0.27,0.62]$ \\
\hline Park 1996 & $1 \mid / 23$ & $21 / 26$ & $\longleftrightarrow$ & 4.6 & $0.22[0.06,0.78]$ \\
\hline Total (95\% Cl) & 636 & 635 & 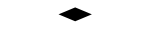 & 100.0 & $0.24[0.18,0.32]$ \\
\hline \multicolumn{6}{|c|}{ Total events: 360 (Treatment), 527 (Control) } \\
\hline \multicolumn{6}{|c|}{ Test for heterogeneity chi-square $=17.34 \mathrm{df}=4 \mathrm{p}=0.002 \mathrm{I}=76.9 \%$} \\
\hline \multicolumn{6}{|c|}{ Test for overall effect $z=10.19 \quad p<0.00001$} \\
\hline
\end{tabular}

Interventions used to improve control of blood pressure in patients with hypertension (Review) 


\section{Analysis 01.4I. Comparison $0 \mathrm{I}$ Active intervention versus control, Outcome 4I Organisation/protocol driven}

care (systolic blood pressure)

\begin{tabular}{|c|c|c|c|c|c|c|c|c|c|}
\hline \multicolumn{10}{|c|}{ Comparison: $\quad 01$ Active intervention versus control } \\
\hline \multicolumn{10}{|c|}{ Outcome: 4l Organisation/protocol driven care (systolic blood pressure) } \\
\hline \multirow[t]{2}{*}{ Study } & \multicolumn{2}{|r|}{ Treatment } & \multicolumn{2}{|r|}{ Control } & \multirow{2}{*}{\multicolumn{3}{|c|}{$\begin{array}{l}\text { Weighted Mean Difference (Fixed) } \\
\qquad 95 \% \mathrm{Cl}\end{array}$}} & \multirow{2}{*}{$\begin{array}{c}\text { Weight } \\
(\%)\end{array}$} & \multirow{2}{*}{$\begin{array}{l}\text { Weighted Mean Difference (Fixed) } \\
\qquad 95 \% \mathrm{Cl}\end{array}$} \\
\hline & N & Mean(SD) & $\mathrm{N}$ & Mean(SD) & & & & & \\
\hline Bulpitt 1976 & 80 & $-28.80(17.60)$ & 71 & $-28.40(17.10)$ & & & - & 2.3 & $-0.40[-5.94,5.14]$ \\
\hline Dickinson 1981 & 51 & $-12.00(19.70)$ & 33 & $-11.00(23.80)$ & & & & 0.8 & $-1.00[-10.76,8.76]$ \\
\hline Hypertension 1979 & 2872 & $-23.60(16.20)$ & 1718 & $-15.40(17.50)$ & 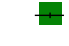 & & & 69.2 & $-8.20[-9.22,-7.18]$ \\
\hline Takala 1979 & 39 & $-26.00(18.40)$ & 36 & $-29.00(17.50)$ & & & & 1.1 & $3.00[-5.13,11.13]$ \\
\hline Takala 1983 & 36 & $-35.00(18.50)$ & 34 & $-38.00(18.00)$ & & & & 1.0 & $3.00[-5.55,11.55]$ \\
\hline Hypertension 1979a & 811 & $-38.90(17.50)$ & 542 & $-27.20(\mid 8.60)$ & 4 & & & 18.4 & $-11.70[-13.68,-9.72]$ \\
\hline Hypertension 1982 & 438 & $-52.30(21.90)$ & 311 & $-41.70(21.40)$ & $\longleftarrow$ & & & 7.3 & $-10.60[-13.74,-7.46]$ \\
\hline Total $(95 \% \mathrm{Cl})$ & 4327 & & 2745 & & $\bullet$ & & & 100.0 & $-8.55[-9.40,-7.70]$ \\
\hline \multicolumn{10}{|c|}{ Test for heterogeneity chi-square $=37.24 \mathrm{df}=6 \mathrm{p}=<0.000 \mathrm{I} \mathrm{I}=83.9 \%$} \\
\hline \multicolumn{10}{|c|}{ Test for overall effect $z=19.79 \quad p<0.00001$} \\
\hline & & & & & -10.0 & -5.0 & 10.0 & & \\
\hline & & & & & vours tre & eatment & Favours control & & \\
\hline
\end{tabular}

\section{Analysis 01.42. Comparison 0 I Active intervention versus control, Outcome 42 Organisation/protocol driven care (diastolic blood pressure)}

Review: Interventions used to improve control of blood pressure in patients with hypertension

Comparison: 0 I Active intervention versus control

Outcome: 42 Organisation/protocol driven care (diastolic blood pressure)

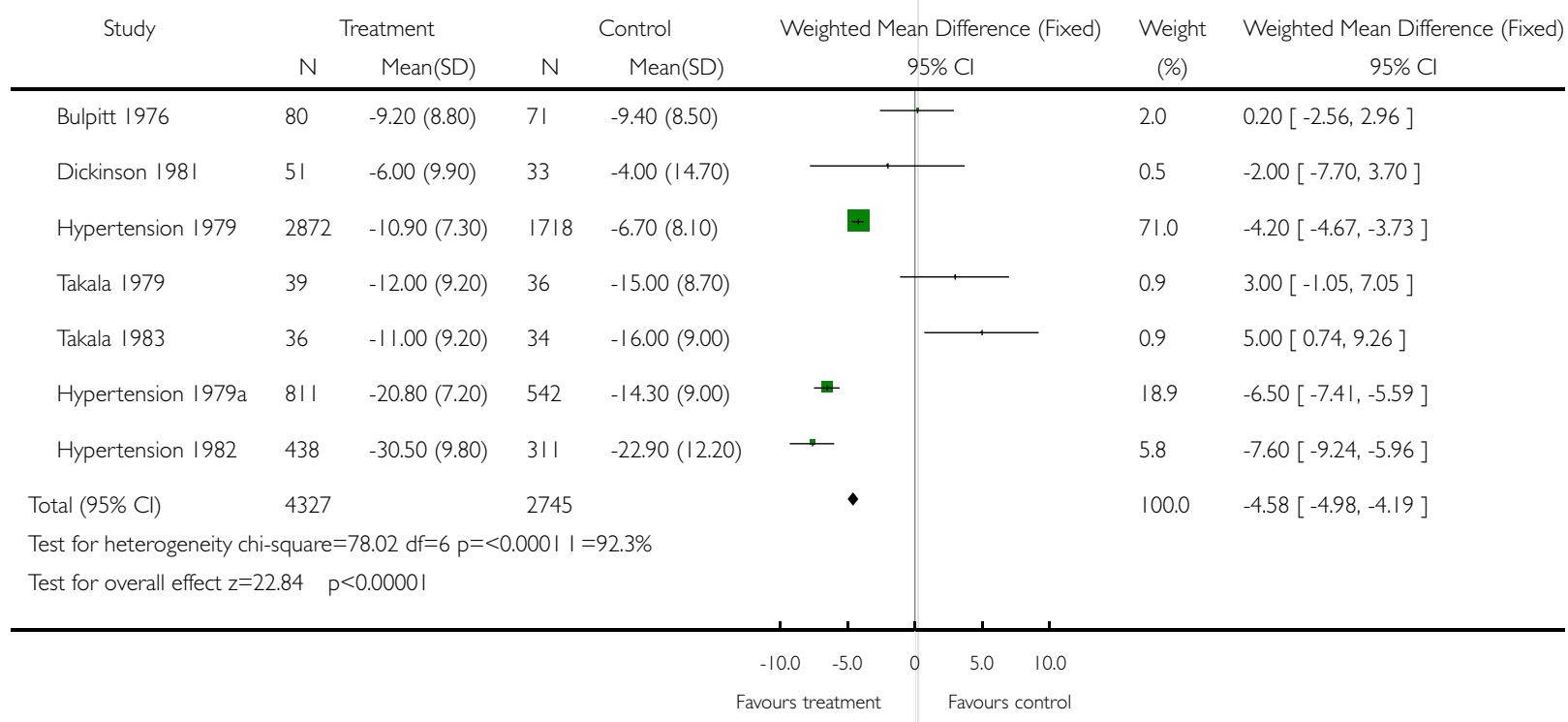

Interventions used to improve control of blood pressure in patients with hypertension (Review) 


\section{Analysis 01.43. Comparison 0I Active intervention versus control, Outcome 43 Organisation/protocol driven}

care

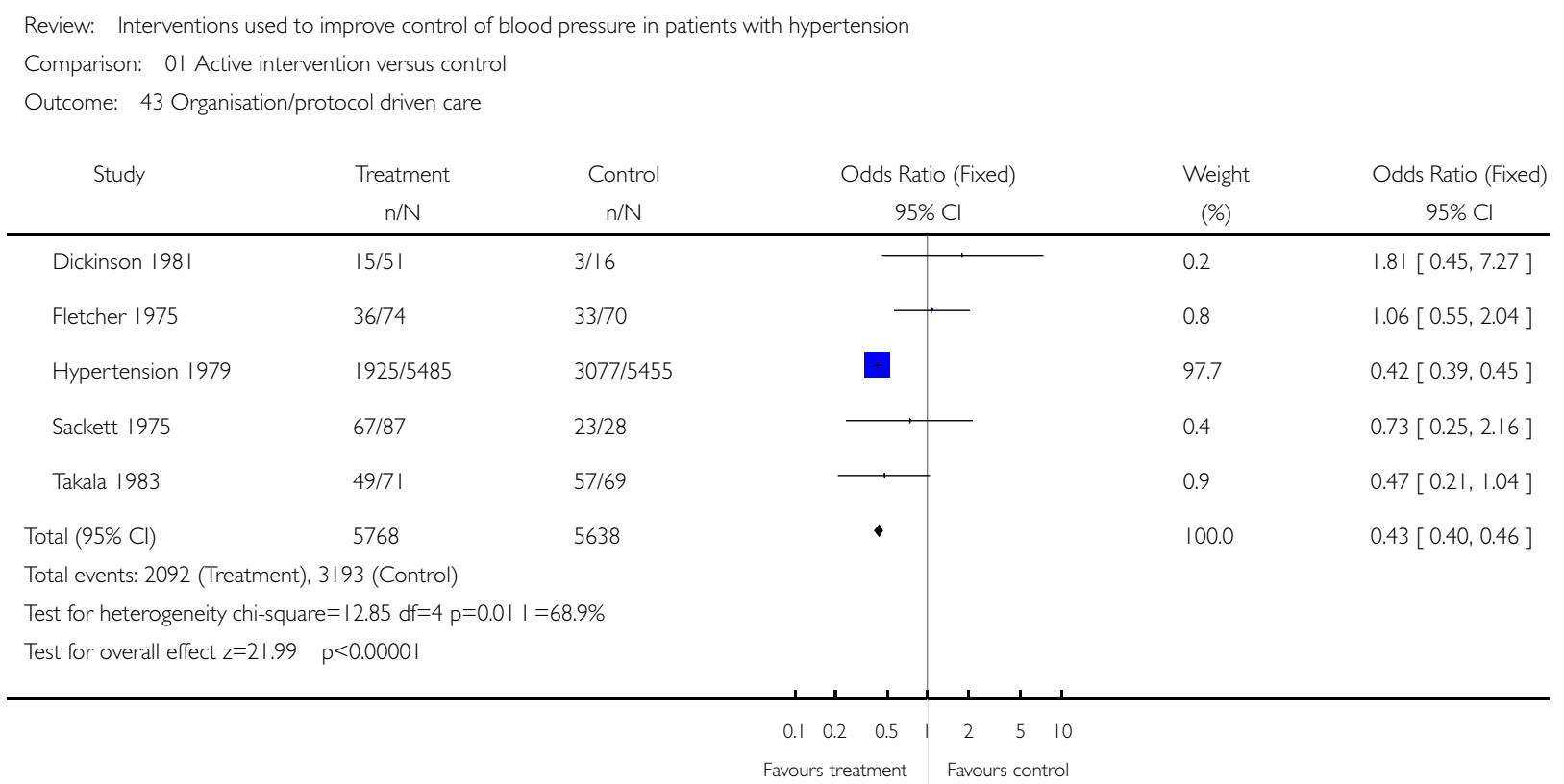

\section{Analysis 01.5 I. Comparison $0 \mathrm{I}$ Active intervention versus control, Outcome $5 \mathrm{I}$ Appointment reminder (appointment interventions) (outcome: lost to follow up at clinic)}

Review: Interventions used to improve control of blood pressure in patients with hypertension

Comparison: 01 Active intervention versus control

Outcome: 51 Appointment reminder (appointment interventions) (outcome: lost to follow up at clinic)

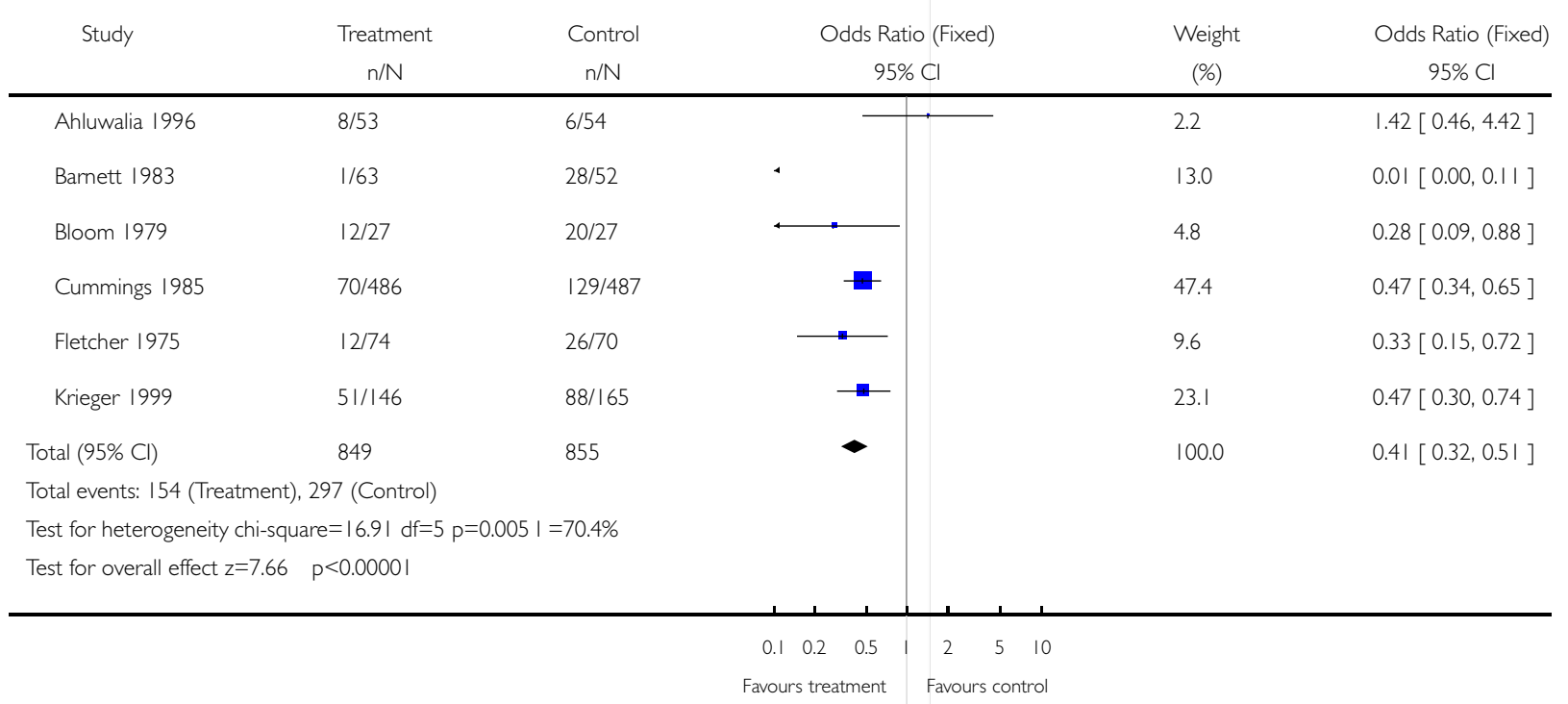

Interventions used to improve control of blood pressure in patients with hypertension (Review) 